\title{
Commentary on Spent Fuel Storage at Morris Operation
}

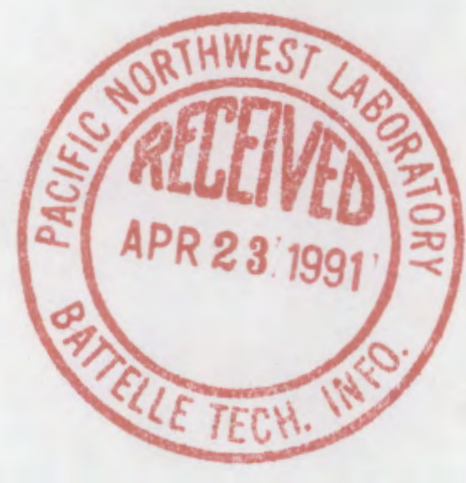
K. J. Eger

G. E. Zima

July 1979

Prepared for

the U.S. Nuclear Regulatory Commission

Pacific Northwest Laboratory

Operated for the U.S. Department of Energy

by Battelle Memorial Institute

\section{*Balielle}

艺

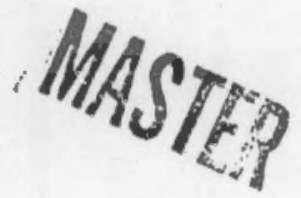


NUREG/CR-0956

PNL-3065

$\mathrm{RW}$

COMMENTARY ON SPENT FUEL STORAGE

AT MORRIS OPERATION

K. J. Eger

General Electric

G. E. Zima

Battelle Pacific Northwest Laboratory

Manuscr ipt Completec: July 1979

Date ?ublished: October 1979

Prepared for

the U.S. Nuclear Regulatory Commission

under a Related Services Agrcement

with the U.S. Department of Energy

Contrac' EY-76-C-06-1830

FIN NNo. b21199

Pacific Northwest Laboratory

Richland, Washington 99352 


\section{ABSTRACT}

Under Contract B-63060-A-P, the General Electric Company is providing technical support to Battelle Pacific Northwest Laboratories in the analysis of the design, operation, and maintenance experience in the handling of nuclear fuel at an Independent Spent Fuel Storage Facility.

The purpose of this report is to provide a description of spent fuel handling activities and systems, and an andlysis of the storage performance as developed over the seven year operational history of the Morris Operation.

Design considerations and performance are analyzed for both the basin and key supporting systems. The bases for this analysis are the provisions for containing radinactive by-product materials, for shielving from the radiation they emit, and for preventing the formation of a critical array.

These provisions have been met effectively over the history of storage at Morris. The release of radioactive inaterials is minimized by the protection of the cladding integrity, the containment of the basin water, the removal of radioactive and other contamirants from the water, and by filtering and then dispersing the basin air. Four auxiliary systems are provided to accomplish this, the basin leak detection system, the filter, the coolers, and the building ventilation system. This successful history notwithstanding, action to reduce personnel exposure, to improve fuel handling reliability and to lessen the potential for accidents continues to be taken. 


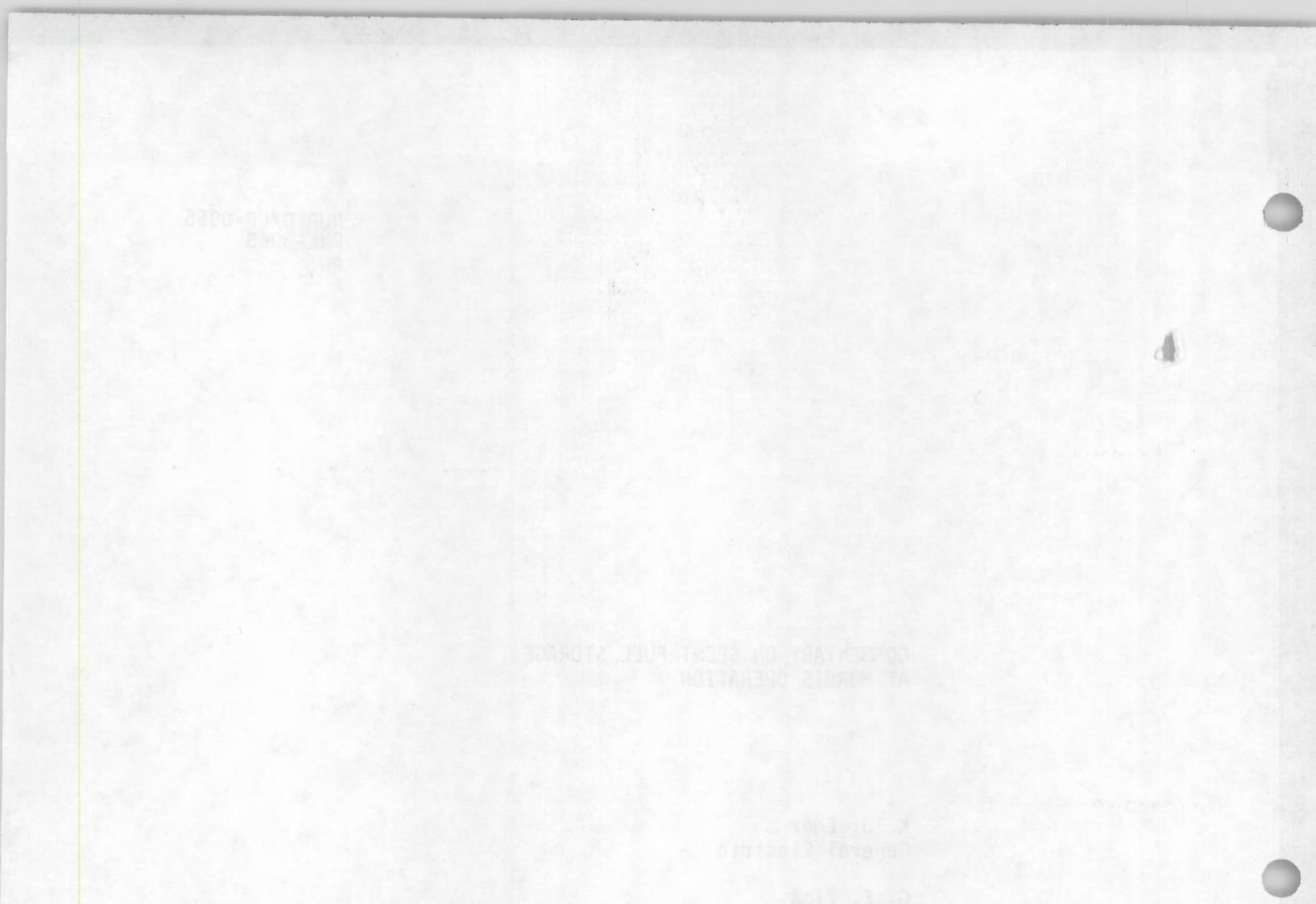




\section{ACKNOWLEDGEMENT}

The operating and maintenance activities for spent fuel storage at the Morris Operation are based on equipment and procedures developed over the past seven years by a large number of engineers, technicians, and craftsmen. The authors gratefully acknowledge the integrated efforts of many General Electric co-workers, and the specific support of E. E. Voiland, N. P. Shaikh, J. W. Doman, A. C. Shorkey, R. C. Paul, R. V. Kinzler and K. A. Astrom. 



\section{CONTENTS}

ABSTRACT

ACKNOWLEDGEMENT

INTRODUCTION

SUMMARY

I. THE BASIN

Description

Operating Priorities and Limits

Basin Performance. . . . . . . . . 11

Analysis . . . . . . . . . . . 15

II. WATER PURIFICATION . . . . . . . . 17

Description . . . . . . . . . 17

Operating Priorities and Limits . . . . . 23

Performance . . . . . . . . . . 24

Analysis . . . . . . . . . . . 29

III. THE BASIN COOLERS . . . . . . . . . 33

Description . . . . . . . . . 33

Operating Priorities and Limits . . . . . 34

Cooler Performance . . . . . . . . . 37

Analysis . . . . . . . . . . . . 42

IV. CASK HANDLING EQUIPMENT . . . . . . . . 45

Description . . . . . . . . . . 45

Operating Priorities and Limits . . . . . 47

Performance . . . . . . . . . . . 48

Analysis . . . . . . . . . . . 50

V. FUEL HANDLING EQUIPMENT . . . . . . . . 51

Description . . . . . . . . 51

Operating Priorities and Limits . . . . . 53

Performance . . . . . . . . . . 55

Analysis . . . . . . . . . . . 57

VI. SUPPORT SYSTEMS . . . . . . . . . 59

Ventilation System . . . . . . . . . 59

Description . . . . . . . . . 59 


\section{CONTENTS (Continued)}

\begin{tabular}{|c|c|c|c|c|c|c|c|c|c|c|}
\hline \multicolumn{3}{|c|}{ Operating Priorities } & \multicolumn{3}{|c|}{ s and Limits } & \multicolumn{2}{|c|}{. $\quad$. } & $\cdot$ & \multirow{2}{*}{$\cdot$} & \multirow{2}{*}{$60^{\circ}$} \\
\hline & Performance & . & . & . & • & . & . & · & & \\
\hline & Analysis & . & . & - & . & . & - & · & . & 64 \\
\hline Radwa & iste System & . & . & . & . & . & - & - & . & 64 \\
\hline & Description & - & . & - & - & . & · & - & · & 64 \\
\hline & Operating Pr & oriti & ies an & in Lin & mits & · & . & . & • & 66 \\
\hline & Performance & . & . & . & · & · & - & · & · & 66 \\
\hline & Analysis & . & . & - & . & . & · & - & . & 67 \\
\hline SHIPP & ING EXPERIEN & & - & - & . & - & - & · & - & 69 \\
\hline Cescr & iption . & - & . & $\cdot$ & · & . & - & $\cdot$ & · & 69 \\
\hline Analy & sis & . & . & · & . & . & - & · & · & 81 \\
\hline & Shipping Time & & $\cdot$ & - & . & - & - & - & - & 81 \\
\hline & Cask Skin Ten & nperati & tures & . & . & · & - & - & - & 82 \\
\hline & Shielding & · & - & - & · & - & - & . & . & 85 \\
\hline & Cask Coolant & - & · & - & - & . & . & . & - & 87 \\
\hline FUEL & UNLOADING AN & CASK & K TURN & AAROUi & & - & . & - & . & 91 \\
\hline Descr & iption . & . & · & . & . & - & - & - & · & 91 \\
\hline Cask & Preparation & for Un & nloadi & ing & - & - & • & - & - & 92 \\
\hline Under & water Work & - & - & - & . & - & . & . & - & 94 \\
\hline Prepa & aration for $\mathrm{St}$ & hippin & & - & . & . & - & - & . & 95 \\
\hline Analy & sis & · & . & . & - & . & . & - & . & 96 \\
\hline & Cask Prepara & tion & - & . & - & . & - & - & - & 96 \\
\hline & Underwater W & ork & . & . & $\cdot$ & - & - & - & . & 99 \\
\hline & Shipping Pre & parati & ion & - & $\cdot$ & . & . & - & - & 102 \\
\hline Overa & 11 Performan & & - & . & . & . & - & - & - & 105 \\
\hline SUTION & V. . & . & . & . & $\cdot$ & - & - & - & . & Distr-1 \\
\hline
\end{tabular}




\section{LIST OF FIGURES}

1. Spent Fuel Storage Systems . . . . . . . 2

2. Fuel Unloading and Storage Basin Configuration . . . 8

3. Fuel Storage Baskets and Grids . . . . . . 10

4. Gamma Exfosure Rates Above Spent Fuel . . . . . 15

5. The Basin Filter System . . . . . . . . 18

6. Operation of a Screen Tuie Filter . . . . . . 19

7. Early History of Basin Water Contamination . . 20

8. Transfer of Radionuclides to the Basin Water During a Planned Filter Outage. . . . . . . . . 21

9. The Temperature Dependence of Transfer Rates . . . . 23

10. Removal of Cesium Using Zeolon-100 . . . . . . 27

11. True Ion Exchange Behavior for Zeolon-100 . . . . 28

12. Basin Cooler Cross Section . . . . . . . 33

13. Basin Cooler Piping Options . . . . . . . 34

14. History of Waste Heat Generation in the Storage Basin . . 36

15. Basin Heating During Cooler Outage . . . . . 36

16. History of Exposures from Coolers . . . . . . 40

17. Cask Handling Equipment and Elevations . . . . . 46

18. Fuel Handling Equipment and Elevations . . . . . 52

19. Grappling Mechanism for PWR Bundles . . . . . 52

2i. Grappling Mechanism for BWR Bundles . . . . . 53

21. Building Ventilation Diagram for Key Locations . . . 60

22. Distribution of Burnup for Fuel Shr, ed to morris Operation . 7

23. Time in Transit for Spent Fuel Shipments to Morris Operation 72

24. Time in Storage for Shipments from Connecticut Yankee . . 73

25. Cask Skin Telıperature at Time of Unloading . . . . . 75

26. Exposure Rates at the Cask Surface for Shipments Received
at Morris Operation.

27. Exposure Rate Three Feet from the Cask on Receipt . . . 76

28. Exposure Rate Six Feet from the Transport Vehicle . . . 77

29. Exposure Rates in the Cab of the Transport Vehicle . . 78

30. Cask Coolant Activity on Receipt . . . . . . 79 


\section{LIST OF FIGURES (Continued)}

31. Rate of Spent Fuel Movement . . . . . . . . 81

32. The Dependence of Cask Skin Temperature on the Ambient

33. Effects of Heatload and Handling on Cask Skin Temperature . 85

34. Fuel Burnup and Cooling Time Effects on Surface Exposure Rate on Surface Exposure Rate in the Cask Midsection . . . 88

35. Times Requirt' to Move the Cask into the Decontamination Area . . . . . . . . . . 97

36. Time in the Decontamination Area Prior to Immersion . . 98

37. Delay Times Before Beginning the Unloading of Dresden Shipments. . . . . . . . 100

38. Time for Underwater Work . . . . . . . . 101

39. Time for Preparing the Empty Cask for Shipment . . . 103

40. Time for Loading the Cask onto the Transport Vehicle . . 104

4i. Pre-Shipping Delays for $; 976$ Campäigns . . . . . 106

42. Turnaround Times for Cask Unloading at Morris Operation . 107

43. Temporal Distribution of Shipping Campaigns . . . . 109 
LIST OF TABLES

1. Typical Exposure Rates in Storage Basin Areas

2. History of Transfer Rates for Cobalt and Cesium

3. Comparative Basin Water Quality

4. Overall Heat Transfer Coefficients for Basin Coolers

5. Summary of Grapple Use at Morris Operation

6. Concentrations of Airborne Activity from Fuel Storage Operations.

7. Releases of Radionuclide from Fuel Storage Operations.

8. Fuel Shipping Summary

9. Cask and Trailer Maintenance Items .

10. Cask Skin Temperatures at Time of Unloading .

11. Average Surface Exposure Rates for Individual Casks Carrying Comparable Fuel
14

22

26

39

56

63

63

70

80

85 

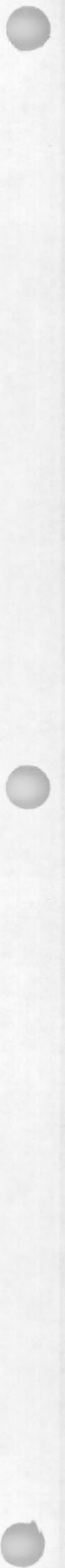


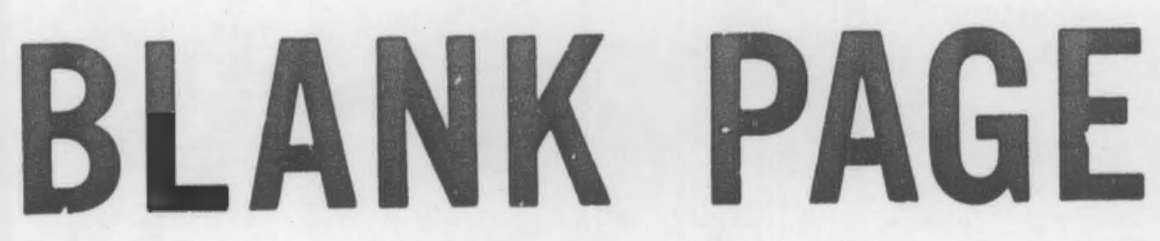




\author{
K. J. Eyer (a) \\ G. E. Zima $(b)$
}

\title{
INTRODUCTION
}

Spent nuclear fuel is stored at General Electric's Morris Operation in a critically safe array under more than 10 feet of water. The water serves as a shield and heat transfer medium and provides for seconcary containment of radionuclides. Handling the fuel underwater with long tools is straightforward. Auxiliary systems provide necessary support functions for carrying out fuel receipt and storage. These systems are shown diagrammatically in figure 1. They consist of 1) heavy lifting equioment for placing shipping casks inte the water, 2) lifting equipment for moving the fuel under water so that it cannot be raised too near the surface, 3) equipment for cooling the water, 4) equipment for maintaining the water purity, and 5) equipment provided to treat and/or contain the radioactivity incident to the storage. Utility and monitoring systems are aiso provided. However, these will not be discussed since they conform in general to industry and health physics standards.

In succeeding chapters, the basin and each of the four major auxiliary systems will be treated individually. In each treatment there will be a detailed description of the system, an enumeration of the operating concerns and limits, and a summary of the performance of that system in achieving those concerns and/or meeting those limits. An analysis of that performance will cunclude each chapter.

In the final four chapters, a time study will be used for assessing the impact of each of these five systems (the basin and the four major support systems) on the receipt, handling and storage of spent nuc?ear fuel.

(a) General Electric

(b) Pacific Northwest Laboratory 


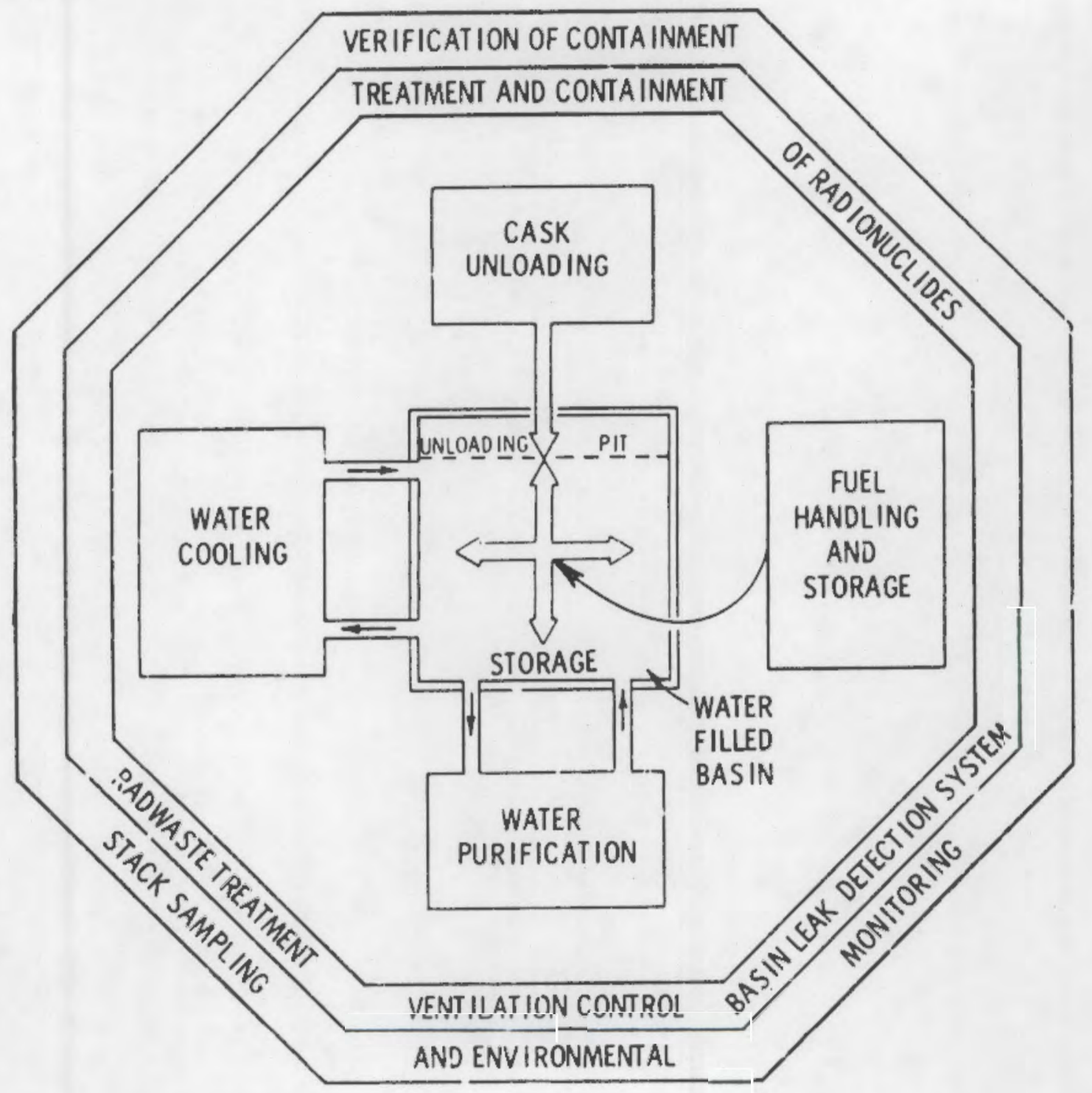

FIGURE 1. Spent Fuel Storage Systems 


\section{SUMMARY}

The storage of spent nuclear fuel at Morris Operation began in January 1972. Since then, a total of 310 MT of fuel has been received in 486 shipments and is currently stured. This report is an evaluation of the design and operation of that facility, based on experience accrued during the intervening seven years.

Design considerations and persormance are analyzed for both the bas in and key suppriting systems. The bases for this analysis are the provisions for containing radioactive by-product materiais, for shielding from the radiction they emit, and for preventing the formation of a critical array.

These provisions have been met effectively over the history of storage at Morris. The release of radioactive materials is minimized by the protection of the cladding integrity, the containment of the basin water, the removal of radioactive and other contaminants from the water, and by filterinr, and then dispersing the basin air. Four auxiliary systems are provided to accomplish this, the basin leak detection system, the filter, the coolers, and the building ventilation system.

The basin leak detection system consists of a series of grooves between the stainless steel basin liner and the adjacent concrete walis. Any leakage of water through the liner is collected, and an alarm system serves to notify Operations personnel of that fact.

A screen tube filter is used routinely to purify the water. This reduces both the concentrations of ions which could chemically attack the cladding or the basin liner, and the concentrations of radionuclides present as well. Any water which might escape would carry very little radioactivity with it.

For cooling, the basin water is passed through a finned tube heat exchanger and ambient air is blown across the fins. For present and past heat loads, active cooling is not required, but the water temperature achieved by use of the coolers serves to reduce the rate of any in-basin corrosion, and the rate that radioactivity is transferred from the fuel to the water. Conditions of high heat and humidity which would adversely affect work in the area are also minimized. 
The building ventilation system draws air from the basin area and passes it through a bed of sand. Once filtered, it is exhausted via a $300 \mathrm{ft}$ stack. Any radioactive materials not filtered out are dispersed to a point where they are not detectable in the environs.

An adequate depth of shielding water is maintained when handling fuel by the use or crane-tool combinations and storage baskets. Criticality is prevented by limiting the types of fuel stored and the storage geometry. The stainless steel baskets consisting of welded tubular sections are a key item for both shielding and criticality considerations. The $13 \mathrm{ft}$ long baskets fit in one-foot-high square grids on the storage basin floor. They can be moved in or out with a lift of just $2 \mathrm{ft}$. By using rigid tools of the proper length, adequate shielding is assured. The iron, chromium and nickel in the baskets act as poisons and in the basket configuration used, fuel eririched to 4.1 percent uranium-235 can be safely stored.

This success in achieving safe storage without environmental impact is enhanced by the benign nature of the fuel storage basin. Water temperature (held near $29^{\circ} \mathrm{C}$ ) and flow (by natural convection) are small fractions of those experienced previously by the fuel in a reactor core where the water temperature is ahove $260^{\circ} \mathrm{C}$, the pressures exceed $2000 \mathrm{psi}$, and flows (for steam in BWR's) reach $10 \mathrm{mph}$. The potential for abrupt changes in storage conditions is also quite limited. The driving force for release of radioactive material is low and decreases as the decay rate in the spent fuel lessens. In addition, the large volume of basin water provides containment for the small amount of radioactivity that transfers from fuel to water and a sink for the decay heat released. The heat generation rate for the fuel of average age $(6.8$ years as of June 1979) is less than 0.004 percent of the rate during operation.

The volume of the basin water $(680,000$ gallons $)$ heats slowly and effectively dilutes any material injected into it. Hence, continuous operation of the auxiliary systems, i.e., the coolers and the filter is not required. Indeed, the coolers and the filter have been shut down for periods of 44 and 54 days, respectively, and limiting conditions of operation were not approached. 
Assessment of cask and fuel handling operations is based on their ability to provide reliable containment during transit, and safe fuel transfer from the cask to storage. This routine receiving and handling operation has been conducted intermittently throughout the seven year period without any measurable effect on the environs, and without any over-exposure of personnel. The only significant accident, the cask tipping incident discussed in Chapter II, also had no impact on either the public or personnel, but fuel handling operations had to be delayed until repairs were complete.

Nevertheless, action to reouce personnel exposure, to improve handling reliability and to lessen the potential for accidents continues to be taken. 


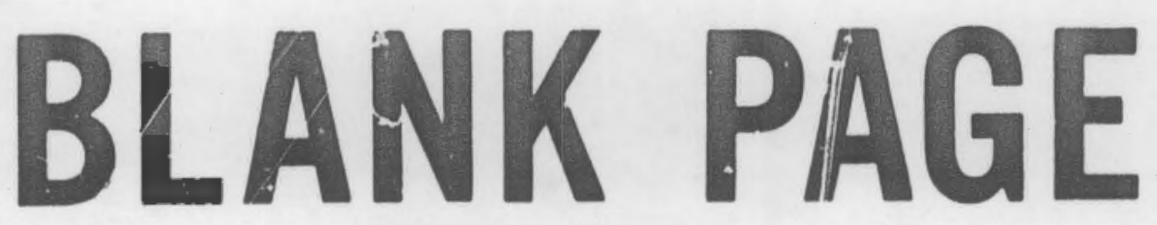




\section{THE BASIN}

\section{DESCRIPTION}

The basin is a below-grade water filled pool made of reinforced concrete. It was poured up against bedrock and lined with stainless steel.

Channels in the concrete just behind the liner serve to convey any water which might leak out through the liner or in thrugh the concrete down to a sump. The sump is equipped with a level detection and alarm systeri and a jetout system which enables one to detect a leak in the basin liner and to remove any leakage or intrusion water which migh.t accumulate there.

The pool is divided into three interconnected parts, the cask unloading basin, and fuel storage basins 1 and 2 . The cask unloading basin is $48 \mathrm{ft}$ deep. It has a shelf under $18-1 / 2 \mathrm{ft}$ of water where casks are placed while handlig equipment is changed. Figure 2 shows two views of the basin configuration. The floors of the shelf and the unloading jasin include provisions to dissipate impact loads, i.e., in the event of a cask drop. The shelf has a 7-in.-thick crushable impact pad made of 1 and $1-1 / 2$ in. steel sheet; and the deep pit has a $2 \mathrm{in.} \mathrm{steel} \mathrm{plate.} \mathrm{The} \mathrm{floors} \mathrm{of} \mathrm{the} \mathrm{storage} \mathrm{basins} \mathrm{are} \mathrm{under} 28-1 / 2 \mathrm{ft}$ of water. The areas of these two storage basins are $1150 \mathrm{ft}^{2}$ and $1850 \mathrm{ft}^{2}$ respectively. Altogether, the three basins hold about 683,000 gallons of wa ter.

The passage way between the unloading pit (48-1/2 ft deep) and the storage basins (28-1/2 ft deep) is protected so that a basket if dropped cannot tip upside down and empty its contents on the unloading pit floor. The unti-tipping gate which accomplishes this is a $4 \mathrm{ft} \times 10 \mathrm{ft}$ rectangle hinged at the level of the storage basin floor. The top ordinarily extends into the unloading pit about $23^{\circ}$ so that the only way that a fuel basket may pass through it is vertically in the upright position.

In the initial design and construction, provisions were made for future expansion of the basin by the inclusion of a gate in the south wall. This is presently sealed on both sides by concrete barriers. The inner one is lined with stainless steel. The area between the two barriers has a liquid level detector and an electric pump out system for the removal of minor leakage. 

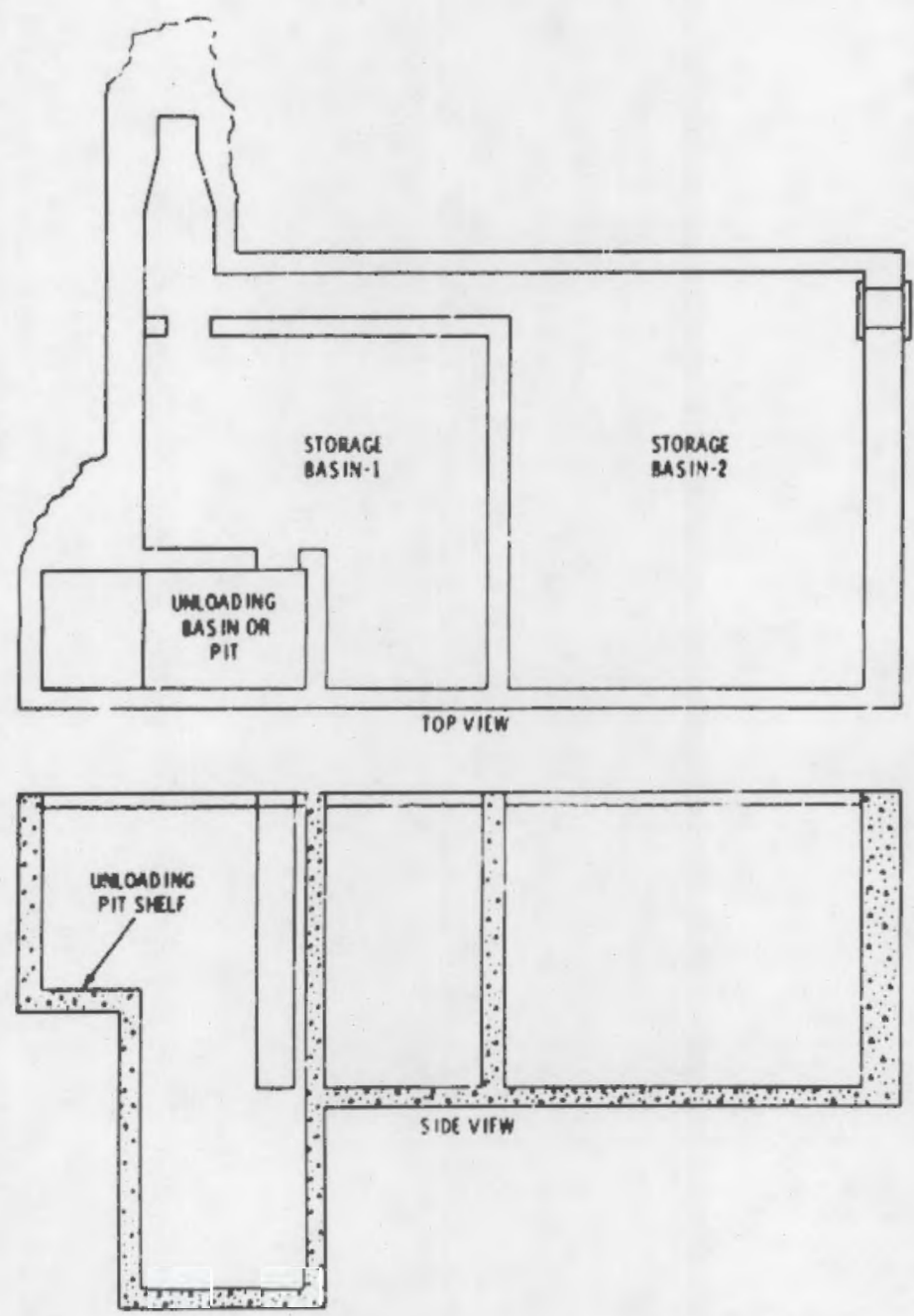

FIGURE 2. Fuel Unloading and Storage Basin Configuration

All penetrations of the basin wall were made within $4 \mathrm{ft}$ of the surface to prevent accidental draining and auxiliary systems were placed above this water level to eliminate any possibility of siphoning.

A stainless steel grid of $27 \mathrm{in}$. souares occupies most of the floor area of each storage basin. The grids are about $1 \mathrm{ft}$ high and are braced against the side of the basins. A casting at each intersection in the grid provides latching and support for fuel baskets. 
There are 151 of these latching squares in Basin 1 and 264 in Basin 2, making a total of 415 . Each one is capable of holuing a single basket. Three additional latching squares are installed in the unloading pit to hold baskets in place during loading.

There are two kinds of baskets; one holds up to four PWR fuel assemblies and the other up to nine BWR assemblies. The two kinds of baskets are interchangeable and may alternatively be moved to any vacant storage location.

Diagrams of the baskets are shown in Figure 3 . The iron, nickel and chromium content in the baskets (304 SS) was considered in determining the criticality limits for storage.

The maximum storage capacity of the basin is 747 metric tons, but this is only attainable if BWR fuel would be stored exclusively. However, since only about 40 percent of the available spaces are expected to be filled with BWR fuel, the effective capacity is about 700 metric tons.

\section{OPERATING PRIORITIES AND LIMITS}

Shielding

The first criterion in the operation of the basin is to provide shielding from the spent fuel. This is accomplished by :toring the fuel under $14 \mathrm{ft}$ of water and by restricting handing operations sc that water coverage of the fuel is always at least $9 \mathrm{ft}$. Two things need to be done to meet this requirement. First, one needs to assure that adequate water is present and second, that fuel cannot be lifted too close to the surface.

Continuous monitoring of the basin water level is achieved through the operation of the basin water level indicator and the basin leak detection system (LDS). The first system monitors the actual basin level and alarms if the level should drop $2 \mathrm{in}$. below the ordinary operating level. It is sensitive to the loss of 4000 gallons. The second provides an indication and alarm if the water in the collection sump for leakage from behind the basin liner reaches a preset level. It is sensitive to a leak of just 40 gallons. Several systems are available to replace this lost water via the demineralized water supply. Potable or fire water could be added in an emergency, and water could even be hauled from a nearby river. 


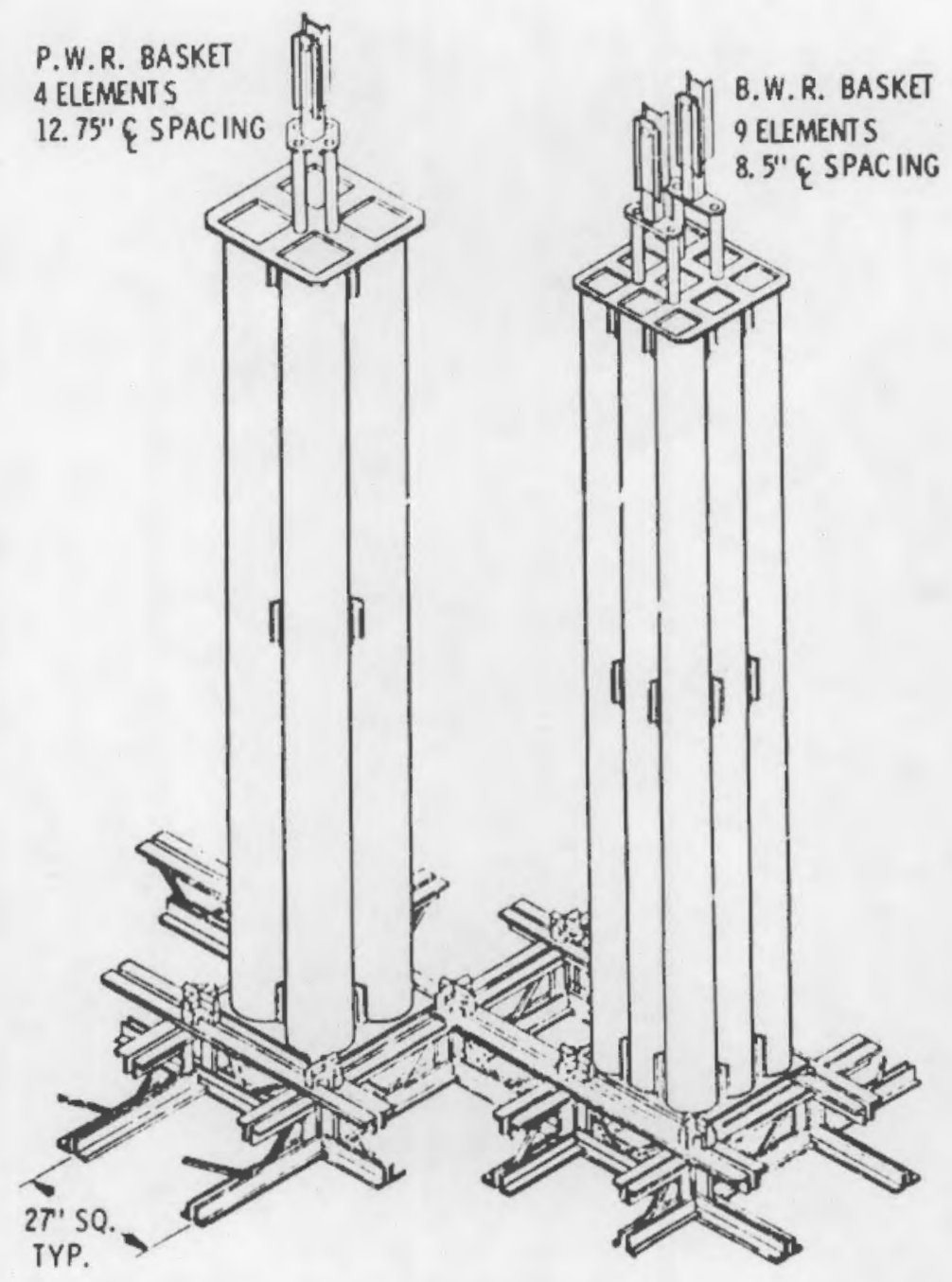

FIGURE 3. Fuel Storage Baskets and Grids

Rigid tools are used to move fuel so that fuel cannot be lifted too close to the surface. The length of the tools is selected so that even with the crane fully up the minimum water Jepth is maintained. The grapples used with the fuel handling crane are $41 \mathrm{ft}$ long and basket hooks used with the basin crane are $14 \mathrm{ft}$ long. The tools are discussed further in Chapter VI.

\section{Criticality Safety}

A second criterion is to provide criticality-safe storage. A license commitment and condition limits the effective multiplication factor ( $k_{\text {eff }}$ ) 
to values less than 0.95 . Operation within this limit is achieved by restricting the available storage geometries to two and by limiting the kind of material stored.

Fuel must be stored in one of the two kinds of baskets (shown in figure 3) and these baskets must be placed in the grid work covering the basin floor. This establishes a minimum spacing between bundles and provides a poisoning effect of the iron, nickel and chromium in the stainless steel tubes which surround $e, h$ one. Each different kind of fuel bundle considered for storage is analyzeu, see that it will not cause the $k_{\text {eff }}$ limit to be exceeded if it were to be stored in this configuration. (a)

The baskets and latching mechanism were designed to resist forces (inherent in earthquakes) arising from ground acceleration of $0.2 \mathrm{~g}$, and tested suciessfully under like conditions. Hence they can be expected to continue to provide safe storage.

\section{Containment}

The third criterion is in the containment of radionuclides that transfer from the fuel to the water. Both the liner and the concrete basin wali serve as barriers for this purpose, and the leak detection system effectively isolates the basin water from the neighboring ground water. That is, there can be no transfer of water from the basin to the ground water (or vire versa) unless this water passes through the LDS. Monitoring of the accumulation of water in the leak detection system and analyzing samples of it enables leaks to be identified promptly.

The maintenance of the level in the LDS below adjacent ground water leveis prevents any radioactive material which might have leaked through the liner from going any further.

\section{BASIN PERFORMANCE}

Operation of the basin for seven years has met design expectations. There have been no major losses of water, and no deviations from criticality-safe

(a) No credit has been taken in this kind of analys is for the decrease in reactivity which comes with increasing burnup. 
storage. The cask tipping incident in 1972, which ruptured the liner did result in some water loss, but the water level dropped less than I in. In this event, an empty IF-100 cask $^{(a)}$ and its lifting yoke became jammed together. Efforts to separate them then resulted in the tipping of the cask against the unloading pit wall. The liner was torn and the leak detection system filled up with water. Recovery from the incident was rapid and successful. The cask was uprighted and removed and a temporary patch was installed within $24 \mathrm{hr}$. A perminent patch was installed 12 days later.

\section{Liner}

Very little ?eakage through the liner has been seen. Water is found to accumulate in the basin leak detection systen at the current rate of about 0.6 liters/day. The concentration of the radioact:vity in this water is much lower than that in the bas in however, and suggests that at least 90 yercent of the accuriulation comes from outside. This was confirmed when a gamma isotopic analysis of the LDS water was made. The ratio of concentrations of cesium-137 to that of cesium-134 in this water was about nine, while in basin water now the ratio is about four. Hence the activity found in the LDS is not coming from existing leaks, rather it must be left over from the cask tipping incident - (the cesium-134 has had three half iives to decay) having been leached off of the LOS surfaces by the incoming water. The success in mininizing leakage is due in part to careful inspection of welds during construction. Vacuum box, ultrasonic and bubble test techniques were all used with varying results. The most successful test, however, consisted of incrementally filling the LOS to a level $4 \mathrm{ft}$ higher than the basin water level and then the checking of the inner surface of welds for leaks.

A small leak has occurred in the liner of the expansion gate and the water is collected in the area between the two barriers. The rate of leakage was first measured in 1975 and has varied from nothing to 2 liters/hr depending in part on the temperature of the basin water and the surroundings. Since the rate has been small and is not worsening, a major effort to correct it has not been justified. Instead the water that accumulates is periouically pumped to the iow activity waste vault.

(a) Single element cask, now obsolete. 


\section{Grids and Baskets}

The baskets and grids which define the safe storage array have been latched and unlatched with ease. Over 1500 such latching and unlatching events have been made estabilishing the reliability of this system at about 0.998 . One reason for this reliability is the QA performed on the grids and the baskets first by the vendor and then at Morris. A go-no-go gauge was used to check the grids for fit prior to installation and a baskel was used afterwards. The baskets are checked in a "standard" grid section (for fit and proper latching) and in a vertical test envelop (for plumbness) before being put in the basin.

The only deviation from perfect performance occurred when an empty basket which was being lifted from the unloading pit grid did not properly disengage. This resulted in the grid being raised along with the basket. The basket was lowered to reset the latches and then raised again to separate it from the grid. Once free, the basket, grid and wedge braces were removed from the basin and inspected. The grid and braces were found to be undamaged and were subsequently reinstalled. The basket was removed from service. Less than a single day's operational delay resulted from this evert.

\section{Makeup Water}

The manual addition of water to the basin has never proved a problem. This is partly due to the inherently large margin of safety, i.e., water loss mechanisms are slow and a large loss is required before detrimental effects are seen. Water losses have been due to evaporation (about $200 \mathrm{gal} / \mathrm{day}$ ) and cask or filter flushing (basin water is used to flush out cask cavities and to backwash the filter). These are ordinarily made up by an addition of 1000 to 3000 gallons of demineralized water every week or two. The variations in basin level caused by insertion or removal of a cask, and because of changes in temperature have also been accommodated by this infrequent addition. Shielding

Measurements have been made which verify the shielding adequacy of the depths of water routinely mu $n$ tained. A typical exposure rate at the surface, 
about $1.5 \mathrm{mr} / \mathrm{hr}$, (a) was found to be due to radioactive contaminants aloile. Even this turns out to be small when compared to exposure from other equipment (e.g., the coolers or the vacuum cleaner hose) or from the slight deposit of radioactive materials on the liner at the surface of the water. Comparable values for typical exposure rates are shown in Table I.

The absence of any significant contribution from the fuel is seen by referring to measurements made aoove fuel on three separate occasions. These measurements are shown graphically in Figure 4. From this Figure it is seen that the direct gamma radiation cannot be distinguished from that contribution made by contaminants in the water $(23 \mathrm{mr} / \mathrm{hr})^{(\mathrm{b})}$ more than $8 \mathrm{ft}$ above the fuel.

TABLE 1. Typical Exposure Rates in Storage Basin Areas

\begin{tabular}{lcc}
\multicolumn{1}{c}{ Location } & & $\begin{array}{c}\text { Exposure } \\
\text { Rate } \mathrm{mR} / \mathrm{hr}\end{array}$ \\
\cline { 1 - 1 } Surface of Water & & 10 \\
Wall of Basin at Su:face & & 40 \\
Vacuum Cleaner Hose at l ft & & 15 \\
Basin Aisleway & \\
Basin Aisleway Near Coolers & 3 \\
Basin Aisleway Near & 11 \\
Decontamination Area & 10 \\
Decontamination Area & \\
Pump Room &
\end{tabular}

(a) Semi-infinite source geometry.

(b) Infinite source geometry. 


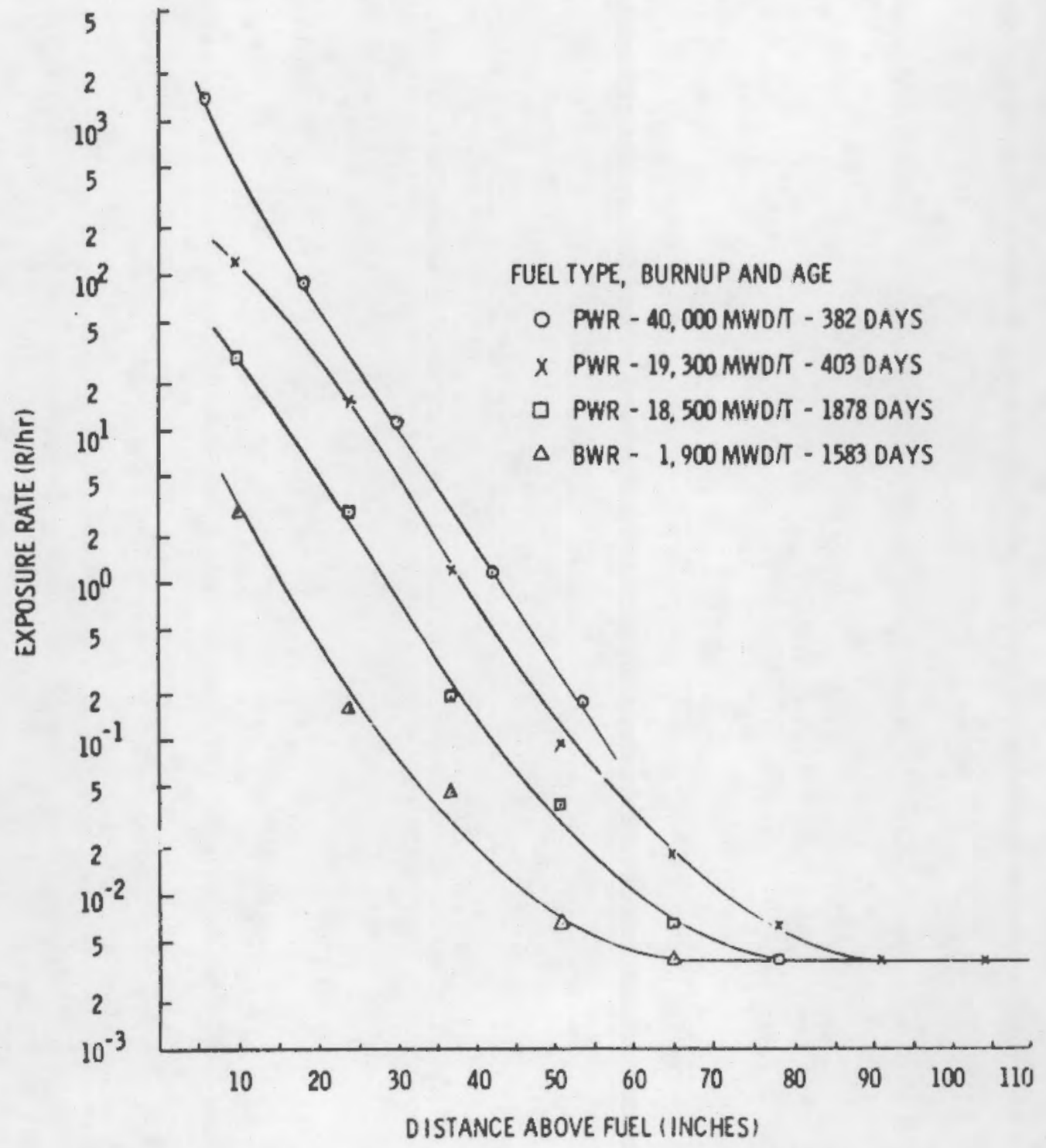

FIGURE 4. Gamma Exposure Rates Above Spent Fuel

ANALYSIS

The basin as designed has provided for shielding of the fuel, secondary containment for radioactive materials which come from the fuel and criticality-safe storage over the life of the facility. In each case there are substantial margins of safecy which permit flexibility in the handing of the fuel. 
The basin leak detection system isolates the basin water from neighboring ground water.

The liner and the concrete basin walls confine the water and radioactive materials in it. Even in the one case when the liner was ruptured, significant. amounts of radioactivity were not released to the environs. The overall integrity of the liner has been demonsirated by the comparative lack of radioactivity in the leak detection system water.

\section{Baskets}

The interchangeability of the baskets perinits the easy retrieval of any basket in the basin and/or the removal of fuel baskets from an area to make it accessible for repairs.

\section{Shielding}

The conservatism in shielding depth which exists permits added flexibility should an emergency develop. Hypothetically, fuel could be raised to depths substantially less than the nine foot limit without creating an imminent hazard to personnel. For example, the temporary presence of exposure rates on the order of $100 \mathrm{mR} / \mathrm{hr}$ at the water surface would not exclude concurrent emergency response in the area.

\section{Criticality}

Conservatism in criteria through which a bundle may be accepted for storage permits movement an. storage without further restriction. Only one bundle or basket is moved at a time, but once the fuel is in a basket the basket can can be moved anywhere through the storage basin and stored in any location. 


\section{WATER PURIFICATION}

\section{DESCRIPTION}

Basin water is purified through use of a Powdex filter system. This sysiem consists of a skimmer, a pump, a screen tube filter and a sludge tank. During filter operation water is pumped from the basin via the skimmers through the filter media and back to the basin. Valve changes permit removing water from any of the three basin areas, and returning it (after filtering) to any one selected. Alternately, a suction (vacuum cleaner) hose may be used as an inlet so that the system may be usted for cleaning the basin floor and walls or other equipmeni.

The basin filter includes two auxiliary piping systems. One of these is a loop which includes an agitated makeup tank. Here a suspension of filter media, such as Solka Floc (a cellulose filter material), can be prepared. It is pumped as a siurry to the filter and coats the screens. Diatomaceous earth, resins, and/or i,n exchangers can then be added in a similar way. Once the filter cakc has been properly set (no bleed-through of the filter media occurs), the system is switched via an automatic sequencer so that bas in water is circulated. Figure 5 shows the components that make up the filter system, and Figure 6 shows the operation of the filter tubes.

In normal operation, the useful life of the filter is determined by the pressure drop across tic filter or by the depletion of the capability of any ion exchanger present in the cake. This in turn depends on the nature and amount of contaminants in the water and the operational needs at the time. When the filter cake needs to be changed, the system is isolated from the basin. After the upper part of the filter vessel has been filled with compressed air, the valve to the sludge tank is suddenly opered. The filter cake and its contents are dislodged, or "bumped", from the screen tube and flow by gravity to the sludge tank along with the water. The sludge tank is subsequently emptied (via a steam jet) to the Low Activity Waste (LAW) vault. Aiternately, the filter may be placed in standby status where the flow through the filter is maintained (and hence the integrity of the filter cake is not disturbed) but where the system is isolated from the basin. The filter and 


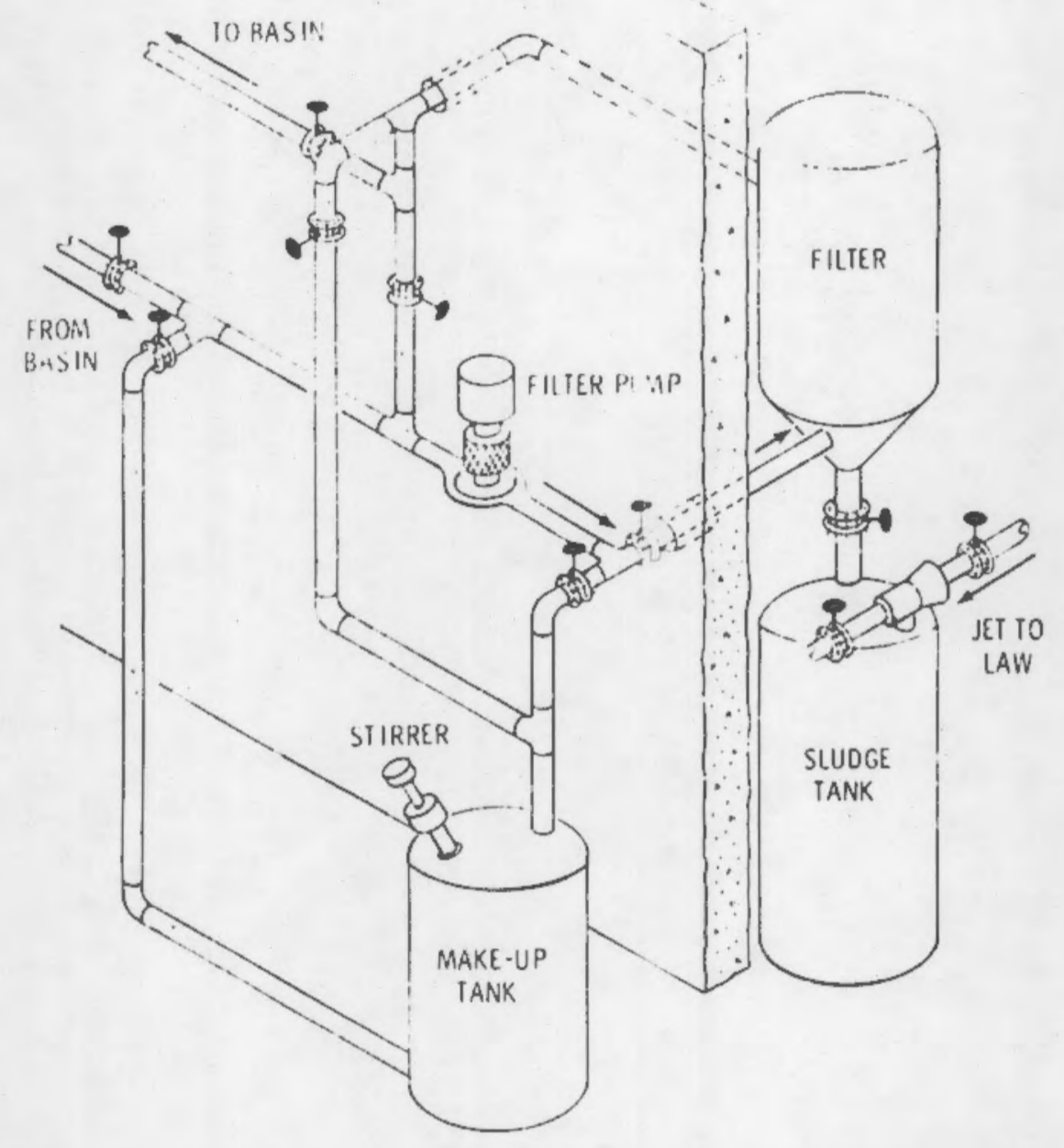

FIGURE 5. The Basin Filter System

the sludge tank are both installed in a room shlelded with $2 \mathrm{ft}$ of concrete. No normal operations require access to that room. Operation of the filter system is by controls located in the adjacent Pump Room.

\section{Water Cleanup Need}

The chief reasons for having a filter system are 1) to control water quality for the prevention of possible corrosion of the basin iner or equipment, and 2) to control the levels of radioactive materials which 


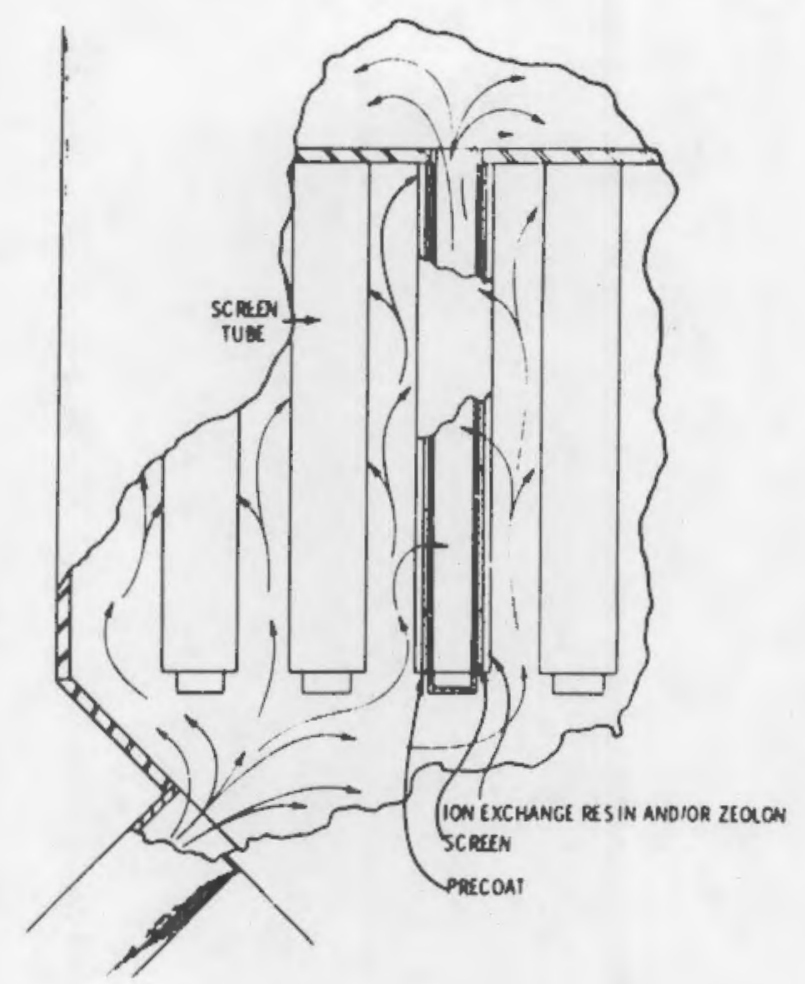

FIGURE 6. Operation of a Screen Tube Filter

transfer from the fuel to the water during handling and storage. Since the radioactivity contributes to personnel exposure and to equipinent and facility contamination, there are strong incentives to minimize it. Adcitional reasons are to maintain water clarity for ease of operations and to remove nonradioactive impurities which may enter the pool, i.e., dirt from casks, settling dust, or debris from overhead work, and corrosion products from auxiliary piping.

The screen-tube filter is ideal for this spectrum of need since the filter media may be selected to $f i c$ the circumstances. Several media can also be mixed, and beds can be changed frequently to heighten the removal capability.

A steady but fairly slow transfer of radioactivity from the fuel to the water has been observed during the seven years of storage here. This can be seen in Figure 7 where the concentration of radioactive species increased 


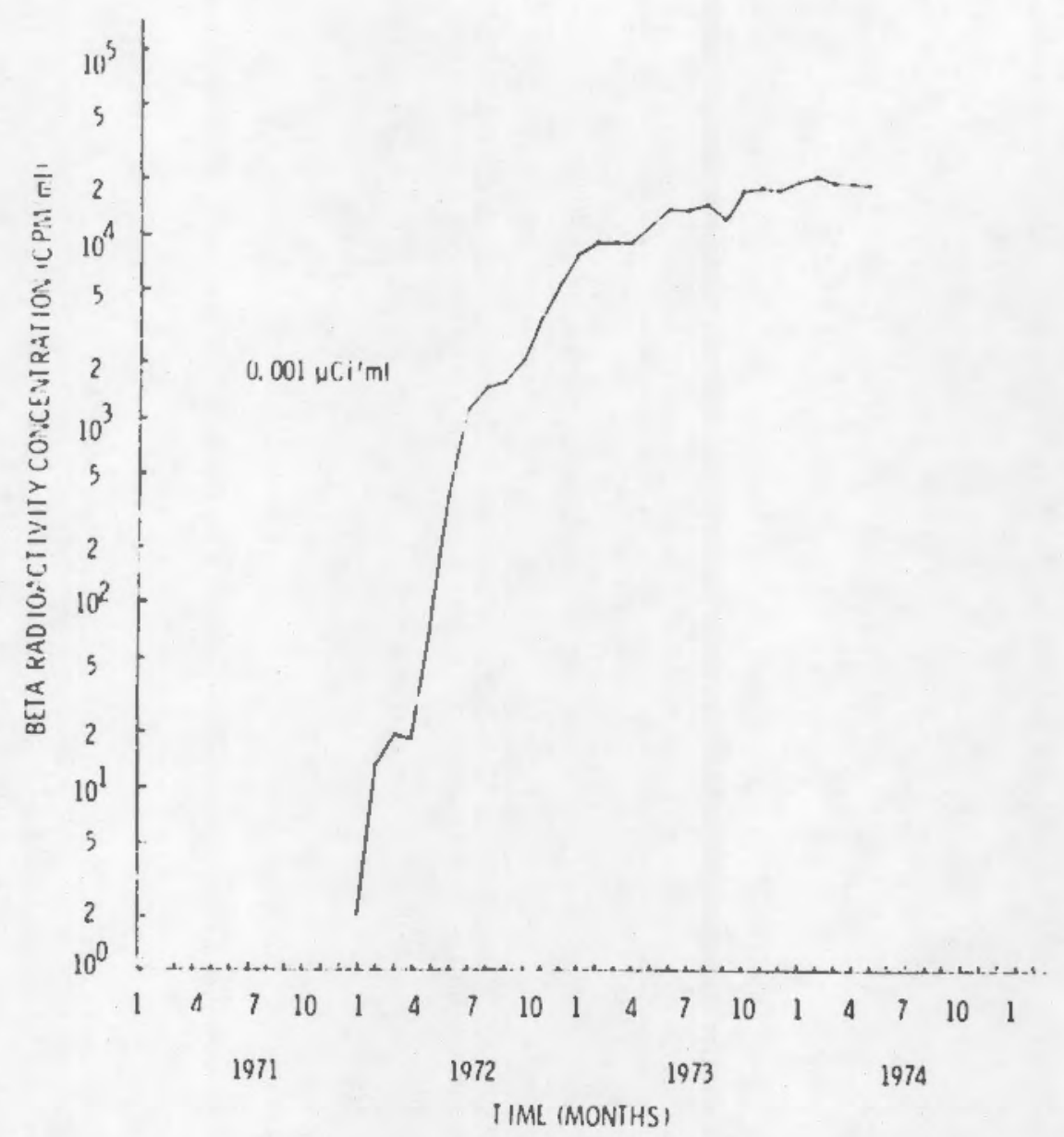

FIGURE $;$. Early History of Bas in Water Contamination

over a period of time to an apparent equilibrium value. Here the rate of removal by the filter must nearly equal the rate of transfer from the fuel.

Further measurements of the rate of transfer were made beginning in 1975 and continuing to the present. The chief isotopes found to transfer this way were cesium -137 and -134 and cobalt -60 and -58 . Rates of transfer were found to vary depending on the length of time the fuel had spent in the pool (the longer the storage, the slower the rate) and on the temperature of the water. This phenomenon of transfer is shown in the two figures and the table which follow. Figure 8 shows the behavior of radiocesium and radiocobalt during periods when the purification system was not operating. 


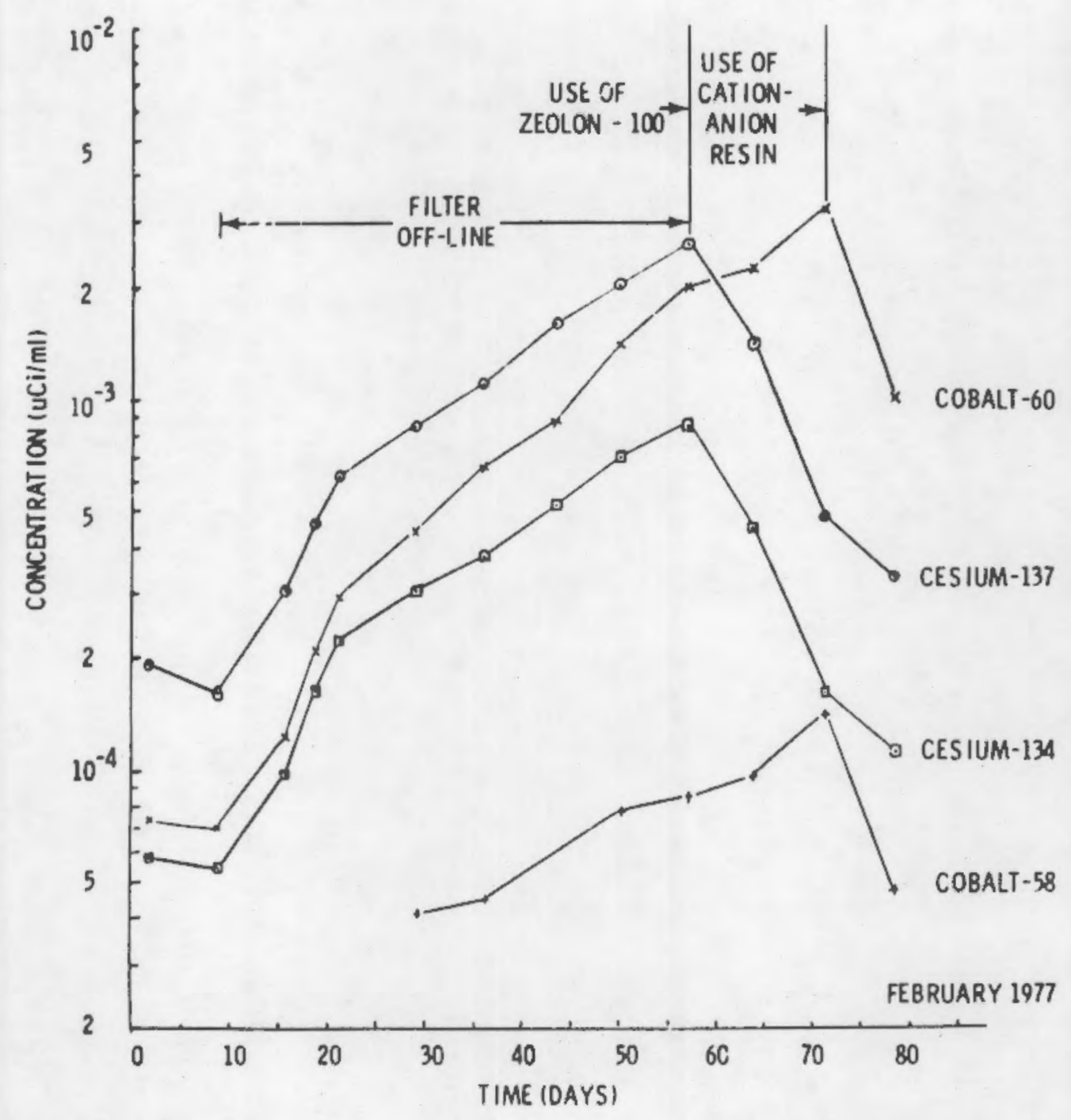

FIGURE 8. Transfer of Radionuclides to the Basin Water During a Planned Filter Outage

Table 2 shows the transfer rates calculated from this and other similar occasions (the values are grouped to show the effect of temperature and fuel age), and Figure 9 shows the temperature effect. 
TABLE 2. History of Transfer Rates for Cobalt and Cesium

\begin{tabular}{|c|c|c|c|}
\hline \multirow{2}{*}{$\begin{array}{c}\text { Time } \\
\text { Month/Year } \\
\end{array}$} & \multirow{2}{*}{$\begin{array}{l}\text { Basin Water } \\
\text { Temperature } \\
\quad{ }^{\circ} \mathrm{C}\end{array}$} & \multicolumn{2}{|c|}{$\begin{array}{c}\text { Transfer Rates } \\
\text { Curies/Day }\end{array}$} \\
\hline & & Cesium-137(b) & Cobalt-60(a) \\
\hline $1 / 77$ & 25 & 0.08 & 0.05 \\
\hline $4 / 78$ & 25 & 0.11 & 0.11 \\
\hline $1 / 76$ & 32 & 0.10 & 0.08 \\
\hline $8 / 77$ & 30 & 0.06 & 0.12 \\
\hline $9 / 77$ & 28.5 & 0.04 & 0.09 \\
\hline $4 / 78$ & 30 & 0.09 & 0.18 \\
\hline $6 / 78$ & 30 & 0.08 & 0.15 \\
\hline $12 / 75$ & 35 & 0.06 & 0.05 \\
\hline $5 / 76$ & 35 & 0.15 & 0.14 \\
\hline $5 / 78$ & 35 & 0.12 & 0.26 \\
\hline $6 / 78$ & 35 & 0.12 & 0.25 \\
\hline $6 / 75$ & 42 & 0.19 & -- \\
\hline $1 / 77$ & 41.5 & 0.22 & 0.22 \\
\hline $5 / 78$ & 40 & 0.12 & 0.37 \\
\hline
\end{tabular}

(a) Cobalt-60 transfer rates increase appreciably with increased temperature, and slightly with time and hence the amount of fuel stored.

(b) Cesium-137 transfer rates increase slightly with temperature, but do not change appreciably with time and amount of fuel stored. 


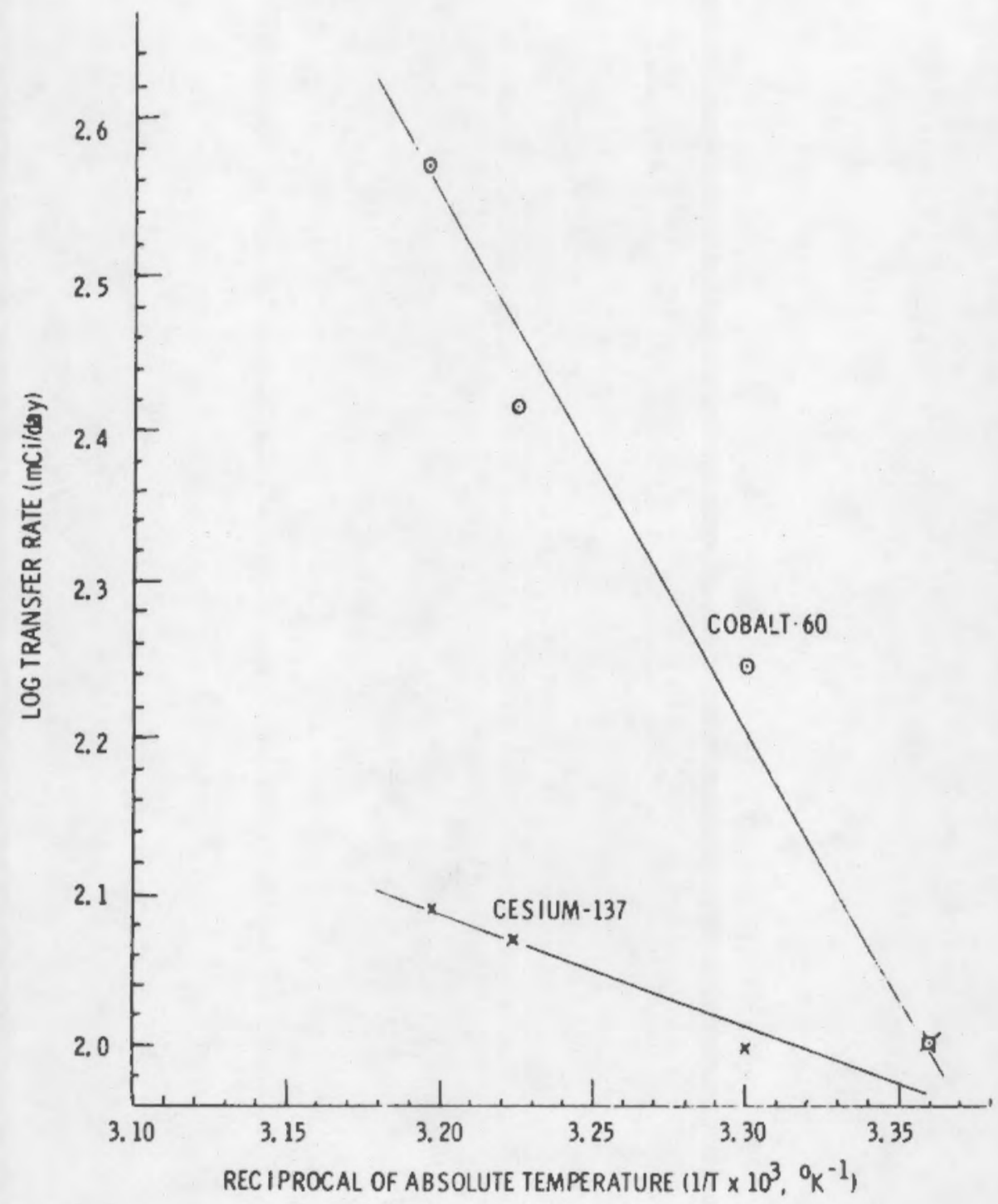

FIGURE 9. The Temperature Dependence of Transfer Rates

\section{OPERATING PRIORITIES AND LIMITS}

A major concern for the purity of the water is the protection of barriers, i.e., fuel cladding and the basin liner, which provide primary and secondary containment for radionuclides in the stored fuel. This concern is addressed by maintaining the $\mathrm{pH}$ and level of contaminants in the water in ranges where chemical attack would not occur appreciably over long periods of time. 
Operationally this is achieved by keeping the $\mathrm{pH}$ between 4.5 and 9 , the sodium nitrate concentration below $200 \mathrm{ppm}$ and the chloride ion concentration below $10 \mathrm{ppm}$. In each case there are license limits which identify these points. A further reduction in the chance for chemical attack is achieved by even tighter operational controls which call for reducing these levels to as low a value as possible through the normal routines. With values well within the limits, trends can be identified and anaiyzed in time to take early action.

A second major concern pertaining to water purity is the contribution it makes to exposure that personnel receive in working over it or nearby. This is addressed in the license by limits placed on the overall beta activity in the basin of 0.02 and $0.1 \mu \mathrm{Ci} / \mathrm{ml}$. Exceeding the first 1 imit requires that some action be taken but fuel receiving and storage operation need not stop. If the second limit is exceeded, all operations must cease until the water quality is restored. Normally, operational leve?s of radioactivity are kept well below these limits so that personnel exposure is reduced, and trends can be seen. Too, the reduction of other contaminants makes control of the radioactive species more readily attained.

A third concern, that the basin water could be lost via a major leak in the filter piping, has also been addressed. Input from the skimmers is limited to the top 2 in. of water. So, if the level drops below that the pump would lose suction and flow would cease.

\section{PERFORMANCE}

The operational history of the basin filter can be divided into two eras. In the first, the operation was not completely understood, and performance was complicated by the presence of a large amount of sodium nitrate (up to $300 \mathrm{ppm}$ ) in the water. The sodium nitrate, which had been used as anti-freeze in early shipments of low thermal-output spent fuel, was an unwanted electrolyte. Furthermore, the presence of the sodium ion limited the ability of the ion exchange resin to remove cesium and the concentration of radiocesium rose to a value of $0.012 \mu \mathrm{Ci} / \mathrm{mi}$ shown earlier (Figure 7 ). The control of $\mathrm{pH}$ of the water was also affected by the sodium nitrate and the basin water $\mathrm{pH}$ approached the lower license limit of 4.5 . The $\mathrm{pH}$ was below five periodically in 1973 and 1974, constantiy from March to September in 1975. 
The low $\mathrm{pH}$ was responsible in part for the corrosion of the original carbon steel coolers in July 1973 (discussed in Chapter IV). Rust that resulted was a second major challenge to the filter system. At first, during cooler operation, the water clarity could not be maintained even with as many as three filter changes per shift. As a result, the water became so colored that the fuel could not be seen. However, once the coolers were shut down, the filter (operating normally with the standard precoat and resin mixture) was able to restore the former crystal clarity. Fuel handling was resumed within a month after only 11 filter changes. The first era of filter operation came to a close as regular use gradually reduced the level of nitrates to about $5 \mathrm{ppm}$. Since sodium nitrate was removed batchwise $(3 \mathrm{~kg}$ with each changeout of the Powdex system) the removal process had been quite slow.

The second era began with a concerted effort in March 1976. The filter was changed daily for eight days and successfully removed 95 percent of the remaining sodium and nitrate ions. With this reduction in nitrate, the chloride removal efficiency improved and concentrations of that ior were also decreased. Chloride concentrations, typically $3 \mathrm{ppm}$, were reduced to $<0.1 \mathrm{ppm}$, and have since remained at that level.

In addition, the mix of cation and anion resin had been adjusted to increase the equilibrium hydroxyl ion concentration and thereby the $\mathrm{pH}$. In the absence of significant ionic impurities the $\mathrm{pH}$ has lieen controlled by the carbon dioxide dissolved in the water and is normally 5.8 .

A final improvement incorporated the use of an inorganic exchanger, Zeolon, which has specific ability to remove cesium. This was first tested in 1975 and used regularly, since the beginning of 1976. The improvement in the basin water quality between the two eras is shown in Table 3 .

The last of these changes, the use of Zeolon, has had a major effect in the operation of the basin. The concentration of radiocesium, once the number one contaminant, was reduced by a factor of 30 , and is kept at that level during routine operation. As a result, interer+ in cobalt-60 has increased and, by default, may be of greater concern. Zec was found to operate as a classical ion exchanger in the high purity basir. er, and this has been 


\section{TABLE 3. Comparative Basin Water Quality}

\begin{tabular}{|c|c|c|c|}
\hline Impurity & Unit & $\begin{array}{l}\text { May } 1,1975 \\
\text { Value }\end{array}$ & $\begin{array}{l}\text { July } 1,1978 \\
\text { Value }\end{array}$ \\
\hline Cesium-1.37 & $\overline{\mu \mathrm{Ci} / \mathrm{ml}}$ & $4.0 \times 10^{-3}$ & $0.15 \times 10^{-3}$ \\
\hline Cesium-134 & $\mu \mathrm{Ci} / \mathrm{ml}$ & $1.6 \times 10^{-3}$ & $0.04 \times 10^{-3}$ \\
\hline Coba $1 t-60$ & $\mu \mathrm{Ci} / \mathrm{ml}$ & $4.0 \times 10^{-4}$ & $2.3 \times 10^{-4}$ \\
\hline Conductivity & umho & 75 & 1.0 \\
\hline Chloride Ion & $\mathrm{ppm}$ & 3 & $<0.1$ \\
\hline Sodium Nitrate & $\mathrm{ppm}$ & 37 & $<0.8$ \\
\hline $\mathrm{pH}$ & & 4.6 & 5.6 \\
\hline
\end{tabular}

the secret of its success. Cesium is partitioned between the resin and the water according to a distribution coefficient $\mathrm{K}_{0}$ of about $10^{7}$ ( $\mu \mathrm{Ci} / \mathrm{g} \mathrm{per}$ $\mu \mathrm{Ci} / \mathrm{ml})$. This means that for the normal charge of resin $(2 \mathrm{Kg})$, about 90 percent of the cesium is removed from the water as it passes through the filter. Ordinarily equilibrium is reached after 100 hours. The removal rate could be enhanced further by using a larger charge or by having sized the filter to handle a greater throughput. Figure 10 shows the effect of adding Zeolon-100 to the filter and Figure 11 shows how the concentration varies in comparison to the classical ion-exchange model.

Ionic cobalt-60 which apparently transfers from the crud on the fuel is effectively removed by the cation-anion ion exchange resin used as part of the filter cake. Forty kilograms of this material was used in the instance shown in Figure 8 and six curies of dissolved cobalt-60 were removed. Continued use of this resin is required to accommodate the amount of new material which is transferring from the fuel surface.

The efficacy of the present systr: was best demonstrated by the recovery after the test period in early 1977 (see Figure 8). The precoat and Zeolon-100 were used first when the filter operation resumed. This caused a dramatic reduction in the concentration of radiocesium (from $3.3 \times 10^{-3}$ to $0.84 \times$ $\left.10^{-3} \mu \mathrm{Ci} / \mathrm{ml}\right)$. Seven curies of cesium were removed in the first run and six curies of cobalt were removed in the second run. 


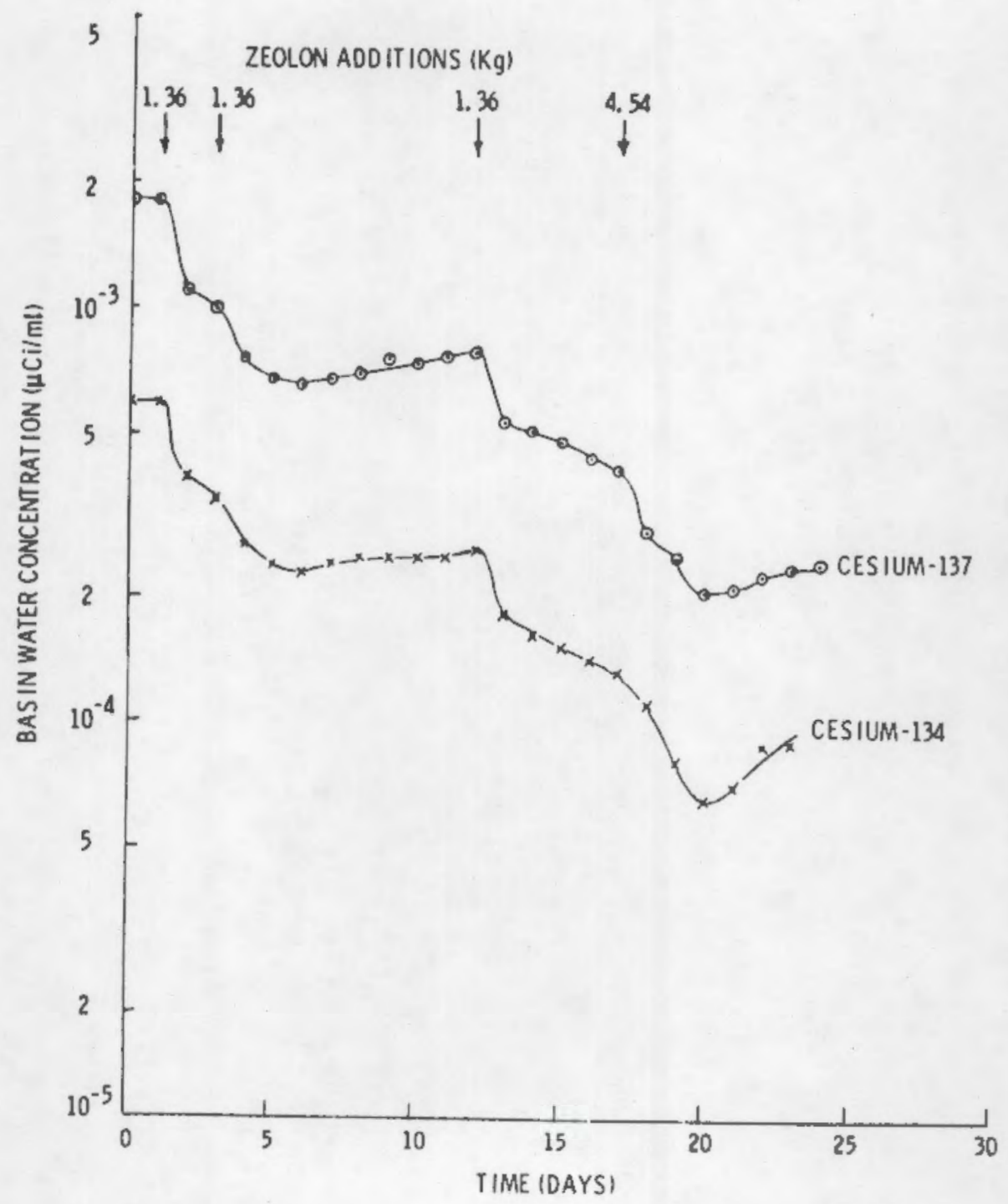

FIGURE 10. Removal of Cesium Using Zeolon-100

\section{Mechanical Operation}

The filter is capable of operating for extended periods of time without rebuilding. The actual length of operation is determined by several priorities. A brief loss of power, for example, stops the flow of water through the filter and the cake immediately begins to slough off. In such an instance the filter must be dumped and remade. A second reason for rebuilding the filter cake 


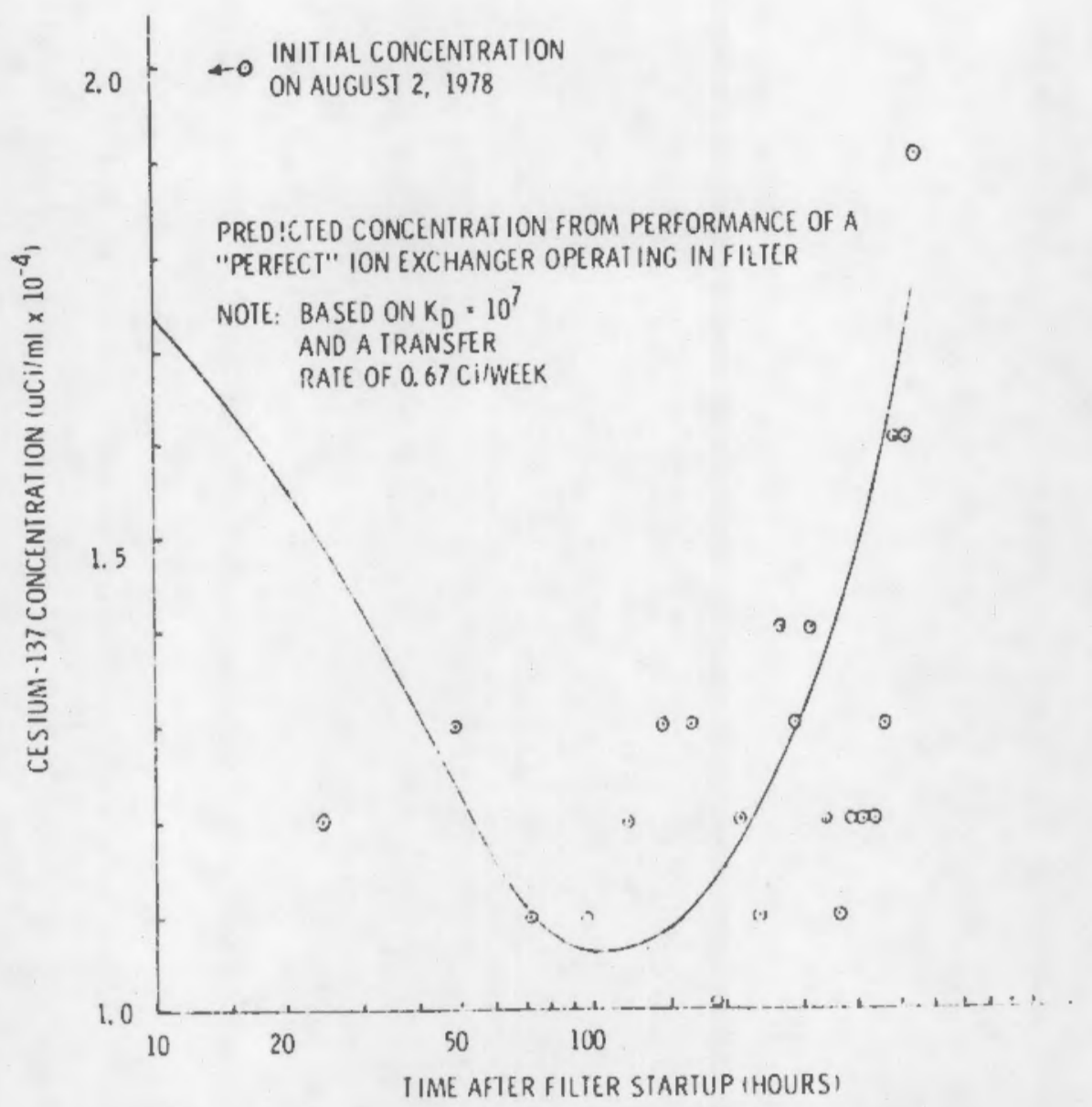

FIGURE 11. True Ion Exchange Gehavior for Zeolon-100

occurs when the pressure drop across it reaches a predetermined value. When the water is free of most particulate matter, the pressure drop builds up very slowly and the same filter cake may be used for several months. Invariably, however, there comes a power loss and the operation is interrupted. To date, the longest filter run has been 50 days. A third reason to shut down the filter and rebuild the cake is to replenish the resin. In 1973, when the sodium nitrate concentration was high, the filter cake was often replaced because its exchange sites became saturated. Later, when cesium concentrations were high, incremental reductions were achieved by successively rebuilding the filter with new Zeolon as soon as the basin water activity had become constant. 
Mechanical difficulties in the fllter renewal system have been limited 1) to sequencing problems, 2) to jet or valve failure in discharging spent resin and 3 ) to the need to mechanically clean the screen tubes. Sequencer problems were frequent in the early operation of the filier. Valves in the system failed to open or close at the proper time and this interfered with the proper building of the filter cake. Fixes for these problems were usually achieved in a matter of an hour or two and represented only slight increases in the amount of time required to make a filter change, normally three to four hours. In one case, a sequencer malfunction allowed water, which was being circulated through the new cake, to enter the already full sludge tank. The overflow which followed went into the air tunnel necessitating clean up. One other outage (in 1972) resulted from a similar overflow. This time steam condensatc was introduced into the sludge tank via a leaky supply valve to the steam jet.

On two occasions the jet for emptying the sludge tank became jammed, and in each case the jet was remo:ed and cleaned out. During the second outage the jet was rebuilt using flanged rather than welded fittings to facilitate future maintenance. Finally, the screen tubes were removed and cleaned twice. This became necessary in 1972 and again in 1974 when the pressure drop across the screens alone was too high.

The overall on-line record for the filter shows that it has been operated 94 percent of the time, while filter changes and outages each account for three percent. One outage that was extended to 47 days for test purposes accounts for a substantial part of the down time.

\section{AIIALYSIS}

Experience at Morris Operation shows that the use of the Powdex filter system modified by the inclusion of Zeclon-100 is fully capable of maintaining the concentrations of impurities at acceptably low values. During routine operation to date, representative values for water contamination are from one to two percent of the license action values. This is illustrated for recent (1978) transfer rates (at $30^{\circ} \mathrm{C}$ ) where a single charge of $80 \mathrm{~kg}$ of 
cation-anion resin mixture and $2 \mathrm{~kg}$ of Zeolon-100 was sufficient to maintain the concentrations of cobalt-60 and cesium- 137 at $2 \times 10^{-4}$ and $1 \times 10^{-4} \mu \mathrm{Ci} / \mathrm{mi}$ respectively for 25 to 30 days.

The high affinity of Zeolon for cesium, and the enhanced performance of ordinary cation-anion resins in high purity water account for this operating margin. Because of it, fuel storage activities are insensitive to filter outages even over an extended period of time. Sudden large influxes of radioactivity, though not experienced to date, could also be readily handled.

The filter is operated remotely, and maintenance is infrequent, hence personnel exposure from its use is not excessive.

Characteristics of the water cleanup system are summarized as follows: Ion Exchange Performance

The distribution coefficient for Zeolon-100 is $10^{7}$ ( $\mu \mathrm{Ci}$ cesium/g resin)/ ( $\mu \mathrm{Ci}$ cesium/ml water).

The distribution coefficient of the Powdex cation exchange resin for the cobalt species found in basin water is $10^{6}$ ( $\mu \mathrm{Ci}$ cobalt/g resin)/( $\mu \mathrm{Ci}$ cobalt/ml water). These values, determined in the laboratory, are consistent with the behavior of the cesium and cobalt during operation of the basin filter and support the hypothesis that both ions are predominately cationic.

\section{Transfer Rates}

Transfer rates in 1978 for cobalt and cesium at $30^{\circ} \mathrm{C}$ are 0.18 and 0.10 curies/day. The transfer rate for cobalt is more sensitive to water temperature, and may vary in accordance with the amount of fuel stored. During filter use, about nine tenths of the radioactive material transferred from the fuel is removed from the water. A single filter cake could be used for more than four years under these radiological conditions without allowing the concentration of radionuclides in the water to reach the action level $(0.02 \mu \mathrm{Ci} / \mathrm{ml})$ defined in the license. 


\section{Filter Usage and Outages}

During 1978, the filter was operable 98.5 percent of the time. The 1.5 percent down time was due to one outage (to make a minor design improvement) and 15 filter changes. Five of the latter changes were precipitated by lossof-power events. While the nuisance of these occasions could be avoided by providing for uninterruptible power to the pump, there is little incentive for improving on this operating record. 


\section{THE BASIN COOLERS}

\section{DESCRIPTION}

The basin water is cooled by passing it through a finned tube heat exchanger and blowing ambient air across the fins. The water makes four passes across the air stream before being returned to the basin. Two $750 \mathrm{gpm}$ pumps are provided to move the water and either one, or both, may be used. The tube bank is divided into three sections and any combination may be used. The fans can operate at either 900 or 1800 RPM.

The choices of one or two pumps, one, two, or three couler sections and off, low, or high speed for the fans gives considerable operating flexibility.

Figure 12 shows a cross-section of the coolers. In Figure 13, an isometric view is given to show how the number of sections or pumps may be selected.

The ratad capacity of the coolers is $6 \times 10^{6} \mathrm{Btu} / \mathrm{hr}$ based on an inlet water temperature of $49^{\circ} \mathrm{C}$, and ambient air at $29^{\circ} \mathrm{C}$.

The coolers are equipped with adjustable louvers on top and with aluminum shrouds which can be closed around the bottom. A propane heater is installed

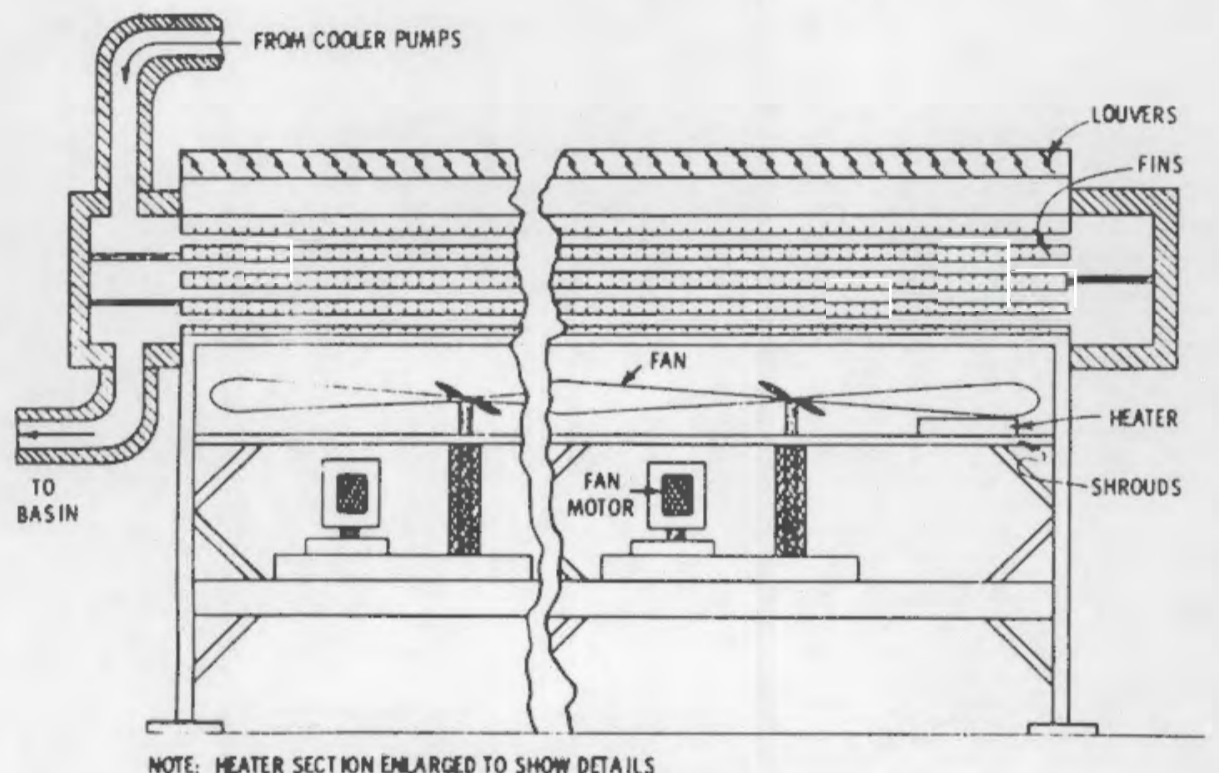

- FIGURE 12. Basin Cooler Cross Section 


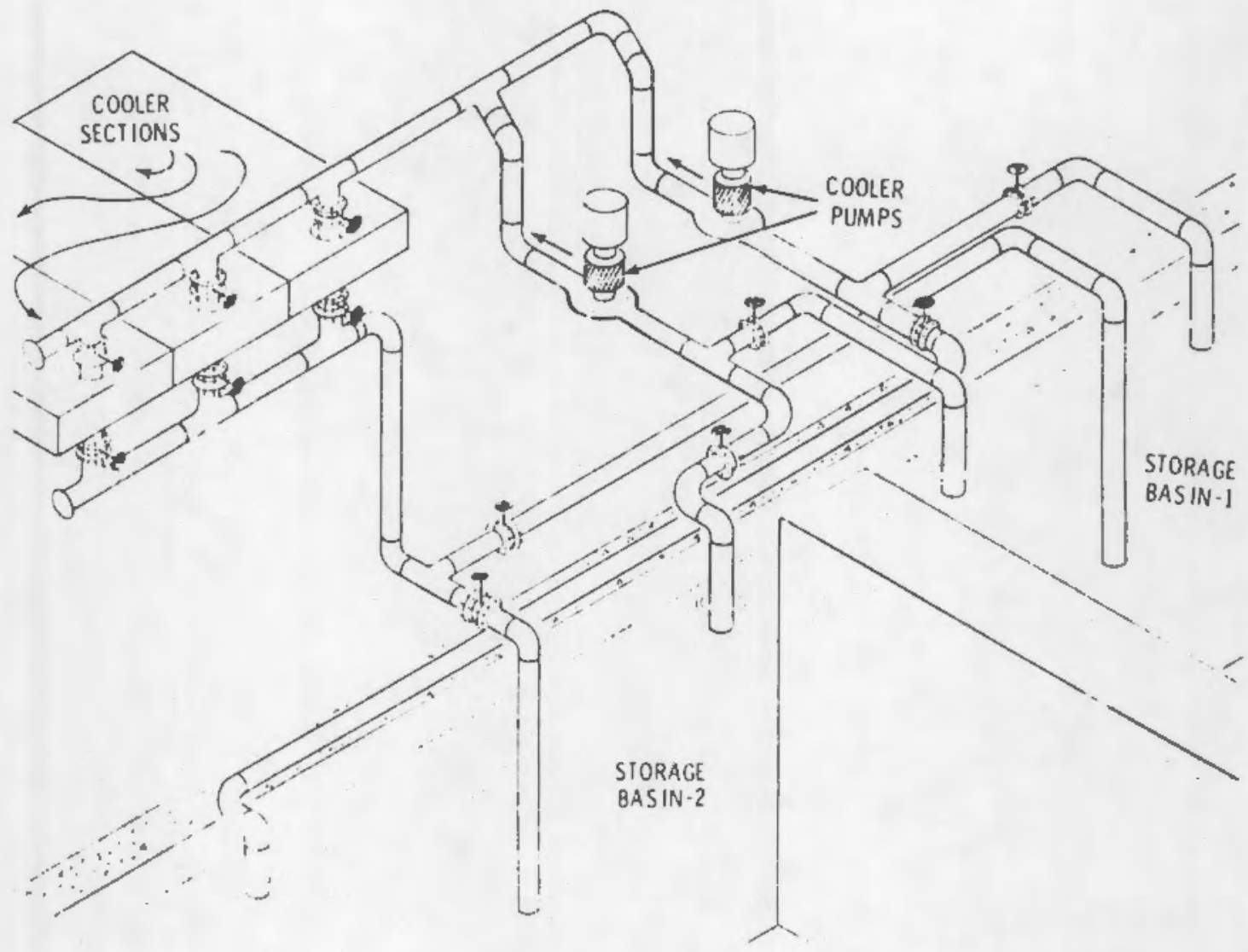

FIGURE 13. Basin Cooler Piping Options

in the intervening space for warming, and an air blow down system is in place to empty the coolers in a hurry if necessary.

Instruments give readings of inlet and outlet water temperature, ambient temperature, local radiation exposure rates, and flow. The flow metering circuit has a low flow alarm to alert personnel to respond.

\section{OPERATING PRIORITIES AND LIMITS}

The major concern in operation of the coolers depends on the amount of heat generated in the basin. This amount has varied with the amount and age 
of the fuel stored and is shown in Figure 14. During most of this time, the heat generated could have been dissipated adequately without the aid of the coolers. This was indeed the case before June 1976, when the coolers were not operated. It is presently true also, as demonstrüted in August and September 1978 when the coolers were turned off for eight consecutive days (for cleaning). Figure 15 shows that the basin water increased to a near equilibrium value of $47^{\circ} \mathrm{C}$.

However, allowing the basin to operate at this temperature causes some operational (but not safety) problems. Areas around the bas in become warm and humid in the sumnier so that working times may be limited occasionally (air with a temperature in excess of $32^{\circ} \mathrm{C}$ and a relative humidity of 90 percent is sometimes seen). In the winter, the moisture condenses on the cool basin walls and can even form a fog above the basin. Besides the nuisance caused by puddles of condensed water in certain areas this high humidity may affect the performance of instruments and electrically operated equipment. In addition, the higher water temperature means more evaporation, and the consequent addition of more inake-up water. Finally, the higher temperature increases the rate of transfer of radioactivity from the fuel to the basin water. Figure 9 shows the increase in transfer rate seen with an increased basin water temperature.

The first concern, at present, is to keep the environmental quality of the basin area fit for the men and equipment which work there.

A second concern is the economy of operation. Continuous operation of the fans at high speeds and both pumps provides more cooling than necessary during cooler weather and may even heat the water during hot summer daj's. The mode of operation can be varied to maximize the rate of heat removal per unit energy expended. This flexibility, which allows intermittent operation, the employment of lower fan speeds, and the running of a single pump, also provides an economy of equipment life.

The third major concern is the long term integrity of the pool structure and liner. For this reason, it was decided, without any particular analysis, to maintain the water at a fairly cool, fairly constant temperature. 


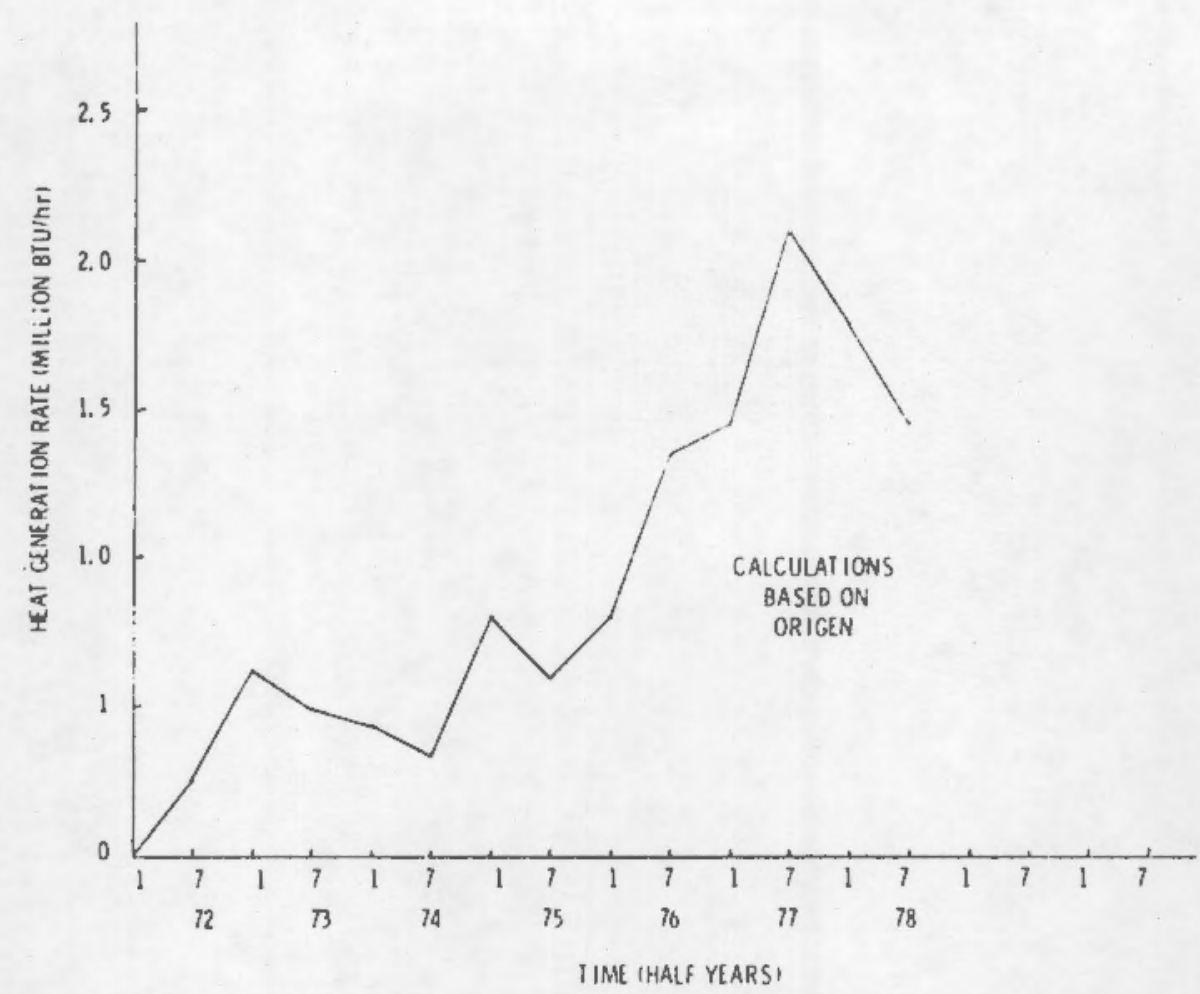

FIGURE 14.. History of Waste Heat Generation in the Storage Basin

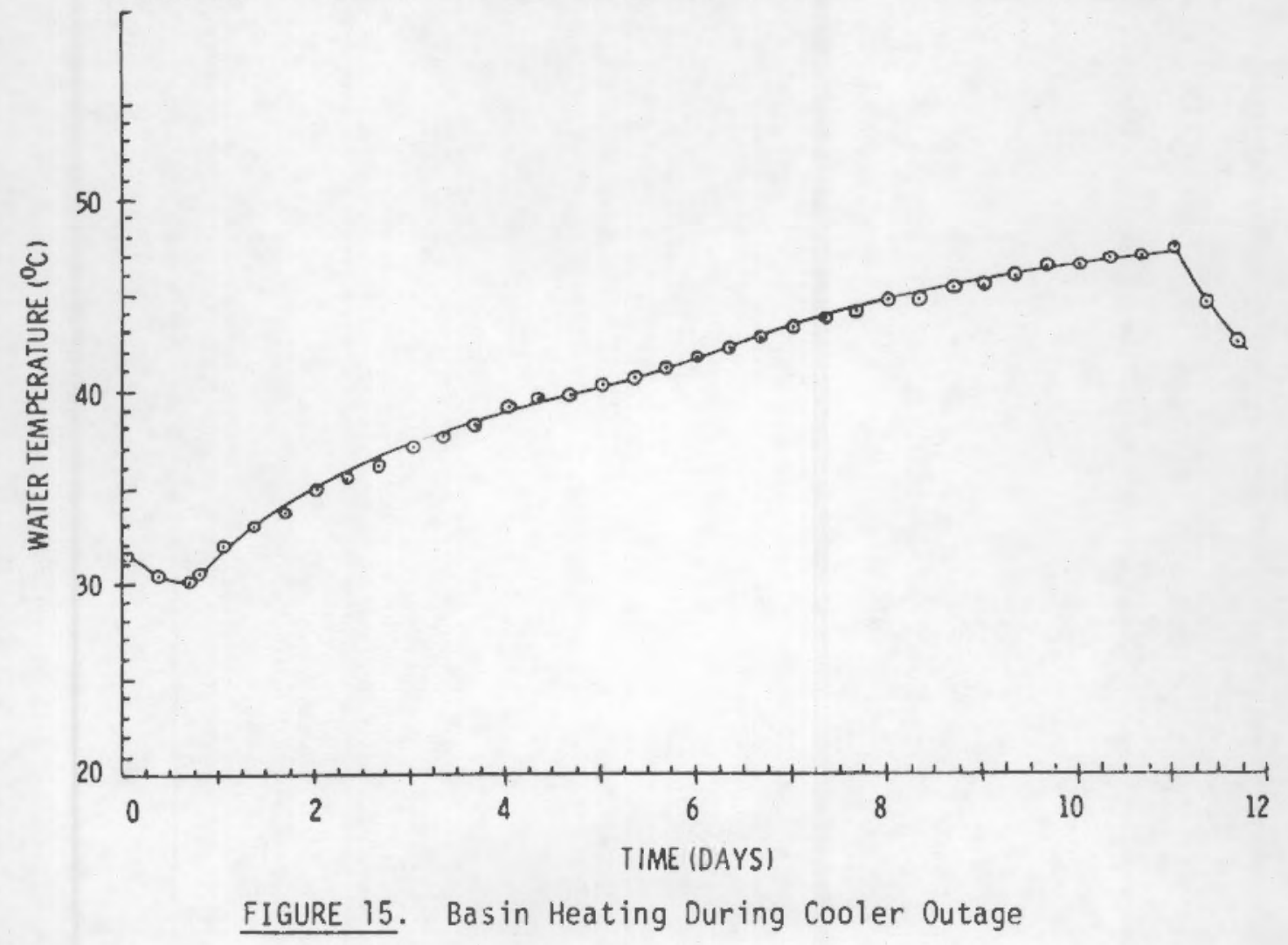


The lower water temperature reduces the potential for chemical corrosion and enhances the capability of the ion exchange materials. Holding the water temperature constarit prevents thermal shocks which might occur from rapid cooling of the water, and/or frequent changes in water temperature. Since no need for rapid cooling has been identified, there is no real impact on operations by choosing to limit this parameter.

Three guidelines have been developed for operation of the basin coolers based on these aforementioned concerns:

1. The basin water temperature is normally held between 25 and $30^{\circ} \mathrm{C}$.

2. Coolers are not operated unless the drop in water temperature across them exceeds $0.5^{\circ} \mathrm{C}$.

3. The cooling rate for the basin water is limited to $7^{\circ} \mathrm{C} /$ day.

\section{COOLER PERFORMANCE}

Operation of the coolers began in July 1973. At that time thare was 48 MT of fuel stored which had a heat generating rate of approximately one million Btu/hr. There were eight sections then, and three sets of fans, but the entire system was made of carbon steel. Despite an initial flush and several subsequent ones, the water passing through the system kept coning out rusty. After seven days of effort the coolers were shut down. The pool water was returned to its original clarity within a month through normal filter aperation. This continual generation of iron oxide was attributed to reaction between the carbon steel and the basin water which was mildly acidic at the time $(\mathrm{pH} 5)$.

From July 1973 to June 1976, the coolers were not used. Heat generated in the pool was dissipated by evaporation and by conduction into the neighboring rock and soil. The basin water temperature roughly paralleled the ambient temperature during this time, rising to 38 and $41.5^{\circ} \mathrm{C}$ in the summers of 1974 and 1975 , and dipping to $30.8,26$ and $32^{\circ} \mathrm{C}$ in the three intervening winters. (a)

(a) The basin heat load changed during this period, dropping initially through decay and then rising in 1975 as more fue? was added. 
In early 1976, stainless steel parts were installed in place of three of the eight original cooler sections and all of the associated carbon steel piping.

Operation of these stainless steel cooler sections began in June 1976 on a routine basis and the rust problem seen in 1973 did not recur. Guidelines for operation defined in the preceding section were gradually developed through operating experience. Evaluations made during this first year indicate that the thermal performance of the coolers has met and possibiy exceeded the design heat removal. Table 4, which gives the overall heat transfer coefficients determined for the design case and from three different operating periods shows this. Since 1976, two significant problems have arisen, but both have been solved.

The first of these occurred coincident with the loss of power during a winter storm in January 1977. The outside temperature was $-28^{\circ} \mathrm{C}$ and the wind chill factor $-55^{\circ} \mathrm{C}$ when a power failure occurred.

Water was being pumped through a single section at the time, but no fans were operating. Efforts to start the propane heater failed because of the extreme cold, and some water in the coolers froze. Two hours later, when power was restored, flow through the coolers was observed to be only $1 / 3$ of normal and erratic. By the time the coolers could be thawed ( $36 \mathrm{hr}$ later) one distribution box which had apparently frozen solid was found to be leaking. Neither the tubes or 'leader box had ruptured; however, enough distortion occurred to cause leakage where the tubes were rolled into the tube plate. The coolers were drained and shut off, and the contamination (from about five gallons of water) was cleaned up.

Either of two other cooler sections could have been placed in service at this time. However, because of the chance that the problem might recur and the difficulty of rerouting the system in sub-zero weather, cooler operation was suspended until the freezing weather abated.

During the intervening 46 days, the basin water temperature rose to an equilibrium value of $47^{\circ} \mathrm{C}$. 
TABLE 4. Overall Heat Transfer Coefficients

Overall

Heat Transfer

$\frac{\text { Conditions }}{\text { Design }}$
3 sections $/ 2$ pumps/fans on high
3 sections $/ 1$ pump/fans on high
3 sections $/ 1$ pump/no fans
Coefficient Btu/hr ft2 ${ }^{\circ} \mathrm{F}$

3.3

$3.5^{(a)}$

0.7

(a) Note that maximu cooling measured meets or slightly exceeds the design performance.

Several actions were taken in response to this event. First, an air blowdown system was installed to enhance the capability for rapidly draining the coolers. As a result a drain time of less than two minutes was achieved. (Calculations indicated that freezing could occur within 16 minutes under conditions present during the storm.) Secondly, the cooler pumps were connected to the emergency power systein so they could be powered by the emergency diesel generator and unprotected (a) portions of the cooler, i.e., the inlet and return piping and the distribution boxes, were insulated. Finally, a larger propane tank was installed to feed the heater.

The events which led to the freezing did not recur in the winter of 1977. However, occasional use of the blowdown system, and dead-of-winter ignition of the heaters were successful and indicate that these existing systems will be able to protect the coolers in the future.

The second problem with the coolers has been the buildup of activity in them. Figure 16 shows the history of exposure measurements made in the immediate vicinity. There was a gradual increase during the first year of operation. This was due to the gradual exchange of diss)lved (and possibly particulate) material from the basin water to the wetted cooler surfaces. The

(a) Outside of the shroud and louvers. 


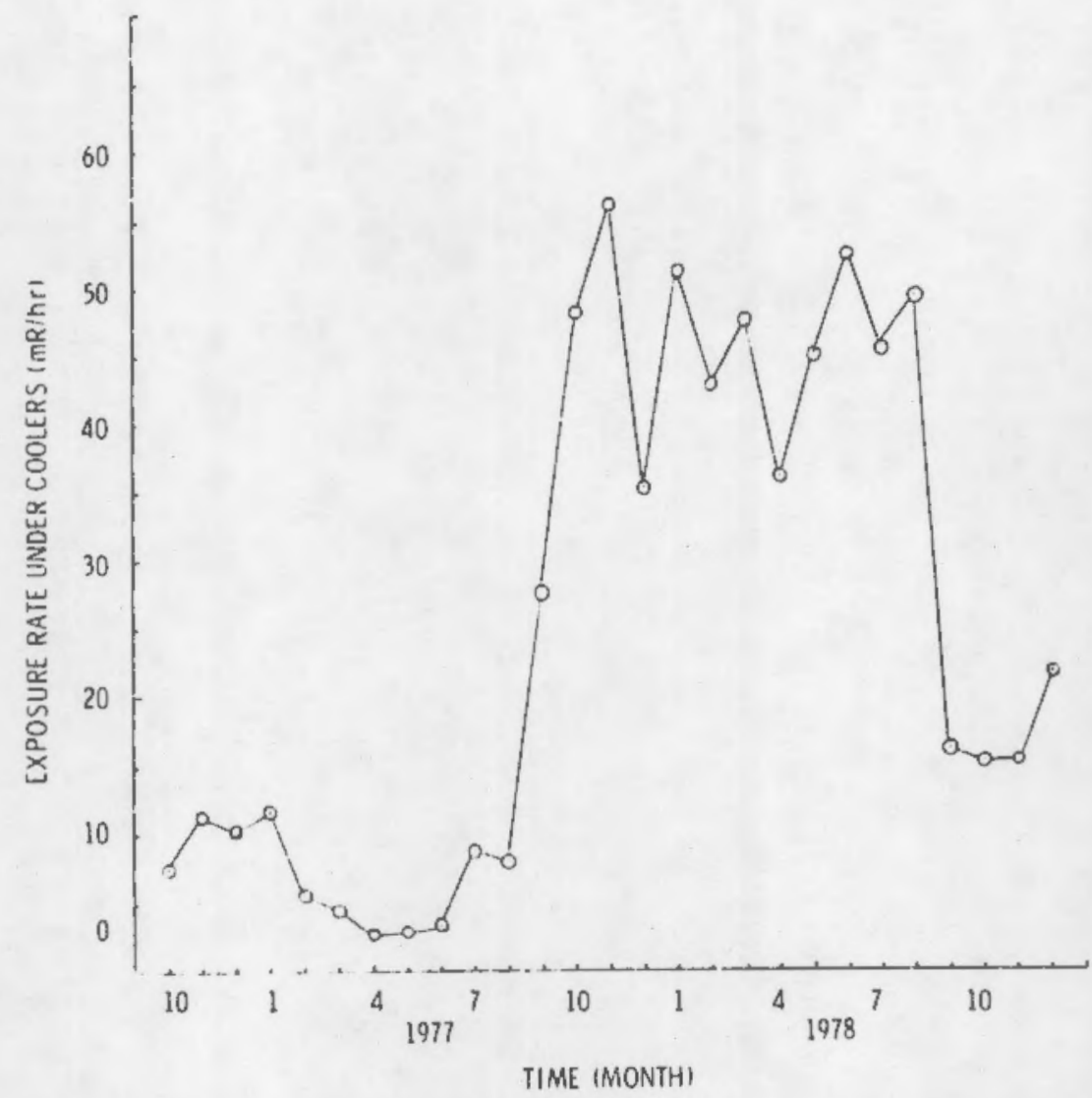

FIGURE 16. History of Exposures from Coolers

rapid increase in September 1977 occurred concurrently with the manual removal of "crud" from an IF-300 cask insert in the unloading pit. Early radiochemical investigation confirmed that this material had indeed been deposited on the internal surfaces of the cooling system loop. Methods for cleaning were reviewed, and the immediate area, which had become a "High Radiation Area", was fenced, per regulation to limit personnel access.

The first effort to clean the coolers was to maximize the flow in hopes of eroding the surface deposit. Both pumps were used on one section at a time, but with little or no success. Decreases in exposure ranged from 5 to 10 percent. This was repeated after allowing the basin water to heat for three days. Some cesium was removed but overall reduction in exposure of less than 3 percent occurred. 
The second distinct effort was an attempt to remove the cesium since 60 percent of the activity identified in the gamma spectrum of the coolers was from radiocesium. The coolers were isolated from the basin and filled with a dilute solution of cesium nitrate. Atter standing for 24 hours they werc emptied to the basin. This technique was successful. A gamma spectrum taken of the coolers after this treatment showed the complete disappearance of the cesium peaks found earlier. The concentration of cesium in the basin water increased abruptly by about $0.0025 \mu \mathrm{Ci} / \mathrm{cm}^{3}$ indicating that a minimum of $6.3 \mathrm{Ci}$ of radiocesium had been removed. Exposure rates in the vicinity of the three cooler sections only decreased by 4,20 , and 26 percent, however because of the strength of the still present cobalt- 60 .

The third cleaning approach was discovered by chance. The coolers had been emptied during freezing weather in late November and were being restarted. Visible particles of red crud were immediately found throughout the basin, and a 31 to 40 percent decrease in the exposure rate from the coolers was seen. This phenomenon was attributed to the loosening of wetted crud in the pipes due to the freezing and thawing of residual water in tha coolers.

Five subsequent freeze-thaw tests were performed, but the successes were not as spectacular as the first. Reductions in exposure of $6,26,2,0$ and 20 percent were seen in these tests.

Between the third and fourth freeze-thaw tests, an erosion test was tried. In this test a dilute water suspension was pumped through the cooler sections. Diatomaceous earth used first, and celite and alumina later, but the flow achievable with available pumps though turbulant was probabiy insufficient, and no reduction was seen.

The cesium flush was tried again in March as there had been an accumulation of cesium since the earlier removal. About one curie of radiocesium was removed, and exposures decreased by about 7 percent. The repeat of this test established that the deposited crud acted as an ion exchanger, removing cesium from the basin water during routine operation, and exchanging it with the stable counterpart during the flushes. 
Ffforts to clean the coolers chemically began in the spring of 1978 when the freeze-thaw technique became impractical. These began with an unsuccessful attempt to contaminate an extra cooler tube in the same way that the coolers had been. It was discovered later, however, that the crud accumulated in areas that were not continuously wetted, and concurrently that a major portion of flow in the coolers was gutter flow. At the same time, other pieces contaminated with red crud were being cleaned successfully in preliminary tests, and provisions were being made to fabricate a cleaning loop which would service the coolers while they were isolated from the basin.

In late August 1978, after additional decontamination and corrosion tests, the chemical cleaning begar. The cleaning solution was circulated through the coolers under conditions such that all surfaces were wetted. The north and south sections were each done twice, and the center one three times. This resulted in a substantial overall decrease in exposure rate as shown in Figure 16.

The demonstrated effectiveness of the cesium flushes and chemical cleaning, and the increased precautions taken to avoid repeated gross contamination provide assurances that future exposure from the coolers will be adequately controlled.

\section{ANALYSIS}

Experience at Morris Operation shows that the use of a single loop system for cooling basin water poses little risk to the environment, or to spent fuel storage operations. This is due in part to the low concintrations of radioactive materials present in the water (see Chapter II) and to the incorporation of supporting equipment which addresses concerns over heat dissipation, leakage, radiation exposure, and equipment outage. 


\section{Heat Dissipation}

The coolers operate at the design heat removal rate.

The actual heat load has been and will be substantially less than the maximum value calculated because of conservatisms in the calculation of the heat load and practical constraints on the rate that new fuel can be adcied. For example, the calculation of the maximum permitted heat generation rate considered the pool to be full of one-year-old fuel. The actual rate corresponds to generation from three-to four-year-old fuel, a value four times lower.

Passive techniques for heat removal (i.e., evaporation and conduction) contribute significantly to the cooling capacity. They reduce impact from prolonged cooler outages provided that the effects of the warmer water can be accommodated.

\section{Leakage}

The coolers have operated without measurable leakage since their start-up except for the freezing incident in 1977.

The compressed air blowdown system and others (heaters, louvers, shrouds, insulation and provision of emergency power) largely protect the coolers from the possibility of future freezing.

The choice of SS 304 as the material for cooler construction provides for long life of the coolers since this material is very resistant to corrosion across the spectrum of operational environments.

Siphoning and pumpout that might result in the unlimited loss of shielding water are ruled out by the elevation of the cooler system, and the depth from which the pumps can draw water.

\section{Radiation Exposure}

Cleanup techniques have been developed for removing cesium and cobalt laden crud from the cooler internais and the capability for isolating the coolers from the basin for cleaning, now temporary, is being made permanent. 


\section{Equipment Dutage}

The system has redundant pumps (2) and finned tube sections (3) which can be operated interchangeably should a failure occur. 'n addition, the long time required for the basin to respond to cooler or filter outages permits ample time for remedial action. 


\section{CASK HANDLING EQUIPMENT}

\section{DESCRIPTION}

Cask handling equipment includes the cask crane, yokes for each kind of cask, the extinsion hook, and the cask flush system.

The cask cane is a 125 ton radio controlled crane. It moves in the north-south direction over the cask receiving area, the decontamination area and the unloading pit. Nowhere in its travel does it pass over areas where fuei is stored. The total lift available is $84 \mathrm{ft}$, but only 37 of this is above grade. The crane has five hoisting speeds ( 0 to $10 \mathrm{ft} / \mathrm{min}$ ) and five traversing speeds for the bridge $(0$ to $30 \mathrm{ft} / \mathrm{min})$. The crane is equipped with a "J" hook.

Yokes allow the crane hook to engage the cask trunnions. Separate yokes have been used for the IF-100 and 200 casks, the NAC/NFS casks, and the IF-300 casks but only the latter two cask types are presently being used.

The yoke for the NAC cask is made for a "J" type hook. It has two legs with eyes for engaging the trunnions. One of these legs pivots outward so that the opening of the yoke may be increased for attaching it to the cask or for its removal. Once installed, the yoke is not removed until the entire unloading sequence is complete. This requires that the crane hook and yoke be separated under water. The yoke is tilted to one side where it rests on the top surface of the cask (via auxiliary arms) at about $45^{\circ}$ to clear the area directly above the cask. This allows the head to be removed and the fuel withdrawn.

The yoke for the IF-300 is also made for a " $J$ " type hook. Each leg of the yoke has a " $\mathrm{J}$ " hook of its own. These two hooks engage the trunnions to lift the cask. The yoke has two other features, bridge supports for holding the yoke upright atop the cask while it is on the unloading pit shelf and attachments for four head lifting cables. The bridge supports allow the cask and yoke to remain engaged and aligned vertically while the cask crane is unhooked. The extension hook is then used to lift the cask and yoke from 
the unloading pit shelf. The head cables, which run from the yoke cross members to the cask head are ordinarily slack. They lift the head after the yoke legs are disengaged from the trunnions in the deep pit. The crane, extension hook, yoke and cask head are then moved to the side so that fuel can be unloaded.

The extension hook is a $28 \mathrm{ft}$ long tool. It has a pin in one end so that it can be engaged by the cask crane and a " $\mathrm{J}$ " hook on the other. It is used for moving casks between the unloading pit shelf and the deep pit. Its use allows the crane access to the lowest levels in the basin without the crane block ever entering the water. This prevents the contamination of the block, the cables, and the crane bridge itself. In addition, it reduces the chance that cable lubricant can get into the basin water. Figure 17 shows the cask lifting equipment and the elevations of the decontamination area, the unloading pit shelf and the deep pit.

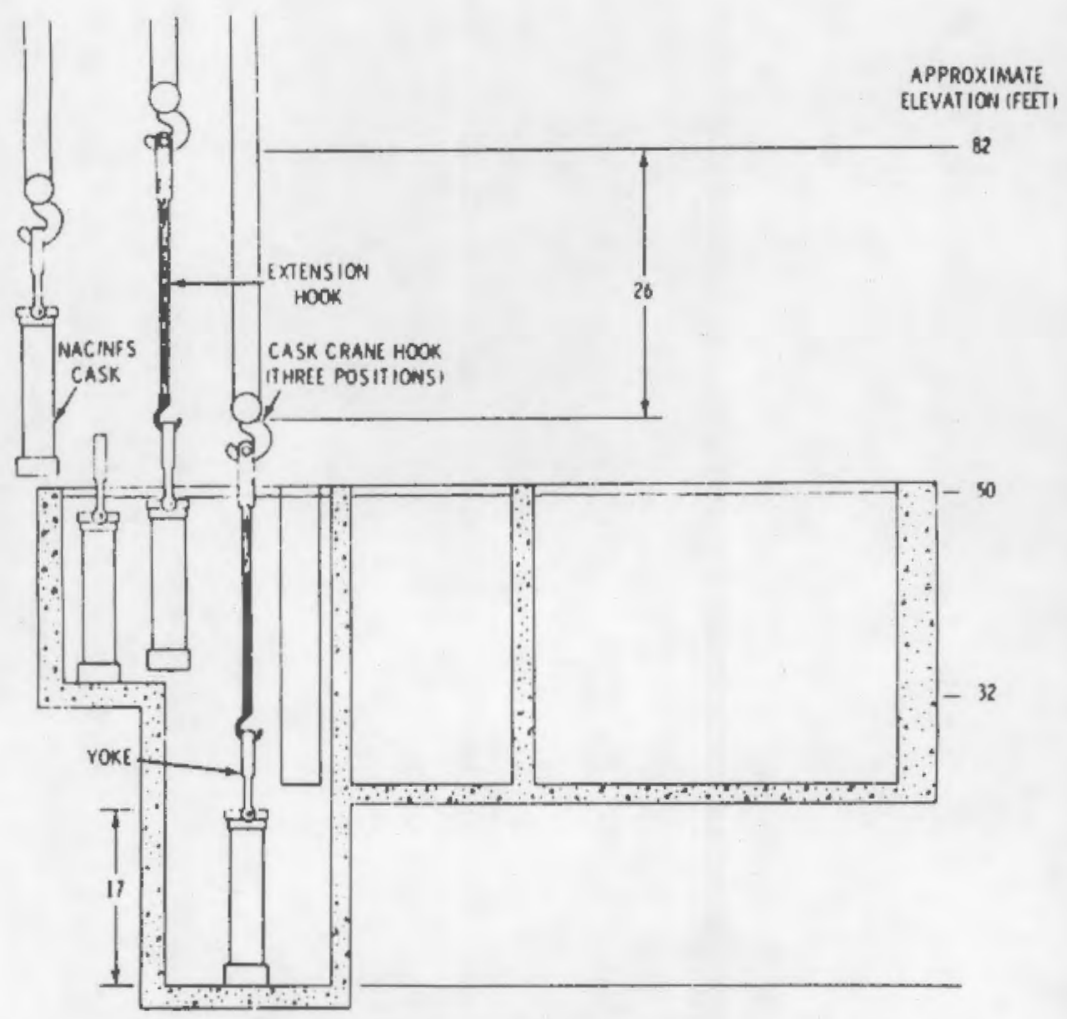

FIGURE 17. Cask Handling Equipment and Elevations 
The cask flush system is not related to the lifting equipment previousiy described. It is a system for venting, sampling, draining, and/or flushing the cask cavity. It consists of a pump which can be attached to the lower cask cavity valve via a flex hose, and a vent line to be attached to the upper cask cavity. The piping associated with the pump can be arranged to move water from the basin to the cask cavity (filling or flushing), or to pump water from the cask to the LAW vault (draining). In both cases the fluids discharged from the cask go to the LAW vault by the same route. This cask flush line is shielded and has a loop which reaches an elevation above the cask to prevent inadvertent draining through the pump. A sample valve is installed on a tee in this line so that samples of cask coolant may be obtained.

\section{OPERATING PRIORITIES AND LIMITS}

The first concern in using the cask crane, yokes, and the extension hook is the security of the lift. This is addressed by design conservatism, frequent inspection and preventive maintenance.

The design conservatism is seen in the cask crane which is rated at 125 tons yet the heaviest lift expected is 70 tons. The extension hook too is designed to handle heavier loads than expected. This hook is capable of lifting 100 tons. In addition, heavy cranes and other heavy lifting equipment have a safety factor of three based on yield strength.

Inspections are made annually according to OSHA requirements. They include non-destructive testing of the stressed areas of the lifting gear and a visual inspection of the entire cask crane. The former inspections are made by the on-site Quality Assurance function, while the latter are made by an independent inspecting firm or by the manufacturer.

Some preventive maintenance jobs are done on the cask crane monthly, others are done semi-annually. Monthly PM includes the lubrication of all moving parts and inspection of the hook, block, brakes and sheaves. Annually the drive gear box grease is changed and the crane level and alignment is inspected. 
Limi is based on these concerns are 1) not to exceed laied loads or to operate with defective equipment, 2) not to lift to unnecessary heights and 3) to use the extension hook and keep the crane block out of the water.

A second concern is the availability of the cask crane. However, all the criteria that respond to the first concern also support the second.

The cask flush system must be available when needed to transfer cask coolant to the low activity waste vault. An operable pump, and open leak free lines are all that is required. The pump is maintained via the preventive maintenance program and the line is inspected and operated routinely. Radiation exposure from this line has been a problem and is a secondary concern. The line has been shielded.

No limits apply to the cask flush system, but hoses, valves and other parts are replaced when local exposure rates are found to be excessive.

\section{PERFORMANCE}

The cask crane, yokes and extensior hook have been used collectiveily for more than 3000 cask lifting operations. Performance has met expectations, in both availability and security. During this period three areas were identified where improvements could be made. In each case, these improvements were incorporated. They include 1) the installation of the radio control for the cask crane, 2) the replacement of the cask crane wire rope and 3) the repair of cracks found in some seal welds on IF-300 yokes.

Controls for the cask crane were changed from the pendant-type to radio control in September of 1975. This was done to free the crane operator so that he could observe tine lift from any accessible position he might choose. Before this change, op?rators had felt the visibility which could be attained from positions within reach of the pendant did not provide them with the desired assurance that the load was properly engaged and that the lift was clear. The practice of using a second person to observe as an aid, although helpful, still did not give the operator the same assurance as seeing it with his own eyes. As installed the radio control can be operated from anywhere within a radius of $200 \mathrm{ft}$. 
The second improvement arose from the finding, during an annual cask crane inspection, of some broken strands in the wire rope. Further inspection by the cable manufacturer identified the breaks as "typical" for the non-lubricated stainless steel cable being used at the time. No breaks within the cable were found nor had there been any significant reduction in cable cross section. (a) The inspection frequency for the crane was increased to monthly and plans were made for replacing the cable. The actual change took place during an outage in August 1976 when a lubricated improved plow steel cable was installed. During the four months time between the initial inspection and replacement of the wire rope there had been no need to de-rate the crane. The new cable is superior to the old in physical properties (strength and flexibility) and it is protected from the environment by the use of lubricant and the practice of never allowing that part of the crane to enter the water.

The third improvement also stemed from inspection findings. Here cracks were found in seal welds in four IF-300 standard yokes (two were new). Then, even though the welds were not in areas subjected to stress during iffing, the yokes were quarantined for study. Examination showed that the parent metal was unaffected, so the defective weld areas were ground out and replaced. After ultrasonic and magnetic particle tests verified that the new welds wcre crack-free the yokes were released again for use.

The cask flush system did not operate with the same reliability demonstrated by the lifting equipment until it was changed from a jet-out system to a pumpout system in May 1972. Since then, it has been used without any major problems.

The original system was designed to operate with a steam jet to pull liquid from the bottom of the cask (draining) or to push basin water into the bottom of the cask (flushing). In either case, the liquid was ultimately sent to the LAW vault. This jet did not operate at design capacity, however, and often did not operate properly at all. It was changed once to decrease the length of the suction leg without success. When it was finally realized that the restrictions in valves, quick-disconnects, and other fittings

(a) Tests on this cable after it had been replaced showed that its strength exceeded + is original specifications. 
presented too much pressure drop for the jet to overcome it was replaced with the present pumpout system. This system provides the same flexibility, by pumping from the bottom of the cask to drain and into the bottom to flush or fill. As in the original system, water displaced during flushing is pushed along to a high point from which it flows to the LAW vault by gravity.

Except for changing pump seals, and replacing fittings, particularly quick-disconnects, operation of the pumpout system has been routine.

\section{ANALYSIS}

Cask handling activities have been routine. This is due to the design conservatism in lifting toois and cranes, and to inspections on preventive maintenance. Furthermore, the performance of the cask handling systems is constantly being reviewed. Design changes can then be made to avoid previous problems or to take advantage of new techniques. This is illustrated by changes to the cask flush system, and the cask crane.

Improvements in cask handling equipment which would be well incorporated in a new facility would be 1) providing both bridge and trolley travel for the cask crane, 2) increasing the flush pump capacity, 3) designing shielding for the cask flush lines initially and 4 ) increasing the size of the working area around the cask.

The use of redundant lifting equipment is not required because the cask crane travel does not extend to areas above fuel storage. 


\section{FUEL HANDLING EQUPMENT}

\section{DESCRIPTION}

Fuel Handling Equipment consists of the fuel handling crane and grapples, and the basin crane and basket hooks. The fuel handling crane and grapples are used to move fuel from a shipping cask to a storage basket, and the basin crane and basket hooks are to move the basket of fuel from the unloading pit to a storage location. One additional piece of equipment which supports these activities is the underwater TV camera.

The fuel handling crane has a five ton capacity. It was iristalled as part of the storage modifications made in late 1975 to service the unloading pit. It has both bridge and trolley motions and can also be used over the shelf and decontamination area for other lifting. Figure 18 shows the elevations of the fuel handling crane, the basin crane, and the associated use of grapples and hooks.

The grapples presently in use are about $41 \mathrm{ft}$ long. One end is comprised of a positioning aid and a latching mechanism; and the other a lifting bale and a manual latching actuator.

In grappling pressurized water reactor (PWR) fuel, guide piris provide accurate positioning; and four fingers which are thrust outward under the lip of the burile nozzle when a center rod is forced downward provide secure latching. When the fuel movement is complete, this latching operation is reversed and the bundle is released. Figure 19 shows the latching mechanism for the PWR grapple.

Skirts are used to position the Boiling Water Reactor (BWR) grapple over a fuel bundle; and a self-latching hook which activates, when the grapple is lowered, serves to attach the bundle to $i t$. The grapple is released by manually drawing aside the hook, and this can only be done if the weight of the bundle no longer rests on the grapple. The basis latching mechanism is shown in Figure 20. 


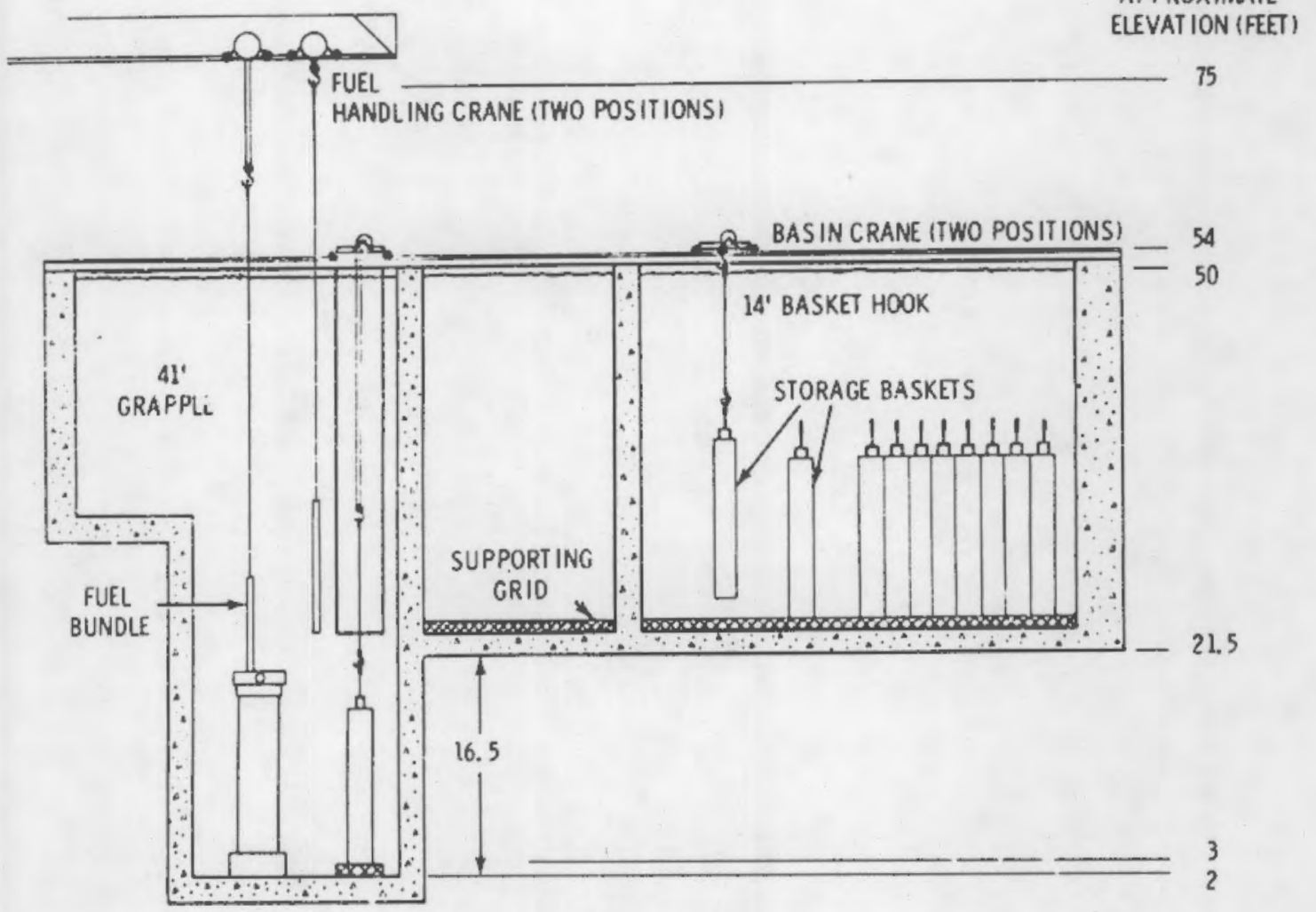

FIGURE 13. Fuel Handling Equipment and Elevations

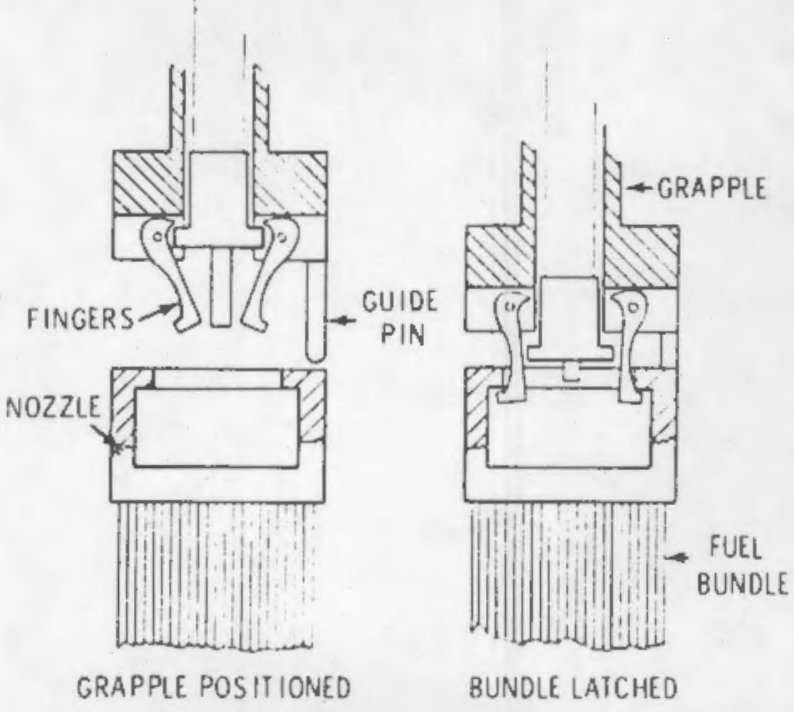

FIGURE 19. Grappling Mechanism for PWR Bundles 


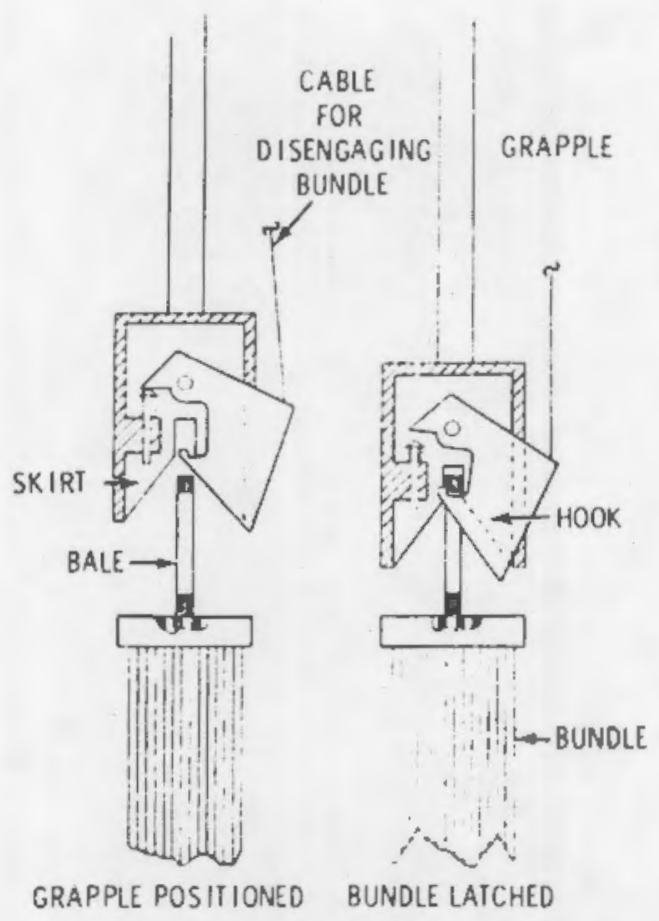

FIGURE 20. Grappling Mechanism for BWR Bundles

The basin crane has a 7.5 ton capacity. It operates over the storage basins and the deep part of the unloading pit. It rides on wall-mounted rails about $4 \mathrm{ft}$ above the level of the water. Both trolley and bridge motions are required. It is used with $14 \mathrm{ft}$ long hooks for moving baskets of fue 1 to-and-from the deep pit and to various storage locatiol. .

\section{OPERATING PRIORITIES AND LIMITS}

The first concern in the design and use of fuel handiing equipment is the potential for lifting fuel to elevations where water shielding would not be adequate. This is addressed by using only long rigid tools which cannot inadvertently be used to raise fuel too high. When the grapples (41 ft long) are used with the fuel handling crane, the height to which the fuel can be raised is limited to a point $9 \mathrm{ft}$ below the surface. Since they can't be used with the basin crane (because they are too long) or the cask crane 
because of the lack of E-W motion, there is no way to err and raise a rue 1 bundle too high. Similarly, the basket hooks only fit on the basin crane. Furthermore, they are too short to reach fuel or baskets in the deep pit even if they could be connected to the fuel handling crane. When used with the basin crane the basket hooks can lift baskets to a point $9 \mathrm{ft}$ below the surface and no further.

Security of the handling and transfer operations is achieved through reliable operation of the grappling mechanism, routine inspection of che lifting equipment, and inspection of and preventive maintenance for the cranes. The grappling mechanism is designed to give a positive indication that latching has taken place. For the PWR grapples, this means that the grapple improperly positioned cannot be activated, and that once activated, the mechanism is secure. The BWR grapple latching is indicated visually by the position of the guides and hook. Once the grapple is engaged, the bundle can't be released until its weight is relieved and the operator manually draws the hook aside.

Inspections of the grapples and basket hooks are made on a twice-a-year basis to verify that parts will function as designed. The basin crane is inspected annually for cable, wheel and track wear, control functions and brake, block, and drum operation. Preventive maintenance includes normal greasing and replacement of marginal switch checks, and checks of the drum, sheaves and brake are made quarterly. Semi-annual checks of electrical parts, wheel and bearing wear and gear case oil are also made. Annually the oil is replaced and wire rope inspected.

One final concern is the handling efficiency. This affects both the reliability of the handling and the time required for it. Two generations of grapple changes have arisen out of this concern.

Operation of the fuel handling equipment is limited to rigid tools which cannot be inadvertently misused and the employment of equipment which has been properly tested, inspected, and maintained. 


\section{PERFORMANCE}

Handling of the 1196 fuel bundles presently on hand has been done without dropping any fuel to the floor of the basin or mistakenly raising any too close to the surface. A number of minor problems that caveloped have been addressed and solved. As a result, major modifications were made, once to the BWR grapple and twice to the PWR grapple. In addition, there have been several small design changes.

The original grapples (pre-fuel handling crane) were $15 \mathrm{ft}$ long, and used with the basin crane. Positioning of the grapple could only be accomplished through trial and error as no "hands-on" steering of the grapple was possible. North-south or east-west adjustments were made with the crane and the grapple was lowered to see if the guide pins fit properly. Latching then was done manually by pulling on a rope. With this system, thirty minutes to an hour were required just to grapple a bundle. The first major change was to replace the rope with a pneumatic cylinder and indicator lights to confirm engagement. Grappling times decreased to 20 or 30 min but this change didn't help with the positioning problem. Furthermore, it required that air and electrical connections be changed each time the basin crane use was changed from moving fuel bundles to baskets or vice versa. In addition to the long operational time required for use of these first two generations of grapples there was frequently the need for repair. Actuator misalignment and water logging of the air actuator system were typical malfunctions. Now with the fuel handling crane and present grapples, positioning is assisted by hand, and there is no need for air or electrical connections. With use of the new system, grappling time was reduced to about $10 \mathrm{~min}$.

Adoption of the new grappling system did require the construction of a platform on the north side of the basin crane to give the operator access to the new grapples. One minor improvement in the new grapples has been made. It involved changing rollers which were used to hold in the spring loaded guide pins on the PWR grapple. Wear had caused one of these rollers to break and the subsequent loss of a guide pin. The broken roller and others like it were replaced with hardened ones having better wear-characteristics. Difficulties in grappling bundles resting far down in the cask cavity were encountered in 
early operations. This difficulty was solved by having a spacer inserted at the bottom of the cask in place of the one attached to the lid. The top of the burdle was thus raised to a position where grappling could be readily observed. In addition, PWR grapples occasionally got caught in the hardware atop the assembiy before they could be properly positioned. At first, this involved a substantial delay, but a tool and technique were developed to free the grapple in a matter of minutes.

Both cranes have been available 99 percent of the time. Repairs to the bas in crane have been typical for that kind of equipment, and done largely during outages or periods when the crane was not needed. These repairs included electrical control and pendant changes and the replacement of the sheave bushings. For the fuel handling crane, only minor adjustments in the 1 imit switches, for example, have been needed. The effectiveness of the preventive maintenance program has alleviated the need for any repairs to date.

Table 5 gives a summary of the use of the various fuel grapples.

TABLE 5. Summary of Grapple Use at Morris Operation

\begin{tabular}{|c|c|c|}
\hline Type of Grapple & $\begin{array}{l}\text { Number of } \\
\text { Lifts }(a)\end{array}$ & Crane Used \\
\hline 01d PWR $(15 \times 15)$ & $207(116)^{(b)}$ & Basin \\
\hline 01d PWR $(14 \times 14)$ & $258\left(75^{(b)}\right.$ & Basin \\
\hline 0ld BWR & 64 & Basin \\
\hline New BWR & 763 & Fuel Handling \\
\hline New PWR $(14 \times 14)$ & 201 & Fuel Handling \\
\hline New PWR $(15 \times 15)$ & -- & Fuel Handiing \\
\hline
\end{tabular}

(a) This excludes lifts made for test purposes.

(b) The first 135 bundles were handled prior to installation of air actuators on the grapples. Lifts in excess of 135 were from transfers of fuel within the basin. 


\section{Analysis}

The movement of fuel from cask-to-basket, and of baskets from the unloading pit to storage location has been done without safety implication. The long lifting tools have prevented exposure of personnel from fuel inadvertently lifted too close to the surface without affecting the ability to securely engage the fuel or basket for transfer.

Inspections, equipment verification tests and preventive maintenance have been successfully employed to assure that the tools will operate as intended. Tool design has also been updated whenever the need has been demonstrated. Changes in length, handling, and in some grappling details all arose because operation experiences were reviewed and analyzed. All of these changes were made in an effort to improve operational efficiency. In no instance was there concern over the safety of the original design. 


\section{SUPPORT SYSTEMS}

\section{VENTILATION SYSTEM}

\section{Description}

The building ventilation system consists of inlet heaters, inlet blowers, a distribution system, a sand filter, exhaust blowers and a stack. In addition, there are dampers to aid in distribution, and backdraft damper-filter combinations to prevent flow reversal, and to filter reverse flow air should any occur. The system was designed for reprocessing and therefore contains many conservative features not needed for fuel storage only. One of these is the once through flow pattern for all air. Figure 21 gives a block diagram for the airflow in the paris of the building related to fuel storage.

Air is drawn into the building by two inlet blowers. These are rated at $15 \mathrm{hp}$ each and may be used singly or together. As air enters it is drawn past steam preheaters designed to raise the air temperature to $16^{\circ} \mathrm{C}$. From here it is distributed to office and otice contamination free areas and to the basin area and the pump roum through a system of ducts. Some of these ducts contain individual air handlers, reheat coils and/or air conditioning coils. All air ultimately goes from here to the air tunnel under the process building usually via the canyon. From the pumis room, however, air goes to the filter room and then directly to the tunnel which terminates at the sand filter. This is an $8 \mathrm{ft}$ desp graded bed of sand and rocks. Large rocks at the bottom help distribute the air and fine grades of sand near the top remove the particulate material. Air is drawn through the sand filter by 60 hp exhaust fans. Ordirarily two are running and one is in stanciby. Air reaching the fans is exhausted through a $300 \mathrm{ft}$ stack.

Air sampling anci monitoring is done to keep track of the amount of radioactivity that becomes airborne, and that portion that is released to the environs. Samples are taken in the exhaust stream, the sand filter inlet (prefilter) and in various work areas. A reference sample is taken of the incoming air for comparison purposes. Many of the samplers used have monitoring capabilities, but this added function is only used for work area, and inlet air surveillance. 


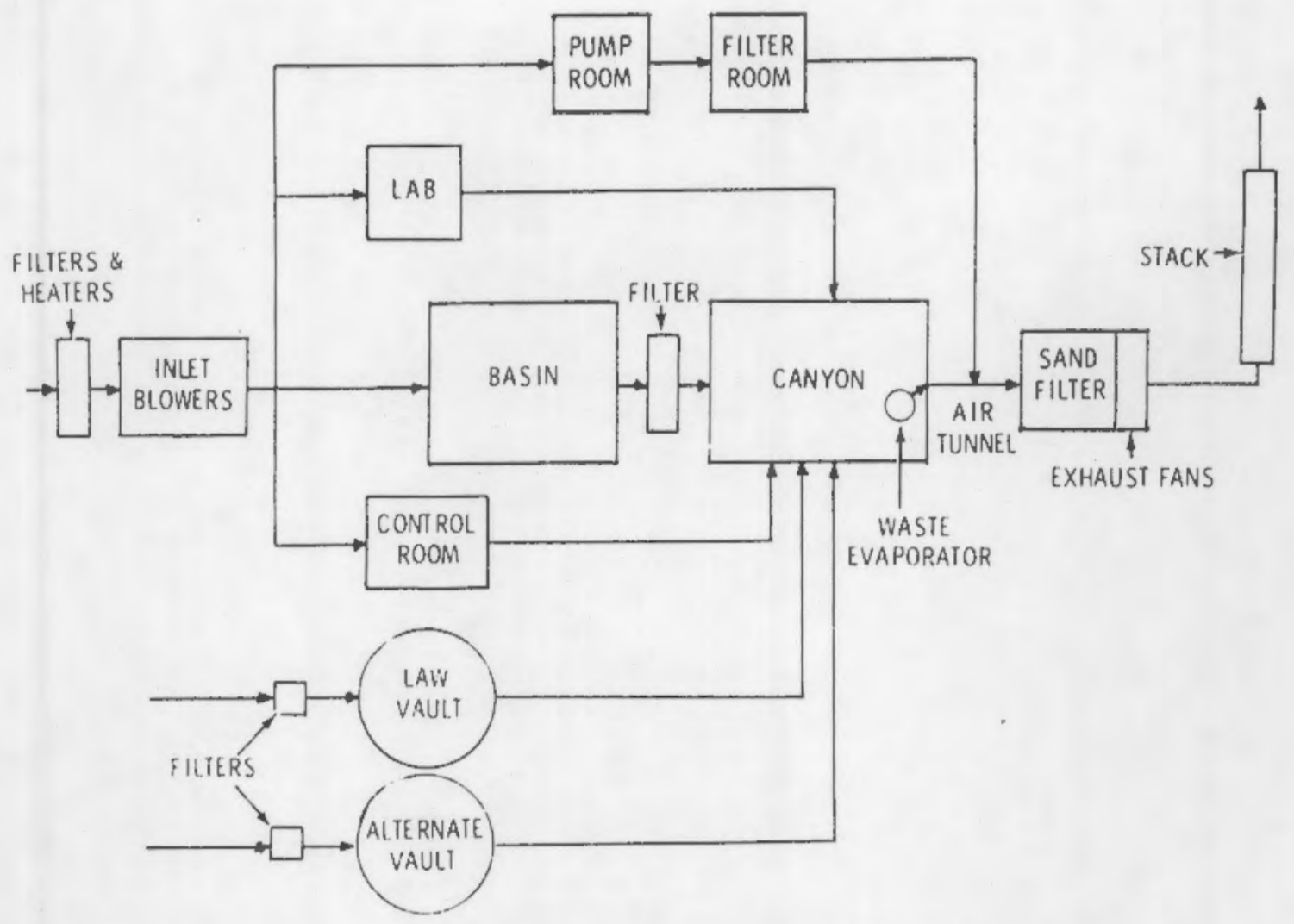

FIGURE 21. Building Ventilation Diagram for Key Locations

\section{Operating Priorities and Limits}

The first concern in the operation of the building ventilation system is the control of contamination. This is addressed by maintaining the proper pressurcs in the various parts of the plant and the desires air: w through each. For example, air flows from the inlet plenum ( $p=+$ room $\left(p=-0.2\right.$ in $\left.\mathrm{H}_{2} \mathrm{O}\right)$ and the filter room $\left(p=-0.6\right.$ in $:_{L}$ I to the pump air tunnel $\left(p=-2.25\right.$ in $\left.\mathrm{H}_{2} \mathrm{O}\right)$. Flow along this pathway is about $300 \mathrm{ft}^{3} / \mathrm{min}$. The basin is ordinarily maintained at a pressure of 0.1 to $0.2 \mathrm{in}$. of $\mathrm{H}_{2} \mathrm{O}$ less than atmospheric, with a flow of $7500 \mathrm{ft}^{3} / \mathrm{min}$.

Since the decontamination area in the basin and the wastewater evaporator in the canyon are the chief sources of airborne contamination, the ventilation flow acts effectively to direct any airborne activity away from occupied areas. (The canyon is nut normally occupied.) 
A second concern is the comfort of the people who must work in these areas. This is provided in part by the preheaters, and miscellaneous other local heaters and air conditioners. However, none of these additional units affect the basin area, and the "weather" there is in a large part determined by the basin water temperature.

The operation of the ventilation system is based on the air tunnel pressure (vacuum). If this is lost, flow patterns become mixed and certain activities which could generate undesirable amounts of airborne activity are curtailed. These include jetting out of the filter sludge tank, venting of cask cavities and operation of the wastewater evaporator. Other activities in contaminated areas could also be suspended, depending largely on the amount of radioactivity present, and the nature of the work.

\section{Performance}

The adequacy of the building ventilation system may be considered in terms of both equipment performance and contamination control. Equipment probiems have been infrequent. Perhaps the most serious one has been the freezing of the preheat coils. This has occurred in the winter when the boiler or the electrical supply to it failed and condensate was frozen before it could drain from the coils. This has been remedied by the installation of better drain lines and the establishment of procedures to see that necessary action is taken promptiy. A second problem comes about because the airflow is not precisely balanced, and because the plant is not beinq used in the manner originally intended. Further balancing of the system has not been necessary, though, because the existing airborne activity is such areas remains well below the applicable limits.

Operation of the sand filter has been interrupted twice because of activities not related to fuel storage. In the first case, vapors containing fluoride electrolyte were carried to the top of the sand filter via the fluorine cell vent header (where gaseous fluorine was produced for reprocessing flowsheet tests). The top layer of the sand became caked, and the pressure drop across the filter increased. The upper layer was raked to rejuvenate the bed and the vent header rerouted to prevent a recurrence. Both actions proved successful. 
A second increase in pressure drop across the filter occurred during start-up activities. A substantial amount of dust and debris were generated and this along with vapor drawn off the top of the processing vessels caused a build up and partial plugging of the inlet screens. These screens were cleaned several times to lower the differential pressure and a removable roughing screen was placed upstream to protect the filter from further plugging. Since reprocessing start-up activities have ceased, this roughing screen has had only to be cleaned occasionally.

A final equipment problem arose when exhaust fan vibration caused failures of the flexible joints connecting the fan and the associated ductwork. Some stack air was released to the room, but concentrations of radioactivity in it, typical of those of storage operations, were too small to be a hazard. New joints of more resilient material were installed to eliminate the problem.

Concentrations of airborne radioactivity everywhere at Morris Operation have been kept below applicable MPC values. Average values for 1977 and the first half of 1978 are shown in Table 6 . In some places, like the laboratory, concentrations are lower than those of the incoming air. This occurs because the incoming air is filtered just upstream of the inlet blowers. The occupied area where the greatest concentration of radioactivity occurs is the lower level of the decontamination area. This area is exposed to cask flush and decontamination solutions, and remains slightly contaminated. A portion of the airborne activity comes from the suspension of this contamination during work there. When contamination levels reach a preset value $\left(50,000 \mathrm{dpm}\right.$ beta/100 $\left.\mathrm{cm}^{2}\right)$ clean-up is initiated. Below that level it does not justify the personnel exposure required to clean it up.

The sand filter has been effective in removing particulate material from the exhaust air. Removal efficiencies for these particles, largely cobalt- 60 and cesium-134 and -137 isotopes were determined by comparing the results from the upstream and two downstream: samplers. Values ranged from 99 to 99.9 for cobalt-60 and 99.7 to 99.9 for cesium. The amount of radioactive material released from Morris Operation is summarized in Table 7 . These values for 1975 through the first half of 1978 are from storage-only activities. 
TABLE 6. Concentrations of Airborne Actjuity from Fuel Storage Operations (a)

\begin{tabular}{|c|c|c|}
\hline \multirow{2}{*}{ Location } & \multicolumn{2}{|c|}{$\begin{array}{l}\text { Concentration of } \\
\text { Radionuclides } \\
\mu \mathrm{Ci} / \mathrm{ml} \times 10^{-12}\end{array}$} \\
\hline & $\begin{array}{c}\text { Alpha } \\
\text { Emitters }\end{array}$ & $\begin{array}{c}\text { Beta } \\
\text { Emitters } \\
\end{array}$ \\
\hline Occupational MPC & $2 \quad(P u)$ & $9000 \quad$ (Co) \\
\hline Decontamination Area & 0.05 & 21.2 \\
\hline Basin Area ${ }^{(b)}$ Exhaust & 0.04 & 3.23 \\
\hline Canyon & 0.04 & 1.33 \\
\hline Laboratory & 0.04 & 0.25 \\
\hline Inlet Air & 0.07 & 0.36 \\
\hline
\end{tabular}

(a) Average over 1977 and first half of 197B.

(b) Includes both air from decontamination area and unloading and storage basins.

TABLE 7. Releases of Radionyclides from Fuel Storage Operations (a)

\begin{tabular}{|c|c|c|}
\hline \multirow[b]{2}{*}{ Half Year } & \multicolumn{2}{|c|}{$\begin{array}{c}\text { Amount of } \\
\text { Radionuclides } \\
(\mu \mathrm{Ci})\end{array}$} \\
\hline & $\begin{array}{l}\text { Alpha } \\
\text { Emitters }\end{array}$ & $\begin{array}{c}\text { Beta } \\
\text { Emitters }\end{array}$ \\
\hline 2nd Half 1974 & 78 & 115 \\
\hline 1st Half 1975 & 16 & 51 \\
\hline 2nd Half 1975 & 10 & 33 \\
\hline 1st Half 1976 & 7 & 18 \\
\hline 2nd Half 1976 & 11 & 28 \\
\hline 1st Hafl 1977 & 4 & 15 \\
\hline 2nd Half 1977 & 6 & 119 \\
\hline 1st Half 1978 & 3 & 15 \\
\hline
\end{tabular}

(a) Released via $300 \mathrm{ft}$ stack. 
There is no need nor facility for the removal of noble gases or tritium from the exhaust system.

Analysis

The building ventilation system has served well in controlling contamination and in providing an adequate work environment. Emissions to the atmosphere are insignificant. However, reaching these same achievements could be done with a much simpler and less cumbersone system. The complexi:y of the existing system results because it was originally designed for a reprocessing plant rather than for its current use. As it is, it serves a large unoccupied and unused portion of the process building.

Designs for storage-only can incorporate the recycling of ventilation air in most areas, except for the cask handling and waste treatment areas; and waste heat from the fuel could be used to warm the inside air. Pump, filter, and dilution requirements for such a facility could be reduced without adversely affecting either the facility or the environs, and more ready access to each part of the ventilation system could be provided.

\section{RADWASTE SYSTEM}

\section{Description}

The major radioactive waste generated at Morris Operation comes from cask flushing and filter backwash operations. Other liquid waste comes from laboratory drains, and decontamination and laundry facilities. Solid radwaste is comparatively minor. Contaminated cloth and paper clothing and cleaning material is compacted and buried as low specific activity (LSA) waste. Contaminated sools and equipment are also shipped to burial grounds as LSA waste.

The system for treating liquid radwaste consists of two major components, a large underground tank for accumulating liquids and a pot-evaporator for reducing the water content in the waste.

The tank is contained within a carbon-steel lined concrete vault. The tank is made from carbon steel, and is lined with a phenoline coating. 
The vault is made of reinforced concrete that was poured up against the bedrock. The liner of this tank served as a form during the pouring of the concrete. Channels between the inner metal wall and the concrete conduct any ground water which might intrude to a sump. From there it can be jetted out and discarded. Between the vault and the tank is an $18 \mathrm{in.}$ annulus that serves to isolate the contents of the vault and the ground water. The annulus, too, has a sump where any leakage or intrusion water is collected. Water from the sump in the annulus can be jetted back into the vault itself.

The vault can hold 680,000 gallons. Air drawn over the top of the vault and through the canyon and sand filter provides ventilation.

The evaporator is located in the canyon. Solution from the LAW vault is pumped into the vessel and steam is introduced by way of internal coils. The portion of the water that is boiled off passes through a demister and is routed directly to the air tunnel. A remaining portion is returned to the LAW vault to minimize the build up of solids.

A second underground vault, the cladding vault is adjacent to the LAW vault but not connected to it. It was intended for storage of contaminated cladding hulls, but today serves to receive some incidental streams of contaminated water, i.e., condensation from the stack, two floor drains, and as back up to the LAW vault.

The cladding vault is a single walled underground tank (capacity $730,000 \mathrm{gal})$. It consists of a reinforced concrete pit, lined with stainless steel. Channels were also provided between the concrete and the liner so leakage and/or intrusion water would be conveyed to a sump. Water from this system, called the cladding vault leak detection system, is jetted back into the cladding vault periodically.

Since there is no direct route from the cladding vault to the evaporator, water there must first be transferred to the LAW vault before it can be evaporated. However, most of the wastewater goes to the LAW vault directly. 
Operating Priorities and Limits

The first concern in the operation of the liquid radwaste system is containment. This is provided through the design of the vaults. Verification that the liquid is properly contained is achieved through operation of the leak detection systems. These are continuously monitored and routinely sampled. For example, water in the LAW vault annulus causes an alarm when it reaches a depth of $12 \mathrm{in.}$ However, since water can enter the annulus by other methods than a leak, i.e., condensation, the accumulated water is partitioned aczording to origin using a pseudo isotope-dilution technique. The "leakage" from the cladding vault is similarly determined and a level of $35 \mathrm{in}$. causes an alarm. Input to the LAW vault is limited to solutions which have a $\mathrm{pH}$ greater than 7 , and the vault contents are maintained at a $\mathrm{pH}$ greater than 12 in order to protect the integrity of the inner wall.

The second concern in operating the radwaste system is in maintaining sufficient capacity to accommodate new waste generated in fuel handling and storage activities. No operating limits have been defined however, since a margin of 200,000 to 250,000 gal is usually maintained in the LAW vault, and the nearly empty cladding vault is in standby. This permits a lot of flexibility since the ordinary input to the vaults averages between 15,000 and 20,000 gal per month.

\section{Performance}

The vault and evaporator have operated within their respective limits and the ranges of concern. There has been no loss of containment, or lack of capacity during the history of the plant. Leak rates for the vaults have been so low ( 0.5 and less than 0.1 gal/day respectively) that there is some question as to whether any current leakage exists or not. In any case, water from the leak detection system is periodically transferred into the respective vault.

Boil off is ordinarily done in the fall when natural gas demand is low. Operation for about two months in each of the past three years has accomodated the liquid accumulated in the intervening time, and during he boil off as well. There has been no long term increase in the volume of vault contents 
since startup efforts in October 1973 when the LAW vault reached 92 percent of its capacity. At that time, some water was transferred to the cladding vault and boiloff rates were enhanced. Since then, the vault has been kept 20 to 65 percent full and the water in the cladding vault has been transferred back and boiled away.

Operation of the evaporator has been hindered by the build up of solids on the coils and in the piping and by the failures of the pumps used to convey radwaste to it. The first problem has been overcome by using frequent flushes. For one hour each shift the steam is turned off and the wastewater is recycled to the vault. Acid flushes $\left(1 \mathrm{M} \mathrm{HNO}_{3}\right)$ of the boiler have also been used successfully on occasion when solids seriously interferred with operation. When this is the case, the acid is neutralized and returned to the vault.

Pump lifetime has been short because of the hot caustic environment. The best kind of pump has been a submersible multi-stage centrifugal pump. It usually lasts through a two or three month campaign, and is best replaced with a new one at the start of the next campaign.

The evaporator itself has been almost free of mechanical maintenance. Provided that the pump is operating, steam is available and that flushes have been regularly done to keep the lines clear, operation of the boiler has been routine.

Analysis

Operation of the liquid radwaste system has successfully met the ongoing operational needs at Morris Operation. Volumes of waste have been limited and well confined, while the capacity for new waste has been maintained with a wide margin. Since little dissolved solids are introduced with the wastewater, operation in the current mode could be carried out more or less indefinitely. The lack of radwaste handling capability has never had any impact on fuel storage. However, the operation at present omits consideration of the ultimate disposal of the waste. This omission will be remedied when current long range planning comes to fruition. These plans call for the installation and use of a facility to solidify this waste so that it can be shipped off-site for burial. Then, the system can be considered to be complete. 


\section{BLANK PAGE}




\section{SHIPPING EXPERIENCE}

\section{DESCRIPTION}

There have been 486 shipments of spent fuel to Morris Operation beginning in January 1972 and extending through January 1979. In all 309 MT has been received. Fuur different types of casks with five different identifications were used. Shipments were from four reactor sites. There are pressurized water reactors (PWR's) at three of these sites and boiling water reactors (BWR's) at the fourth. They are Connecticut Yankee, San Onofre, WEPCO and Dresden respectively.

All of the fuel received is made of sintered $\mathrm{UO}_{2}$ pellets, and except for San Onofre, clad with zircalloy. San Onofre fuel is stainless steel clad.

Shipments to Morris Operation have been made in distinct campaigns wherein fuel from a specific reactor isite is transferred at a fairly constant rate. The set of data concerning fuel shipments, and presented here, is divided into eight groups, five of which correspond directly to campaigns. The other three groups correspond to the consolidation of several small campaigns. This was done for early shipments from Connecticut Yankee and San Onofre and for the shipments from Oresden because some sets of early data are not complete, and because there were too few shipments in some of them for adequate treatment.

The particulars for the shipments for these eight single or consolidated comapigns are given in Table 8. Shipping parameters included in the table are the mileage, campaign dates, and the number of shipments in each period. Cask parameters include model number, gross weight, assemblies per shipment, and transport mode. The fuel data includes assembly and fuel weights, enrichment, cooling time, and core power level. In each case the cooling time is given for the first shipment of each batch of fuel discharged. Average cooling times would be slightly to moderately longer than those noted depending on the duration of the campaign.

Other parameters differed substantially within the campaigns and are presented separately as a series of frequency distributions. The burnup, shipping time, storage time, exposure rate (at four locations), cask surface 
TABLE 8. Fuel Shipping Summary

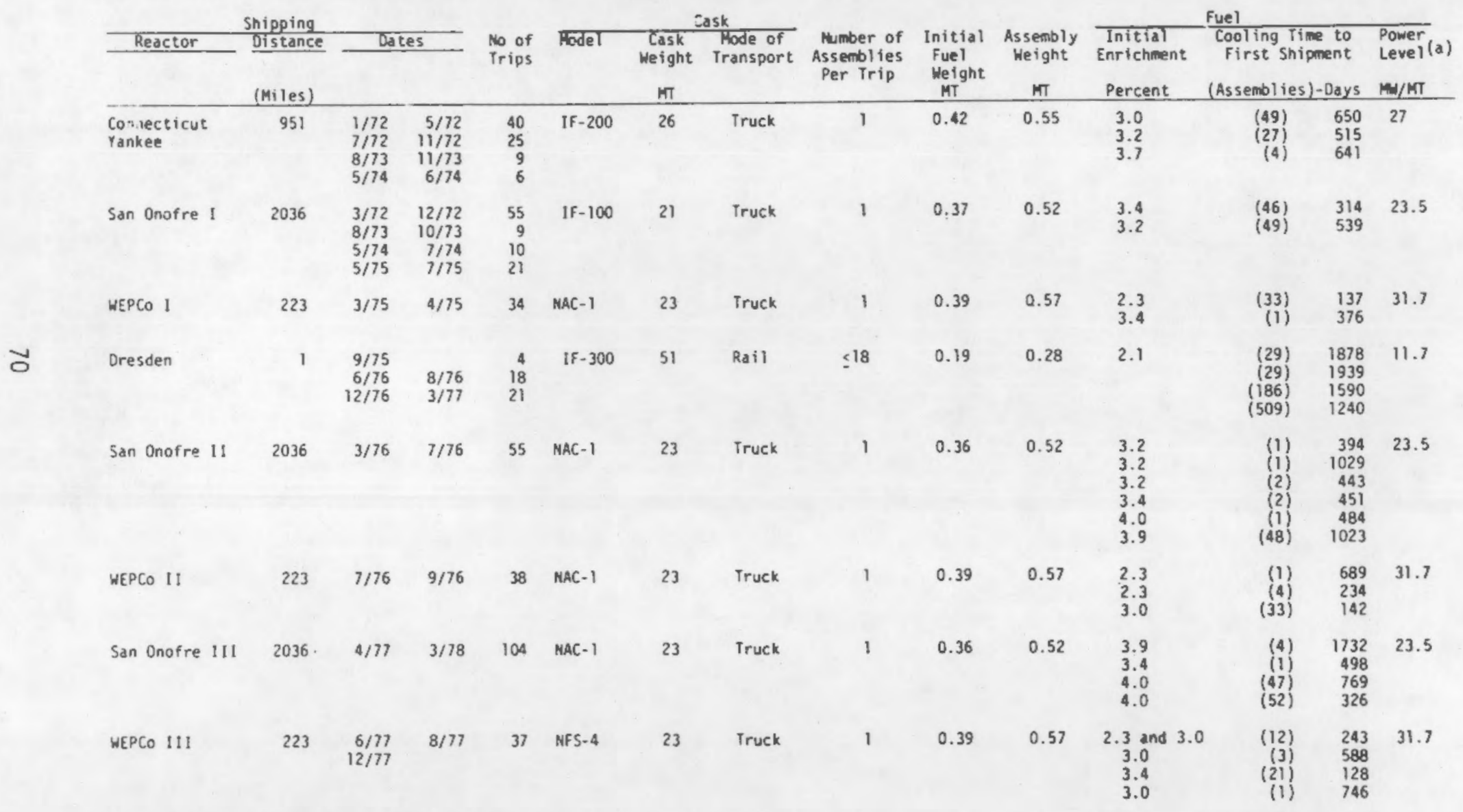

(a) See figure 22 for burnup characterization. 

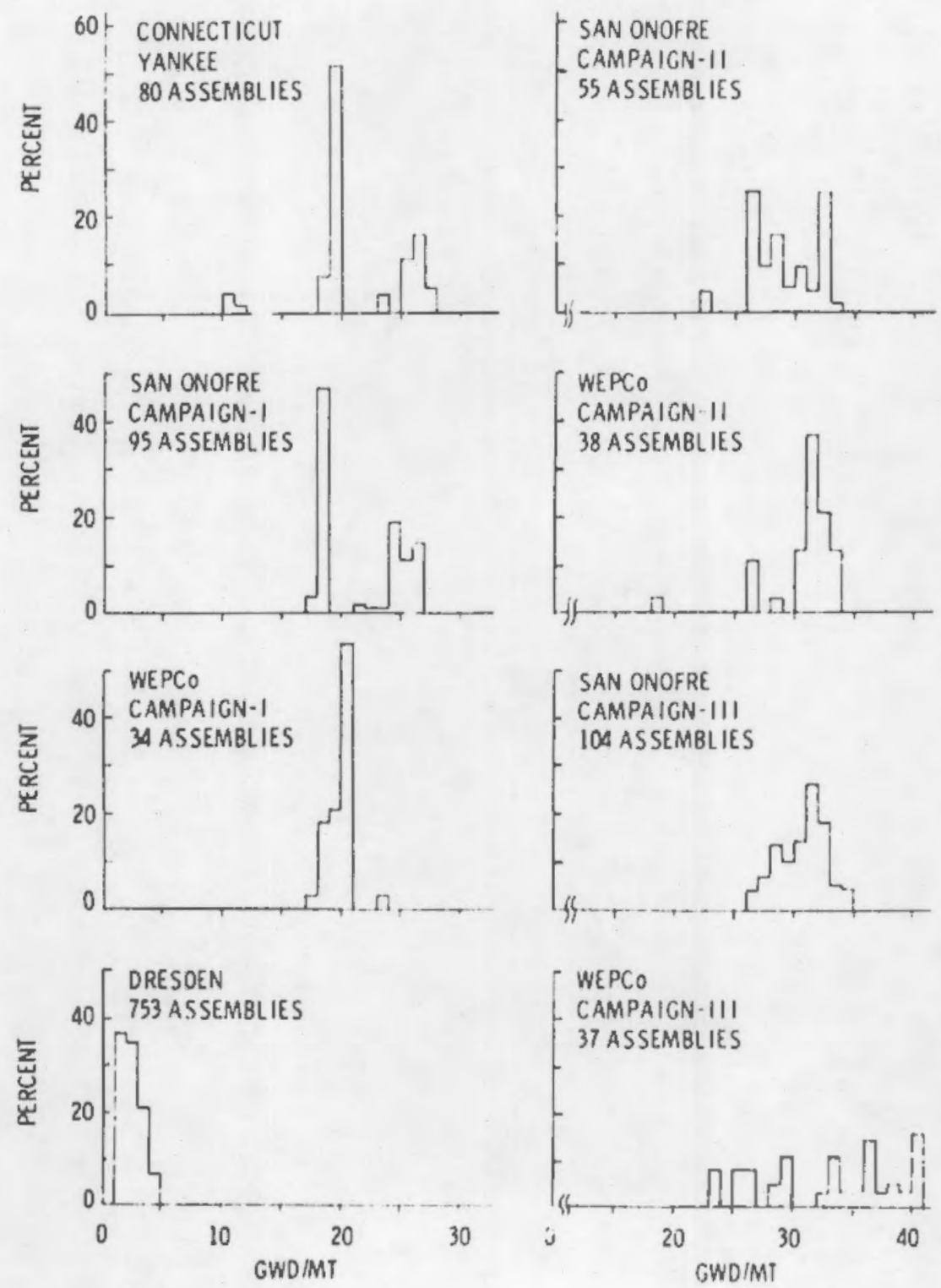

FIGURE 22. Distribution of Burnup for Fuel Shipped to Morris Optration

temperature and cask coolant activity are treated this way. Figures 22 to 30 give these distributions.

The first, Figure 22, gives the fraction of the bundles which fall into each 1 GWD/MT range, for seven campaigns. Dresden shipments were unique in 

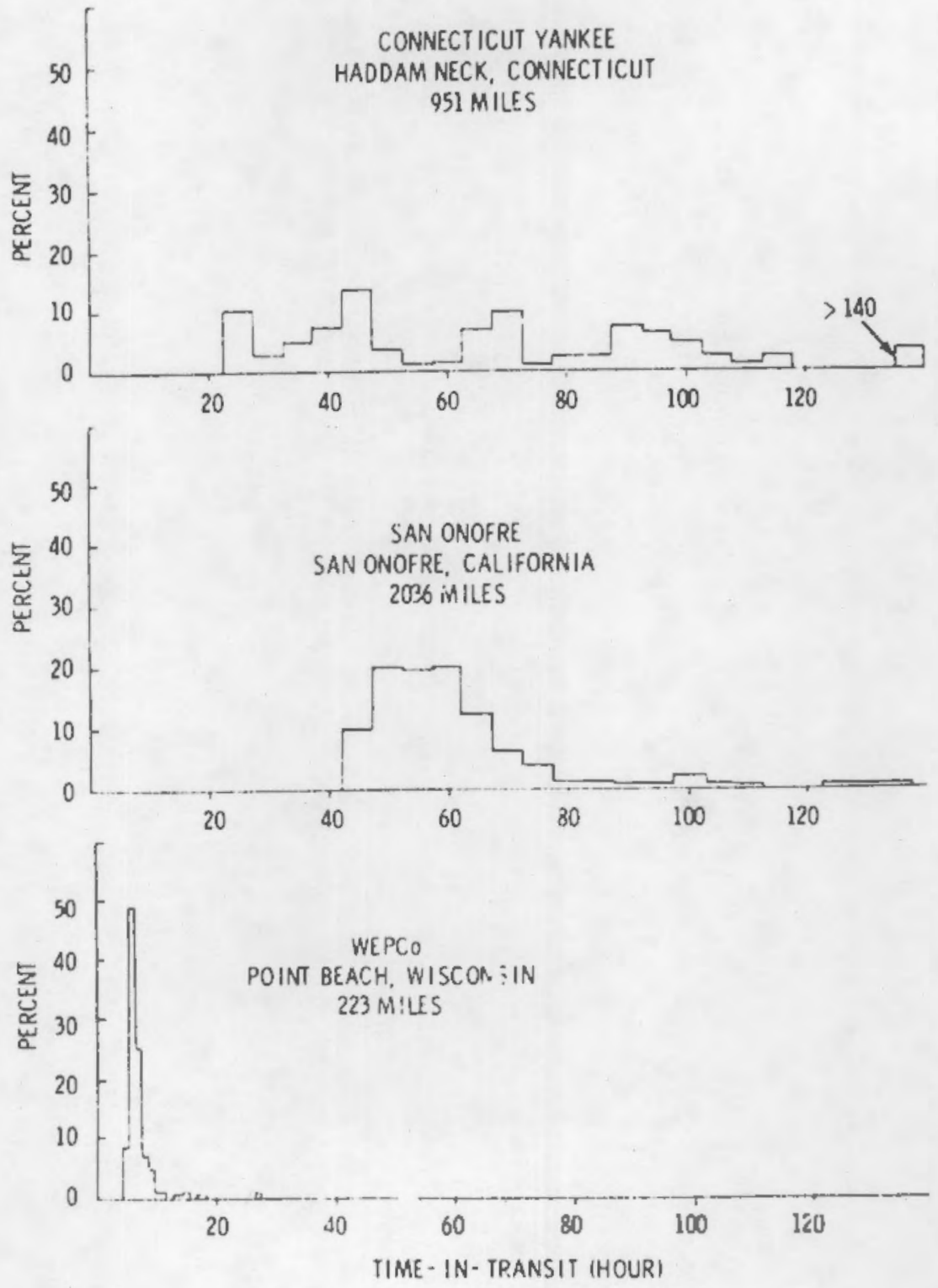

FIGURE 23. Time in Transit for Spent Fuel Shipments to Morris Operation

this respect since each consisted of 5 to 18 assemblies. Burnup shown in this distribution reflects the average value per shipment.

Figure 23 shows the distribution of the shipping times for three of the reactor sites. Again Dresden is unique. These shipments were iess than a 


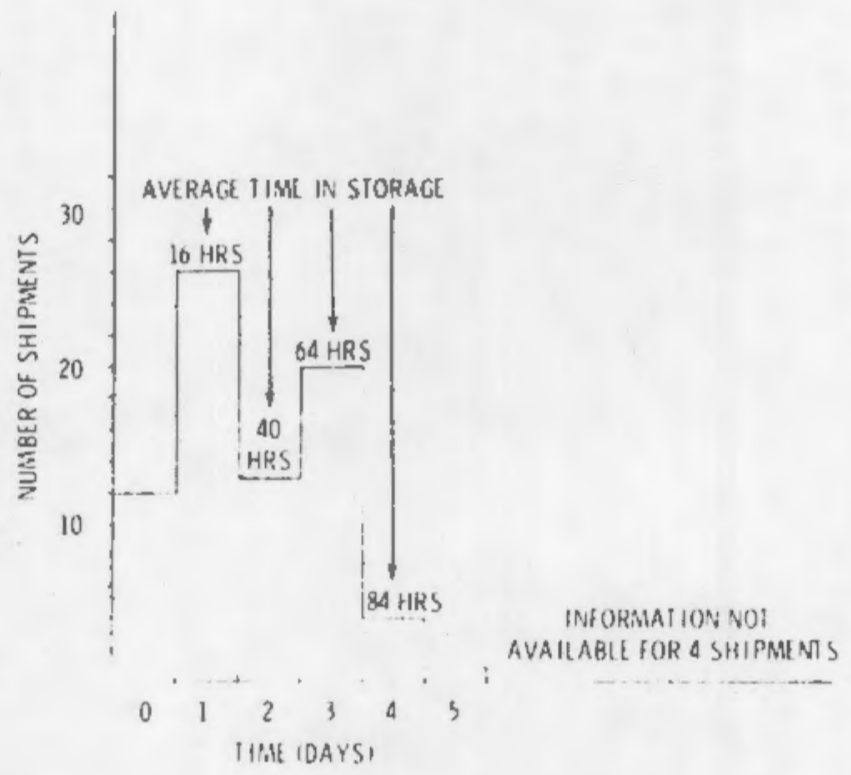

FIGURE 24. Time in Storage for Ship.nents from Connecticut Yankee

mile in length and were accomplished in a matter or minutes. The distributions for San Onofre and WEPCo each represent three campaigns and could have been divided further, however, the distributions had comparable shapes and differed only in the average time-in-transit. The average time-in-transit decreased from 69 to 58 to $55 \mathrm{hr}$ for the first, second and third San Onofre shipping campaigns, and from 7.5 to 6.9 to $6.4 \mathrm{hr}$ for the WLPCo ones. The reasons for the differences are discussed in the analysis section of this chapter.

Figure 24 gives the times in storage during shipment for the Connecticut Yankee campaign. This campaign differed from the others because the IF-200 cask-and-trailer that was used was subject to overweight restrictions. The storage times which resulted fell into quite discrete classes grouped closely around 16, 40, 64 and $80 \mathrm{hr}$. This reflected prohibitions on night driving in Pennsylvania and Illinois, and weekend driving in Pennsylvania. 

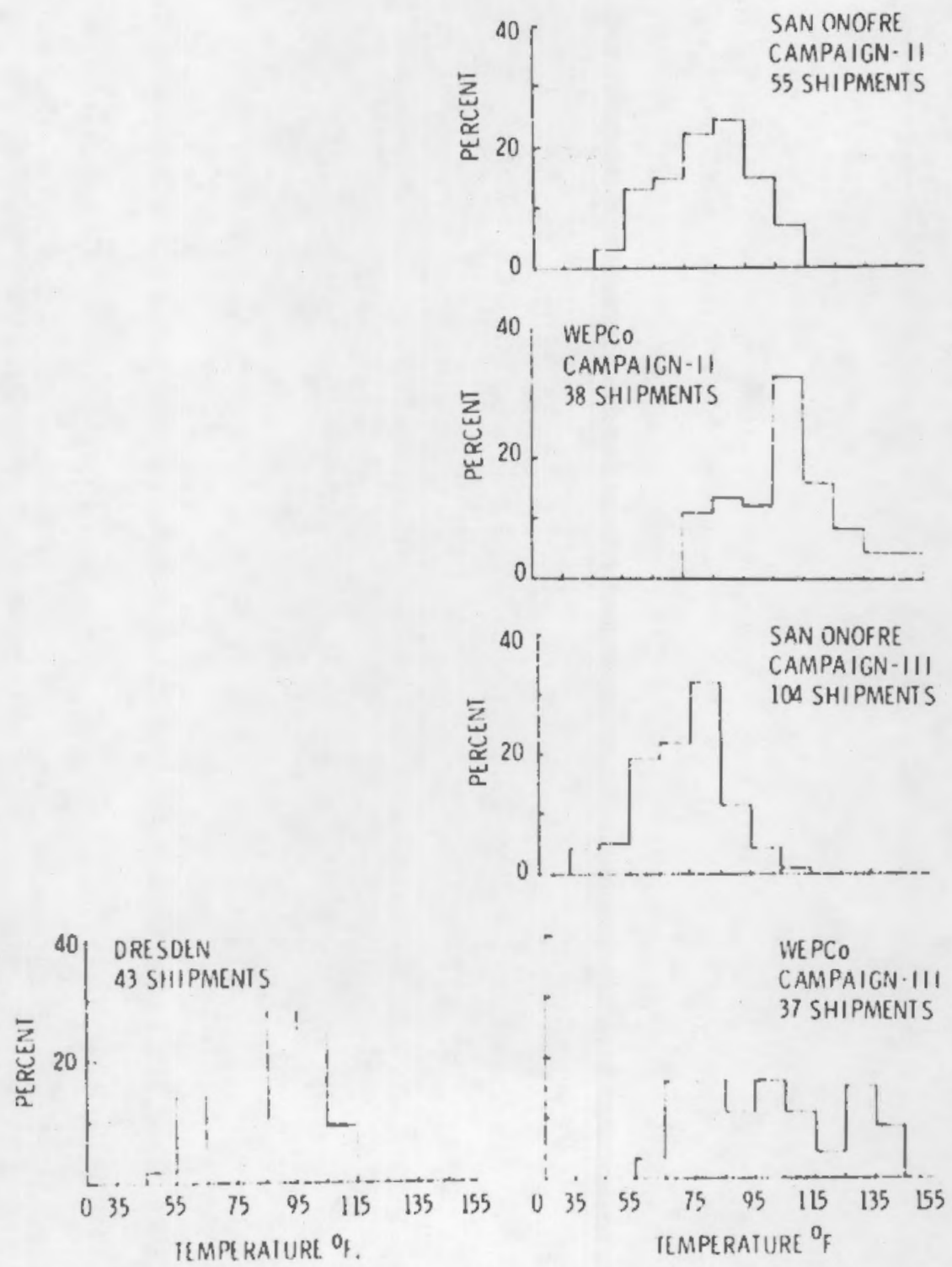

FIGURE 25. Cask Skin Temperature at Time of Unloading

Figure 25 gives the sikin temperatures taken with the casks in the decontamination area during preparation for unloading. No such measurements were made for early shipments, and this accounts for the lack of data for the three earliest campaigns. 

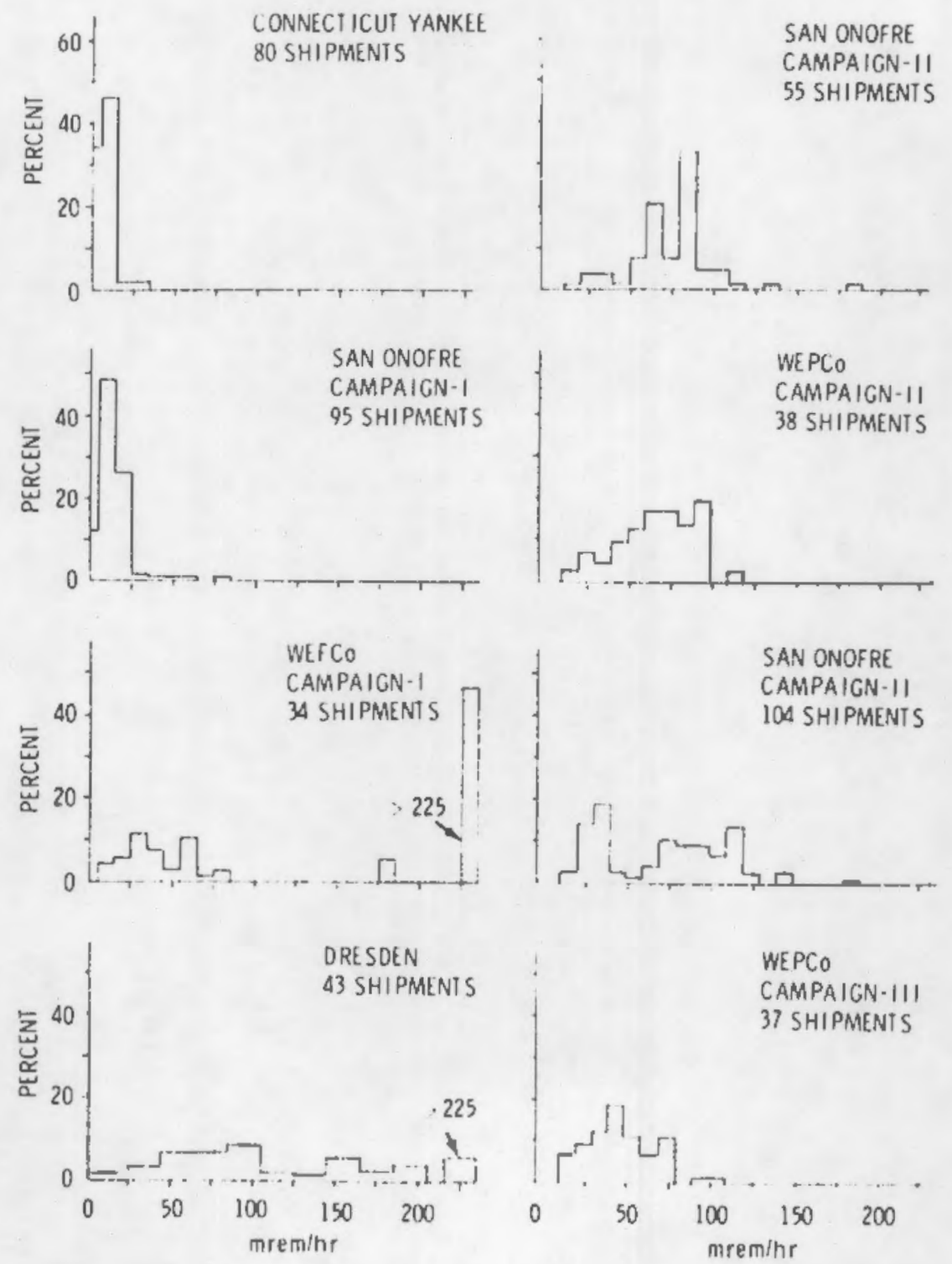

FIGURE 26. Exposure Rates at the Cask Surface for Shipments Received at Morris Operation

Figures 26 through 29 give the highest exposure at various distances from the cask or vehicle, starting at the cask surface, $3 \mathrm{ft}$ from the cask, $6 \mathrm{ft}$ from the vehicle, and in the cab of the truck or railroad engine. Again, the Oresden data should be qualified. All trains were of a single car, and measurements made in the $c$ ab were often reported as $<0.5 \mathrm{mrem} / \mathrm{hr}$. 

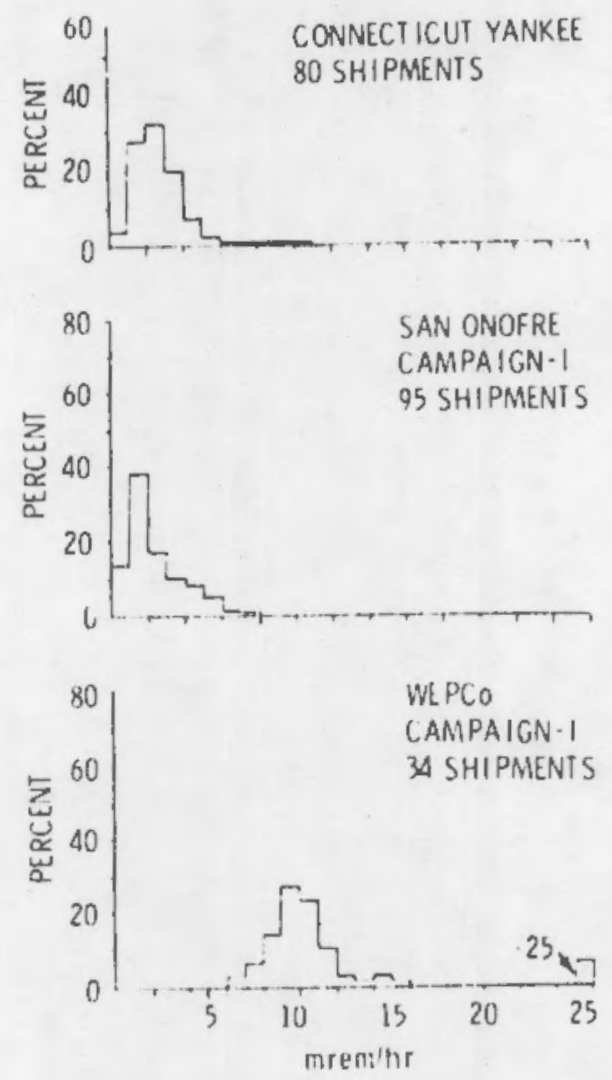

FIGURE 27. Exposure Rate Three Feet from the Cask on Receipt

Three feet readings were not taken on receipt of the more recent shipments and do not appear.

The last of the parameters studied is the cask coolant activity. Values for wet shipments are shown in Figure 30. Shipments from Dresden, and a majority of those from San Onofre (Campaign III) were made with air as the primary coolant and are excluded from this comparison.

Table 9 presents a listing of the numbers and kinds of maintenance items for each campaign which required attention prior to the return of the cask. 

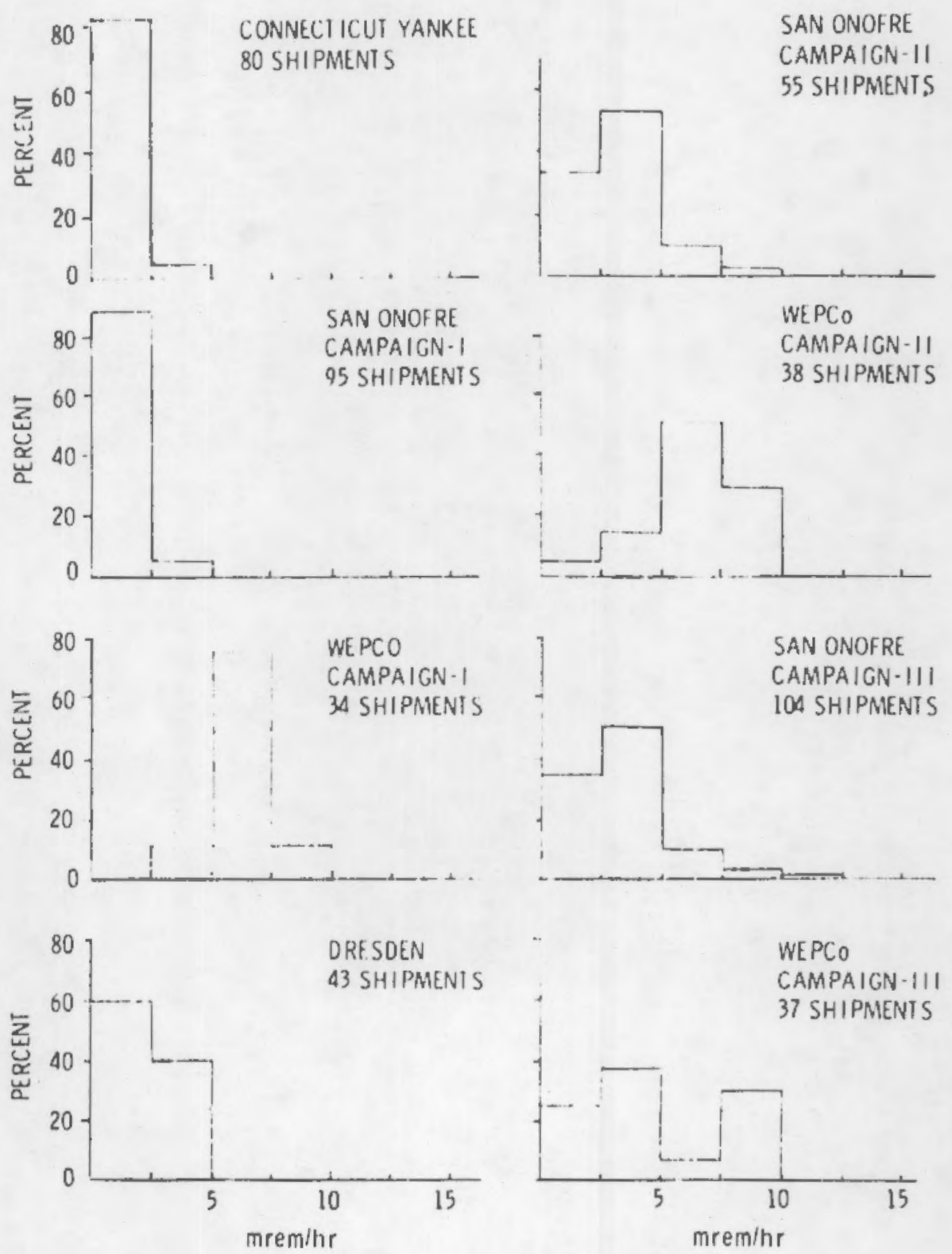

FIGURE 28. Exposure Rate Six Feet from the Transport Vehicle 

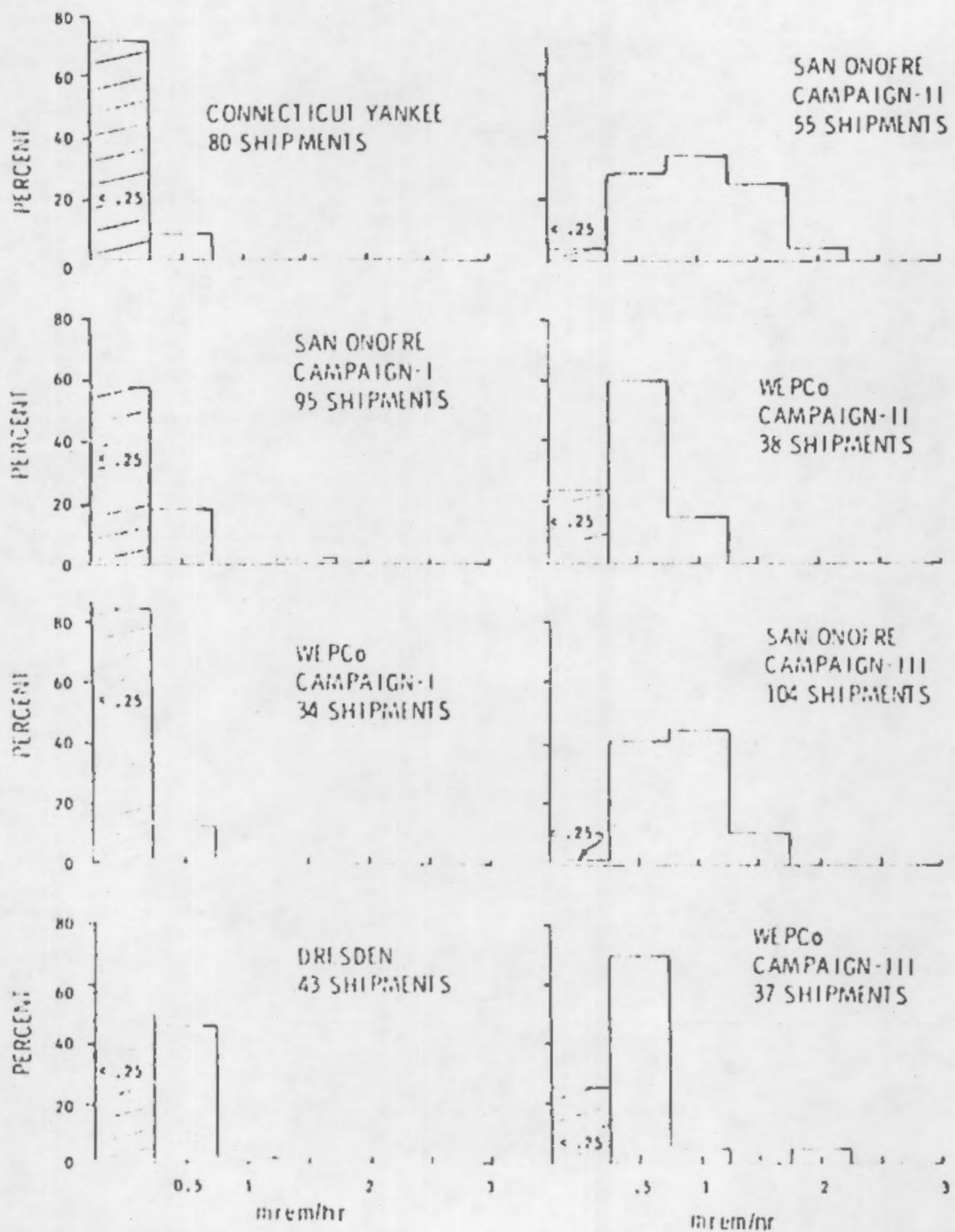

FlGURE 29. Exposure Rates in the Cab of the iransport Vehicle 

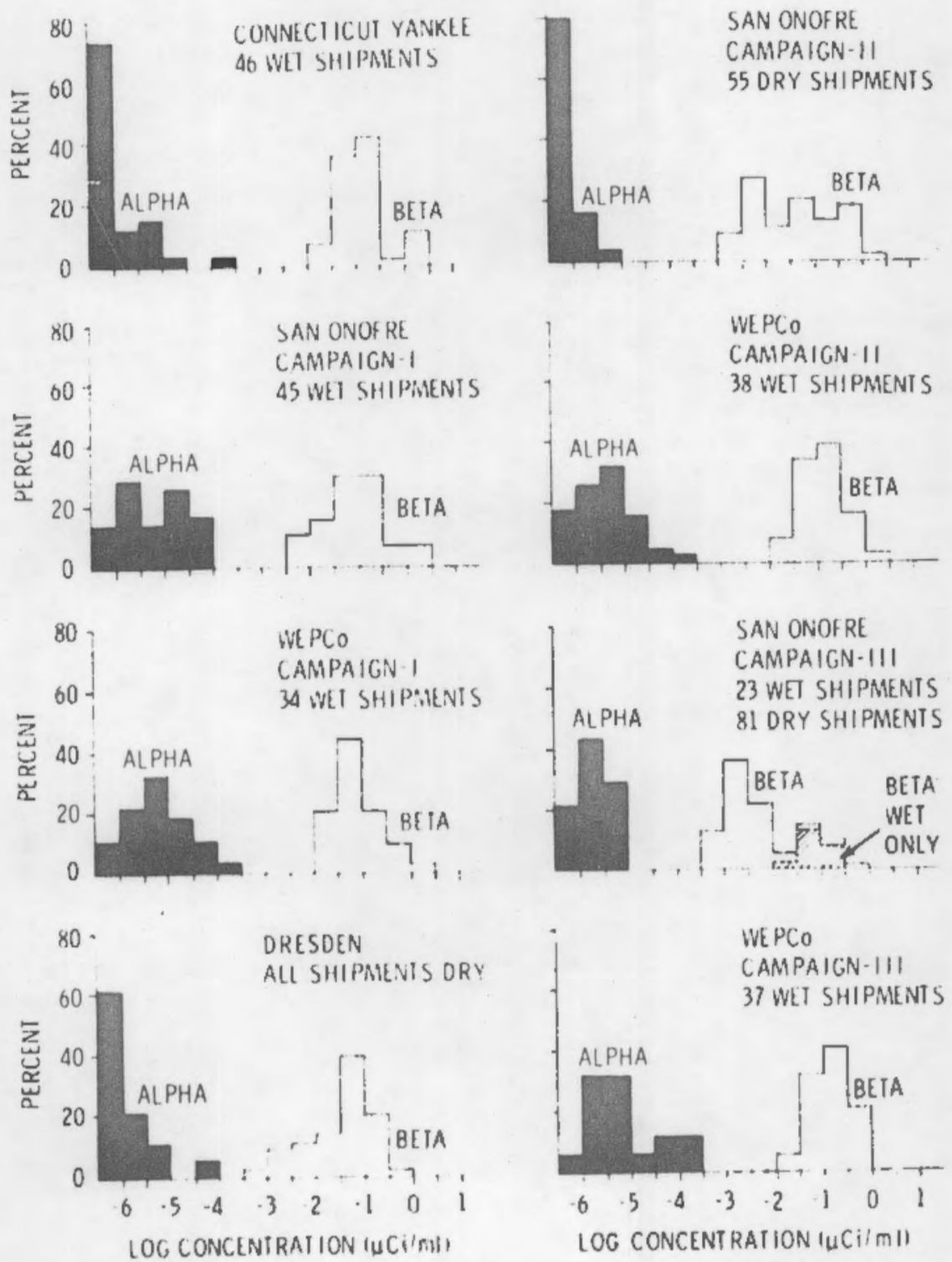

FIGURE 30. Cask Coolant Activity on Receipt 
TABLE 9. Cask and Trailer Maintenance Items

$\frac{\text { Cast: }}{\text { Orain Valves Open }}$
Other Valve Defects
Head Closure Leak

Neutron Shield Rupture Disks Loose or Leaking

Defective Thermocouple Transport Vehicle

Trailer or Trailer Structure Repairs Required
Connecticut San Onofre

Yankee

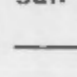

2
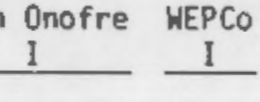

Dresden

San Onofre

$\frac{\text { II }}{1(c)}$

WEPCO
II

${ }^{(c)}$

1

11

1
Minor Repairs (b)

Impact Limiter Support Bolts Broken

Saddle Pad Missing

2

3

5

3

3

Holddown Bolts

Broken

Cracked

Loose

Cask Contents

(n)




\section{ANALYSIS}

Shipping Times

The most important variable which affects fuel shipping times, besides the distance travelled, is the storage in transit for overweight truck shipments. Shipments from Connecticut Yankee (in IF-200 casks) were the only exainple. The wide variation in transit times for these shipments shown in Figure 23 and the comparatively long shipping times demonstrate this. Figure 31 shows the overail rate for straight-through shipments to be approximately $35 \mathrm{mph}$ while the average rate for these overweight shipinents is not quite $15 \mathrm{mph}$.

Other factors which affect the time in transit are 1) the routing, 2) characteristics of the trailer, and 3 ) individual incidents along the road including weather.

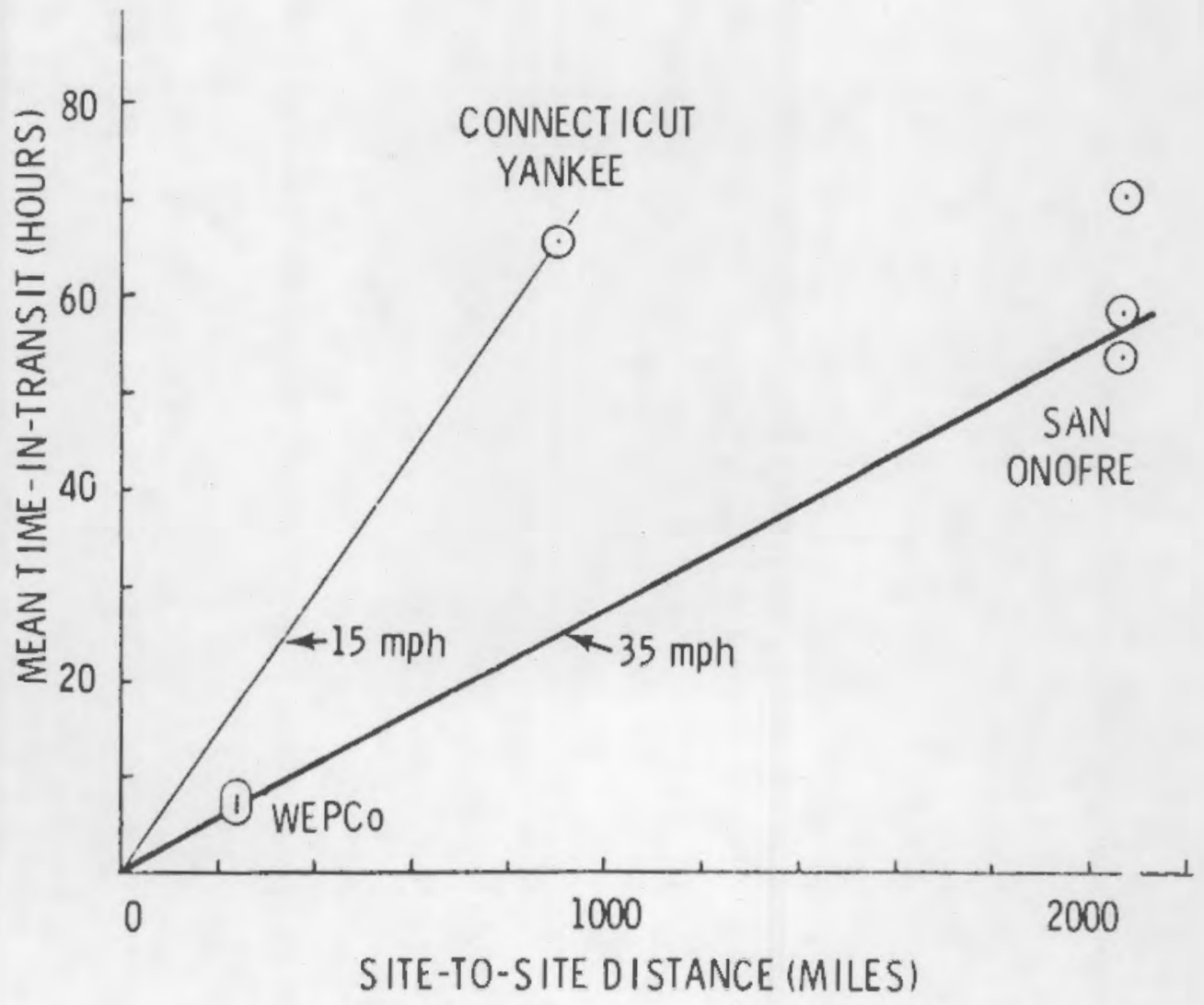

FIGURE 31. Rate of Spent Fuel Movement. 
Routing effects have had the most impact in San Onofre shipments. Northern routes through Utah and Wyoming, poor choices in the winter, are shorter, but have several long hills which must be negotiated. Southern routes through central and southern Arizona provide various protections from cold weather, at least until they turn north toward Illinois. The use of these various routes accounts for some of the spread in the San Onofre data in Figure 23. In addition, each of the three San Onofre campaigns have been completed with different trailers. A flatbed trailer held the IF-100 cask for the first campaign, and an open truss trailer with an oscillating fifth wheel was used in the second. In the third campaign the cask was mounted atop a twin I-beam trailer with air-ride suspension. Each of these changes improved the haulability of the cask and contributed to the reduction in average in-transit times over the three campaigns. The air-ride trailers were also used in the third WEPCO campaign.

Individual incidents have had some impact on shipping times. These have contributed to the spread in the data toward the long delivery times. Snowstorms in Wyoming and 11 linois have stopped the movement of casks in transit. There have also been mechanical problems, including an engine breakdown, the throwing of a fan through the radiator, the locking of brakes and air hoses failures. Oriving rules also have had an impact. Once when one of the two drivers was sick the other had to stop for rest every eight hours; and trips with single drivers (WEPCO) had to be halted occasionally when the driver reached the ICC prescribed driving time limits.

\section{Cask Skin Temperatures}

The cask skin temperature is determined primarily by the local weather and then by the cooling time for the fuel. A third factor is the time between receipt of the shipment and the portion of the unloading procedure where the temperature is taken. Changes in burnup within a campaign have not had any noticeable effect.

The effect of ambient temperature on cask skin temperature is iliustrated in Figure 32 . Here the skin temperature is plotted versus the ambient temperature at arrival. Considerable spread in the data occurs because no effects of wind or precipitation are considered, nor are any effects of delays in 


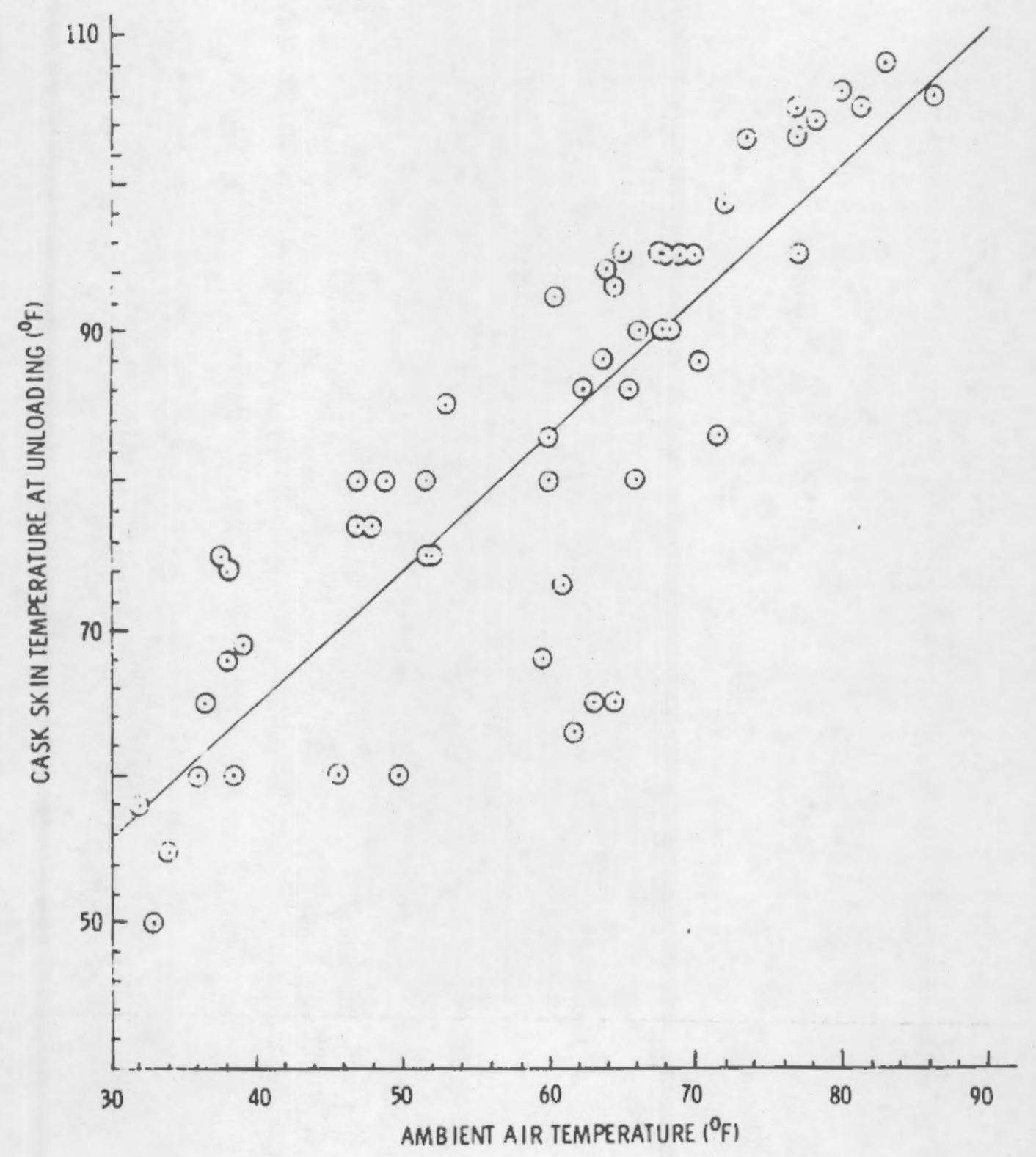

FIGURE 32. The Dependence of Cask Skin Temperature on the Ambient Temperature 
unloading. Nevertheless, the slope of the linear regression line for this data set is 0.92 and the correlation coefficient $(r)$ is 0.91 . On the average NAC casks with heat loads like those in the second San Onofre campaign $(0.68 \mathrm{~kW})$ have skin temperatures about $13^{\prime \prime} \mathrm{C}$ above ambient. A similar analys is done with burnup as the independent variable resulteo in virtually no correlation $(r-0.04)$. The differences in heat load because of burnup just were not big enough to be seen.

Differences in heat load because of different cooling times are greater than those wnich occur for the range of burnups considered, and big changes in $n \in a t$ load do cause noticeable changes in skin temperature. This is illustrated in Table 10. This table gives the average fission product heat load for a large part of three campaigns and two separate parts of a fourth along with two sets of temperature differences. Within each of the five heat load classes the bundle type and discharge date were constant, and the burnups were similar $( \pm 10 \%)$. In one of the sets of temperature $d^{2}+$ ferences measurement of the cask skin temperature was made promptly, and,.. the second the unloading was delayed by five hours or more before the measurement was made. ( $\partial$ ) Hence, the skin temperature in the second case had time to come :o equilibrium with the comparatively still air around it. The ambient temperature used as a reference was the average air temperature for the hour when the cask was received.

The data for both cases can be described by a straight line relationship, is shown in Figure 33. However, the relationship is better for the second (delayed unloading) case than the first. Correlation coefficients for the two cases were 0.968 for the second case and 0.769 for the first. The difference between the two cases occurs because of air cooling during transit. Skin tenperatures on arrival are reduced because of this effective heat removal process, but increase if the cask unloading is delayed.

(a) The cask receiving area and the decontamination area, (where the temperature measurement is made) are enclosed areas where the only effective cooling for the cask is by natural convection. 
IABLE 10. Cask Skin Temperatures at Time of Unioading

\begin{tabular}{|c|c|c|c|c|}
\hline $\begin{array}{c}\text { Partial } \\
\text { Campaign } \\
\end{array}$ & $\begin{array}{l}\text { Heat Load } \\
\mathrm{kW} / \mathrm{MT}\end{array}$ & $\begin{array}{l}\text { No. of } \\
\text { Shipments }\end{array}$ & $\begin{array}{l}\text { Mear } \\
\text { Sk in Temperature } \\
\text { Prompt Unloading }\end{array}$ & $\begin{array}{l}n \text { Cask } \\
\text { Above Ambient }\left({ }^{\circ} \mathrm{F}\right) \\
\text { Delayed Unloaaing }\end{array}$ \\
\hline San Onofre II & 1.7 & 48 & $24 \pm 9$ & $23 \pm 7$ \\
\hline San Onofre III ${ }^{(b)}$ & 2.1 & 47 & $9 \pm 7$ & $14 \pm 13$ \\
\hline San Onofre III ${ }^{(c)}$ & 5.3 & 52 & $24 \pm 12$ & $28 \pm 13$ \\
\hline WEPCO II & 15.4 & 33 & $32 \pm 16$ & $45 \pm 17$ \\
\hline WEPCo III & 17.7 & 21 & $31+13$ & $50+14$ \\
\hline
\end{tabular}

(a) See Figure 22 for burnup characterization.

(b) 769 days minimum cooling.

(c) 326 days minimum cooling.

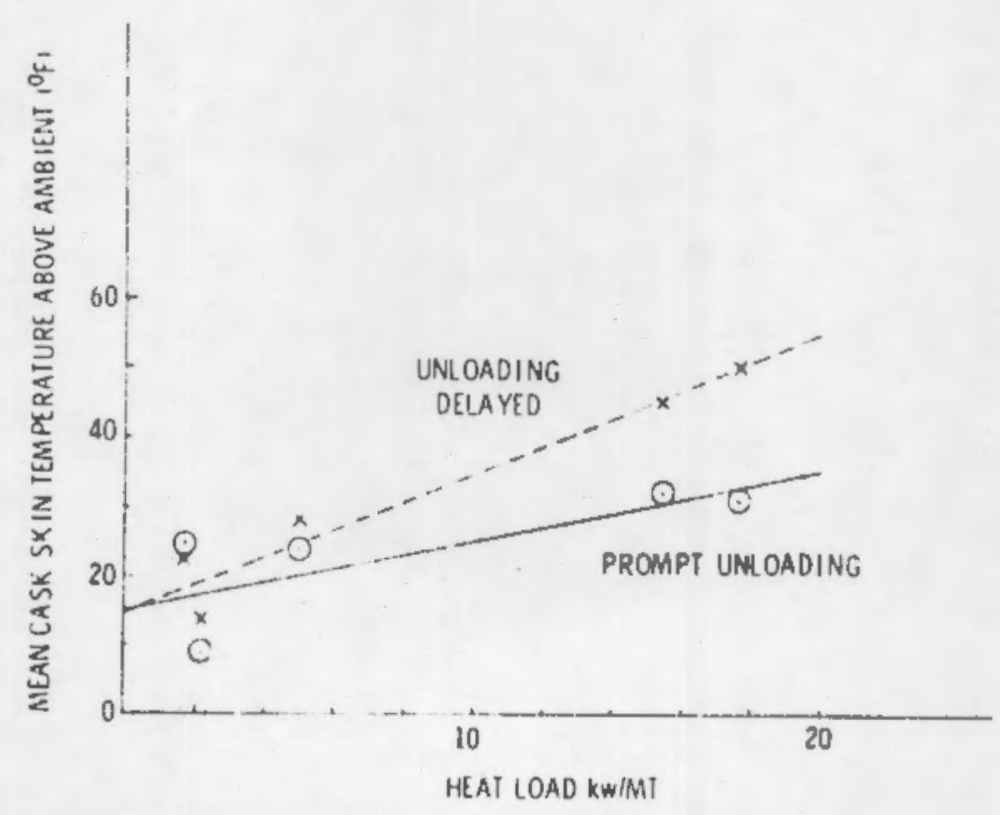

FIGURE 33. Effects of Heatload and Handling on Cask Skin Temperature

\section{Shielding}

Factors affecting the exposure rates external to the cask were 1) the characteristics of the ask type, 2) the cooling time and 3) the burnup. No significant difference could be found between the behavior of individual casks of the same design. 
Figures 26 through 29, which show the distributions for these exposure rates, also show that IF-100 and IF-200 values were consistently low. This occurs because in the other cask types, the NAC-1/NFS-4 and the IF-300, there are 1 imited areas where higher external exposure rates can be found. For the IF-300 loaded with BWR fuel it is around the circumference at the parting line where the head and body of the cask meet.

During the first shipments with the NAC-1 cask there were high exposures at the base. These were shipments in a closed transport behicle and the applicable shipping limits were not exceeded. These shipments account for the values $>25$ in Figure 27 and most of those shown as > 225 in Figure 26 for the first WEPCo Campaign.

Later in this campaign the trailer tops were removed and the closed transport vehicles became "open". About the same time, the casks were modified to reduce the end exposure. First, spacers were moved from the top to the bottom and later shield blocks were inserted at the bottom. As a result, exposure rates at the surface which were all greater than $100 \mathrm{mrem} / \mathrm{hr}$ at the base were reduced to values which ranged fror 5 to $85 \mathrm{mrem} / \mathrm{hr}$. (See Figure 26 WEPCO Campaign I.)

In the subsequent San Onofre Campaign, (I), the spacer was moved back tc the bottom. Readings at the base were reduced substantially, since both the spacer and the shield plug were there. However, exposure rates at the head were increased. This configuration was used for both of the San Onofre Campaigns and the highest exposure rate at the surface was always found at the top. Late in the San Onofre III Campaign a shield plug was also installed in the head. This was done to reduce the exposure to the driver which had increased because the cask-to-driver distance was shorter for the new twin I-beam trailers.

During the WEPCo Campaigns II and III, the spacer was put back into the head. As a result, the maximum surface exposure rates have been found at the base 100 percent of the time.

During the first shipments in the IF-300 cask, high exposure rates were found neal the parting line. These were attributed to cobalt-60 in the BWR fuel bundle bails which are at the same elevation in the cask as the parting 
line. These exposure rates varied with the gap at the parting line during torquing and during shipping if the cask and head surfaces were not metal to metal. Subsequent tests have shown that exposures from loads of PWR fuel are small by comparison, because the bundles have no bail, and fit further down into th? cask.

Al though the exposure rates were permissible for shipping (the If-300 rides in a closed transport vehicle) they produced unwanted personnel exposure during handling which would be increased if high-burnup short-cooled fuel were to be shipped. First, a portable external shield was fabricated to reduce this exposure potential. Since then, the inserts which hold the BWR bundles inside the cask have been fitted with additional shielding in the problem area.

The effect of cooling time and burnup on the exposure rate at the surface can be seen in Figure 34 . The exposure rates were measured in the middle of the cask so that end effects are avoided. Short cooled fuel (WEPCo Campaign II) produced higher exposure rates than longer cooled fuel (San Onofre II) with comparable burnup. However, the difference was not as much as one might predict from the respective heat load or the amount of any single isotope, say ${ }^{144} \mathrm{Ce}$ ${ }^{144} \mathrm{Pr}$ even if differences in spec ${ }^{\circ}$ ic power are considered.

High burnup fuel (WEPCo Campaign III) also produced higher surface exposure rates than fuel with comparable decay times but less burnup (HEPCo Campaign II). In this case the measured exposure rates from the high burnup fuel were greater than one might predict on the basis of burnup alone.

Table 11 gives the average surface exposure rates for casks used in five campaigns. Each set of data is comprised of values taken from the cask mid-section, from shipments with a single fuel type and discharge date. Ilo differences between the casks could be identified.

\section{Cask Coolant}

A review of Figure 30 shows that there are few, if any, substantive differences between coolant samples taken during the various campaigns. (a)

(a) During parts of the first two campaigns, from late 1972 through 1974, some measurements were not recorded. Hence, data for these campaigns is not complete. 


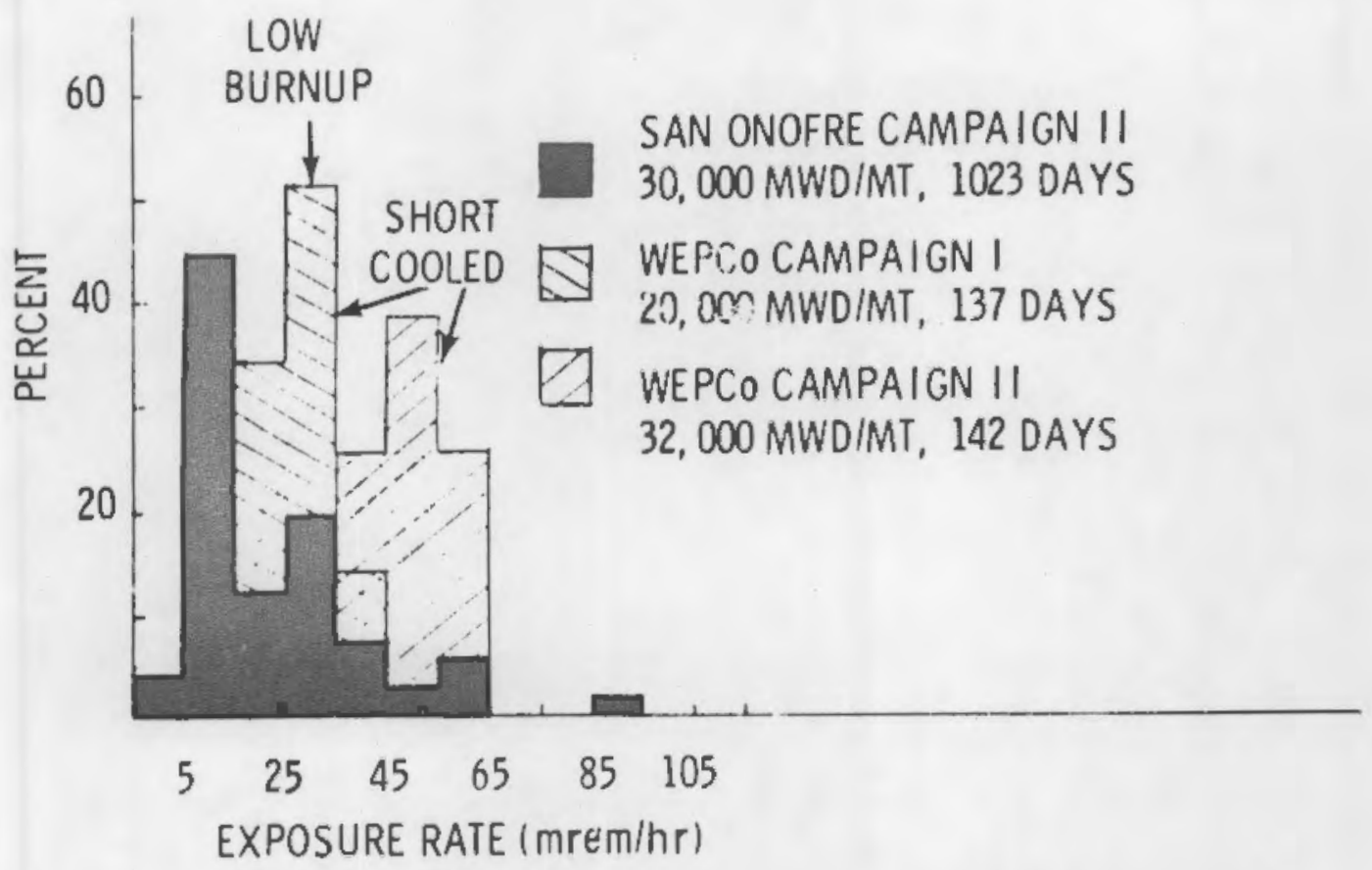

FIGURE 34. Fuel Burnup and Cooling Tiny Effects on Surface Exposure Rate in the Cask Midsection

No beta concentrations exceeded the limits for Group II ${ }^{(a)}$ radionuclides $(5 \mu \mathrm{Ci} / \mathrm{ml})$ defined in 1OCFR71.35. In the last four campaigns, the beta emitting nuclides were partitioned between Group II and Group III. Concentrations of Group III iostopes, largely cobalt and cesium, were determined and subtracted from the concentration of gross beta activity. The unidentified remainder, ascribed to Group II, was found to be less than 10 percent of the total. If this were also true of the first campaigns, coolant samples would all have been at least ten times lower than the limits, and the average concentrations would be 300 times lower.

(a) When concentrations of radionuclides sampled are compared to their respective 1 imits, Group II isotopes form the largest fraction. However, the nature of the analysis for Group II isotopes has the potential for a large error in the conservative direction. 
TABLE 11. Average Surface Exposure Rates for Individual Casks Carrying Comparable Fuel

\begin{tabular}{|c|c|c|c|c|}
\hline Campaign & Cask & $\begin{array}{l}\text { Number of } \\
\text { Shipments }\end{array}$ & $\begin{array}{r}\text { at } \\
\text { Mean } \\
\end{array}$ & $\begin{array}{l}\text { Exposure Rate } \\
\text { Surface (im rem/hr) } \\
\text { and Standard Deviation }\end{array}$ \\
\hline \multirow{2}{*}{ WEPCO-I } & NAC-ID & 15 & & $28.3 \pm 7.7$ \\
\hline & NAC-IC & 17 & & $27.4 \pm 6.3$ \\
\hline \multirow[t]{4}{*}{ San Onofre-II } & NAC-IA & 12 & & $22.5 \pm 12.8$ \\
\hline & $N A C-I B$ & 11 & & $16.8 \pm 10.8$ \\
\hline & NAC-IC & 12 & & $25.4 \pm 19.8$ \\
\hline & NAC-ID & 12 & & $21.3 \pm 13.0$ \\
\hline \multirow[t]{2}{*}{ WEPCO-II } & NAC-IB & 15 & & $46.3 \pm 11.9$ \\
\hline & NAC-ID & 18 & & $48.1 \pm 11.1$ \\
\hline \multirow[t]{3}{*}{ San Onofre-111 } & $N A C-18$ & 35 & & $46.9 \pm 35.5$ \\
\hline & NAC-IC & 27 & & $44.1 \div 31.6$ \\
\hline & NAC-ID & 30 & & $39.7 \pm 32.2$ \\
\hline \multirow[t]{2}{*}{ WEPCO-III } & NFS $-4 A$ & 11 & & \pm 17.4 \\
\hline & NFS- $4 B$ & 10 & & $45 \pm 24.7$ \\
\hline
\end{tabular}

(a) Measured in the midsection of the cask.

The concentrations of alpha emitting radionuclides have also been well below the limits for Group 1 isotopes $(0.11 \mathrm{Ci} / \mathrm{ml})$ also defined in 1OCFR71.35. This trace activity is from transuranium elements (i.e., americium and plutonium) which appear to be associated with the crud.

Since there has been little change in the cesium transfer rate ${ }^{(a)}$ over 1976 and 1977 (over 200 MT of fuel was received in that period), these concentrations of radioactive material seen in the cask coolant must not be associated with problem leakage from the fuel. There was only one instance of leakage identified where an abrupt change of the ratio of cesilim-137 to cesium-134 (a) Transfer rates were discussed in Chapter II and appear in Table 2. 
occurred coincident with the start of the second San Onofre Campaign. Even then there was little impact on the quantity of radioactivity in the basin and the cesium ratio returned to normal after several months. The absence of such changes particularly in later campaigns suggests that the fuel received more recently might be less likely to release radioactive materials into the basin.

Analyses were made for each campaign to see if there was any relation between the time in transit and the "as received" coolant activity. No trends were apparent, and regression lines and correlation coefficients determined for the data sets confirmed this observation. 
VIII. FUEL. UNILOADING AND CASK TURNAROUND

\section{DESCRIPTION}

Fuel unloading begins with the receipt of a loaded cask, and ends when the cask, having been emptied, is ready to go back out the gate. The major activities which take place during this process are 1) the removal of the cask from the vehicle, 2) the preparation of the cask for underwater unloading, 3) unloading and 4) the preparation of the empty cask for shipping. These activities vary slightly from cask-to-cask since each of the four types of casks handled has individual features. Two of these four cask types, the IF-100's and IF-200's are now obsolete, so recent shipments have been made using truck mounted NAC-1/NFS-4 casks for PWR fuel and rail mounted IF-300 casks for BWR fuel.

The cask and vehicle are generally moved directly from the gate to the cask receiving area. (a)

This unloading area is serviced by the cask crane. Once in place, the cask and vehicle are inspected and various tie-down hardware is removed. The cask crane and yoke are attached to the cask trunnions and the cask is tilted from a horizontal to a vertical position. Once vertical, the cask is lifted and transferred to the decontamination area where the final incoming checks are made and dry preparation for unloading is done.

The rask surfaces are smeared to detect any radioactivity which might indicate that leakage during transit had occurred. Then the cask skin temperature is measured and the coolant (if liquid) is sampled.

Pool water is used to displace the cask coolant, if the shioment is wet, or for filling of the cask with water if it is dry. Outflow water is routed directly to the LAW vault. If the shipment is dry, samples are taken of the first rinse water to come out for a measure of the condition of the fuel

Ta) Delays which occur when that area is already occupied will be discussed later. 
inside. Most of the bolts holding on the head are removed and the fixture is installed that is used for removing the head under water.

The cask is now ready for unloading. It is lifted and placed on the unloading pit shelf where the last head bolts are removed. The crane is disencaged and then re-engaged using the extension hook. With this tool in place, the cask is lowered to the bottom of the deep pit. The crane is again disengaged and the head is removed. A fuel storage basket is moved to the grid in the deep pit and fuel grappies are used to move the fuel from the cask into $i t$. Then the basket is removed from the pit, the head placed back on the cask, and the cask is lifted up to the shelf. The extension hook is removed, and the cask is placed back in the decontamination area.

Preparation for shipping includes pumping water from the cask cavity to the LAW vault, removal of the head lifting hardware, securing of the cask head, and decontamination of the cask surface. Tests required before shipping is allowed, which include a cavity pressure test and measurement of residual contamination on the cask and vehicle, are then made. The cask is placed back on the transport vehicle if all is satisfactory. If not, remedial action, which might include a second deco:itamination or replacement of cavity seals or valves, is taken. Once the cask is back on the vehicle, holddowns are installed and arrangements are made for having the cask moved off-site.

Each of the separate activities described briefly in this section is treated in greater detail in following sections.

\section{CASK PREPARATION FUR UNLOADING}

The preparation of a cask for unloading begins as soon as the rail car or truck trailer is positioned in the cask receiving area. The steps which follow can be divided into ones with two different purposes. The first purpose is to remove the cask from the rail car and place it in the decontamination area, in a vertical position. The second is to ready the cask for cinloading underwater. 
Movement to the Decontamination Area

As soon as the vehicie has been spotted in the cask receiving area, a safety survey and a visual vehicle inspection is begun. External radiation levels are measured to cietermine any limitations on work times around the rask and to comply with Federal regulations and the cask surface is surveyed for contamination which might be indicative of leakage during transit. The inspection covers structural and functional parts of both the vehicle and cask.

Removal of auxiliary equipment comes next. The forward impact limiter is the only thing which has to be disengaged from the NAC-1/NFS-4 cask. For the IF-300 cask one must turn off the diesel engines, slide back the enclosures, move the upper air vents aside and remove four valve box covers. The IF-100's and 200 's did not have this kind of equipment.

Next the holddowns are removed and the yoke is engaged. For the NAC-1/NFS-4 cask, the front holddowns are removed and the rear ones loosened until the cask is lifted to a vertical position. Then the rear holddowns are also removec', and the cask is moved to the decontamination area. For the IF-300, two pins fastening the cask to the skid are removed and used to attach the trunnions. The cask is then tipped up using the yoke and crane on one end and a tilting cradle on the other. Once vertical, the cask is lifted out of the tilting cradle and moved to the decontamination area. (a) Tilting of the other casks is done similarly; the IF-100's are rotated on lower trunnions and the IF-200's on a tilting pad.

\section{Pre-Immersion Preparation}

Once in the decontamination area, the skin temperature is measured, and the cask is sampled and flushed out. Upper and lower cask cavity valves are attached via hoses to the cask flush system, and the cask coolant water is pumped out and replaced with basin water. Some of the first water to leave is collected at a lap in the pump output line and analyzed for radioactivity. Leakage of material from the fuel can be assessed this way. If coolant samples me t acceptance criteria, work continues; otherwise, the process is stopped and a further analysis of the fuel condition is made.

(a) The same area, named the decontamination area, is used for 1) preparation of the cask for unloading, 2) decontamination and 3) shipping preparation. 
For dry shipments the cavity air is replaced with basin water in a similar way, and the first of this to overflow through the top cask cavity valve is sampled and analyzed.

Next, the bolts that hold on the head are loosened or removed. If-100's have 16 head bolts, the IF-200's 8 , the NAC-1/NFS-4 6 and the IF-300, 32. These are to be torqued in sequence for the IF-300 to prevent the head from tilting and resultant binding of the studs and guide pins. Two or four bolts are left in place hand tight until the cask is placed in the water so that tipping would not cause the head to come off and the fuel to be exposed.

The last step before the cask is moved into the water is the installation of the mechanism for lifting the head under water. Cables are attached with slack between the head and the yoke for the IF-100's, 200's and 300's, or a liftina bail bolted to the head of the NAC-I/NFS-4 cask.

\section{UNDERWATER WORK}

The cask is moved directly from the decontamination area to the unloading pit shelf. Here the cask crane is disengaged so that the extension hook can be used, and the remaining head bolts are removed. The yoke remains attached to the cask during this change and is supported by brackets on the side of the pool (for the IF-100, 200 and IF-300 models), or by side arms that rest on the top of the cask for the NAC-1/NFS-4 model.

With the extension hook in place, the cask is moved from the sheif and placed at the bottom of the unloading pit. Tlien the head is removed. For the IF-100, 200, and 300 's this involved disengaging the yoke, and aligning it up again above the lifting ears or trunnions. The head was lifted by the cables attached to the yoke when the crane was raised. For the NAC-1/NFS-4 cask, the e:itension hook is disengaged and the yoke allowed to rest on the cask at an angle so that the head is accessible. The basin crane and a basket hook are used to remove the head ard set it aside. A special stano is installed in the basin to receive the head and free the basin crane. The next step is to move an empty or partially-empty basket from a storage basin into the unloading pit. 
The basin crane is used to lower the basket through the anti-tipping gate and insert it in the unloading pit grid. The anti-tipping gate is then drawn out of the way.

At this time, the grapple is used with the fuel handling crane to engage the fuel, lift it from the cask, and place it in a basket.

This grappling step is repeated until the cask is empty or the basket is full, whichever occurs first. (a) In any event, the anti-tipping gate (see Chapter I) is lowered and the basket moved to storage by using the basin crane. Verification of the bundle number is done with the fuel at a minimum depth before it is finally placed in the storage array.

\section{PREPARATION FOR SHIPPING}

Actions taken once the cask is out of the water to prepare it for shipping can be divided into two parts. The first part includes work done on the decontamination area, and the second, work securing the cask to the transport vehicle.

Work on the decontamination begins by attaching hoses from the cask cavity valves to the cask flush system and pumping the water in the cavity to the LAW vault. Head bolts are put in place and torqued down, and any required pressure tests are performed. There are two such tests for the NAC-1/NFS-4 cask, one of the space between two concentric " 0 " ring seals and the other of the cask cavity. For the IF-300 there is a single cavity pressure test performed at this time.

The casks are decontaminated by rinsing, wiping ofttilıes with a decontamination solution, rinsing again, and hand drying. Afterwards, the cask is surveyed to see that any residual contamination is below the Department of Transportation standards. If this is the case, the cask is released for shipment. If not, the decontamination step is repeated partially or wholly and the cask is re-surveyed. The cask car is also surveyed and decontaminated if necessary.

When the cask has been released it can be moved to the trailer or rail car. The unloading sequence is reversed here; the cask is placed on the car, tilted

(a) Since IF-100s, $200 \mathrm{~s}$ and NAC-1/NFS-4 casks have only been used to carry one bundle, grappling was only repeated for the IF-300 shipments. 
to the horizontal position, and disengaged from the crane and yoke. Holddowns are installed in a sequence opposite to their removal on receipt of the cask, and auxiliary hardware put in flace (e.g., impact limiters, or ventilation ducts, and cask enclosures). The IF-300 diesel engines mus'c also be refueled.

\section{ANALYSIS}

\section{Cask Preparations}

The distribution of times required for moving the cask to the decontamination area, and then readying it for immersion are shown in Figures 35 and 36 respectively. Comparison between campaigns is properly done based on the time for the modal group, whereas deviations from these times, particularly toward longer ches, resulted from events largely independent of cask or fuel type.

The first of these figures, Figure 35, shows the time to off-load the cask to range from 0 to 1 or 1 to $2 \mathrm{hr}$ for single element casks and from 2 to $3 \mathrm{hr}$ for the IF-300. Nn reason could be identified to account for the former difference seen between the Connecticut Yankee- and first WEPCo campaign and the others. The Dresden off-loading time is longer as expected, because of the extra auxiliary hardware which must be attended. A second general characteristic shown in this figure is the "greater than 15 hour" category seen in the four right-hand graphs. This is almost exclusively "delay time" that occurred because the incoming cask had to wait for ont already in the process of being unloaded. Characteristically, this is seen in the campaigns which overlapped, i.e., San Onofrt II and WEPCo II overlapped with the Dresden campaign, and the San Onofre III and WEPCO III campaigns overlapped. Dresden incoming delays have been removed from that portion of figure 35 and are shown separately in Figure 37. This was done to facilitate comparison since almost all of the Dresden shipments were delayed. For other campaigns, the fractions were considerably smaller. Additional causes for delay were generic, i.e., waiting for dignitaries, pres $s$ or photographers, or in working around holidays, or specific, like the melting of ice from the cask in cold weather. 

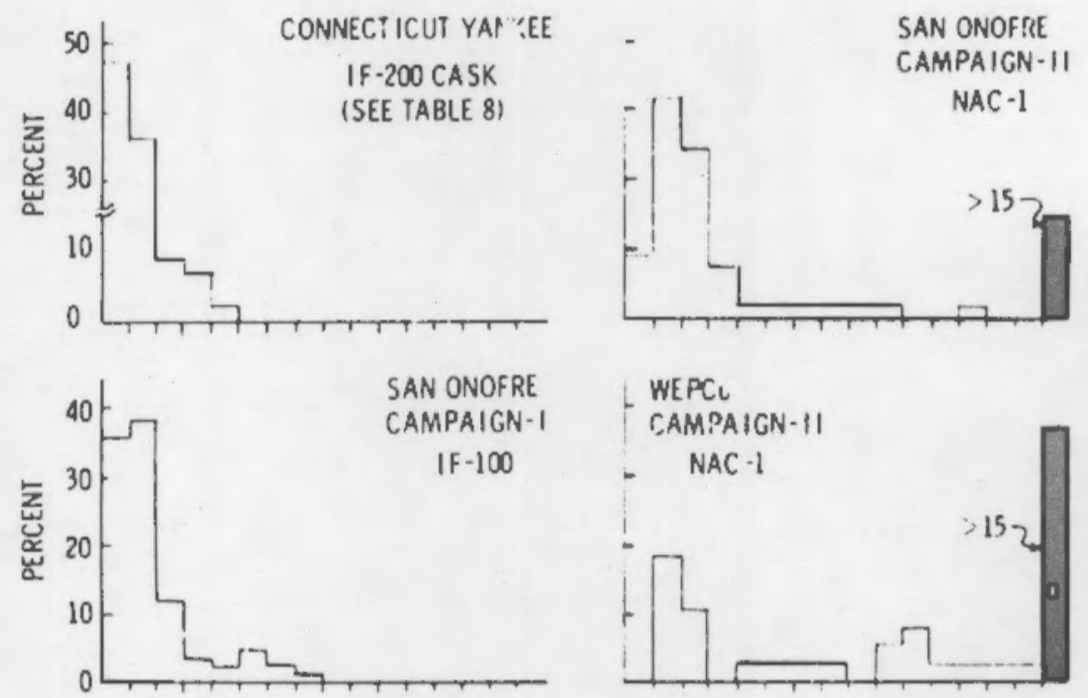

WEPCL

CAMPAIGN-11
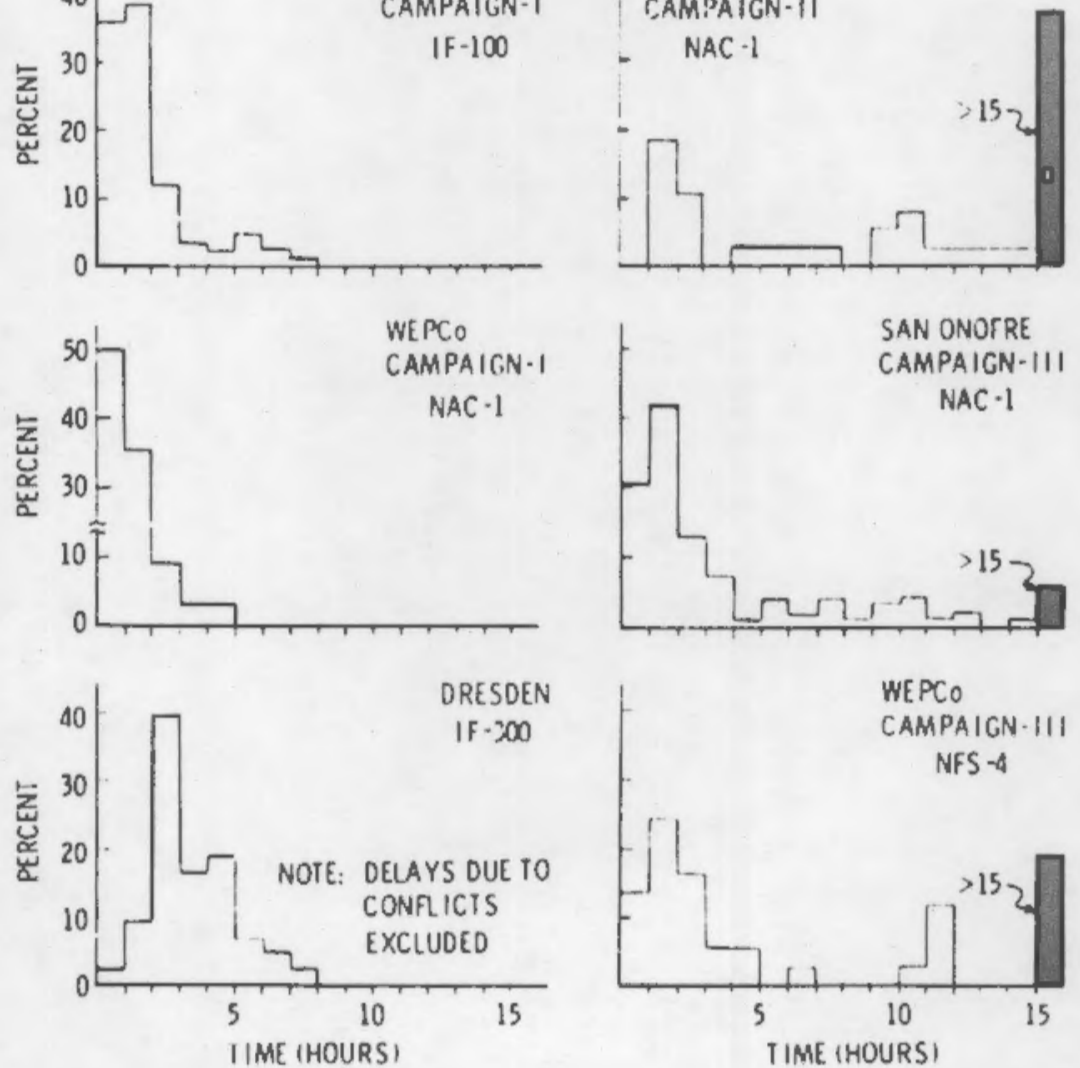

FIGURE 35. Times Required to Move the Cask into the Decontamination Area 

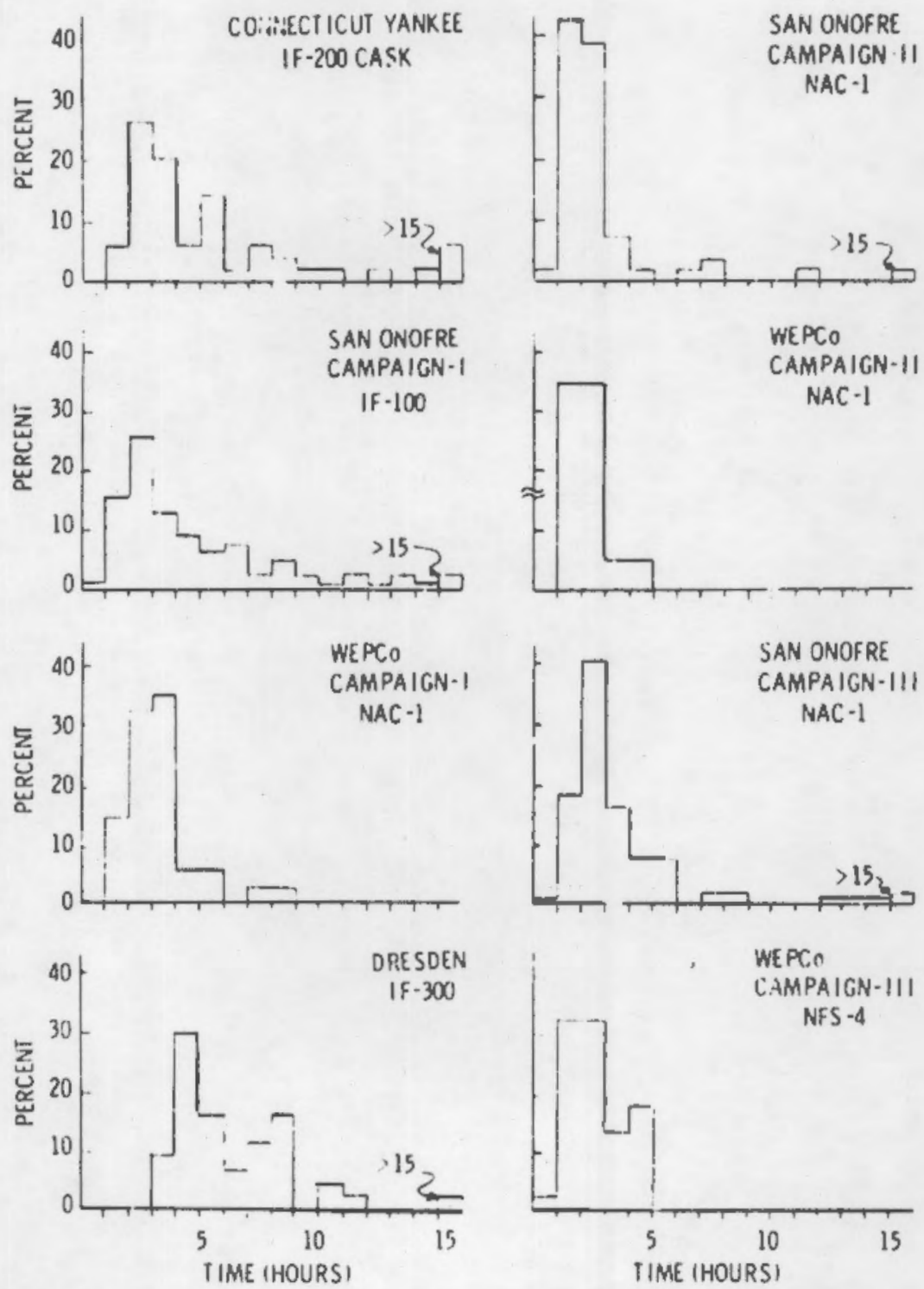

FIGURE 36. Time in the Decontamination Area Prior to Immersion 
The second figure, Figure 36 shows a similarity in times required to attend the single element casks in the decontamination area. Modal times ranged between 1 to $3 \mathrm{hr}$, and in one case 3 to $4 \mathrm{hr}$. The differences are not believed to be significant. Comparable work on the If-300 clearly took longer (the modal time was 4 to $5 \mathrm{hr}$ ) because loosening more bolts at higher torques and the filling or flushing of the greater cask volume is required.

Delays in these steps accounted for the tails seen in several of the graphs. The most apparent are those seen in eariy campaigns. They stem from manpower conflicts during efforts to start up the reprocessing plant and range up to eight or more hours. In these cases, fuel handling was simpl; stopped so other activities could be given greater attention.

There were several other sources f', r delay in this stage. Lifting hardware had to be changed during overlapping campaigns (Dresden versus WEPCo II and San Onofre 11). Unloading was delayed while vaiting for analyses of boron levels in the cask (the boron level in the basin is kept to a minimum), or waiting on cask coolant analyses in early shipments (a quick screening technique is used now so that unloading may progress without waiting for the complete analysis). Finally, washing of road dirt from the cask sometimes took additional time (failure to do this leads to difficulty in the decontamination of the cask when it is removed from the basin).

On one occasion, unloading was delayed because the radioactivity in the coolant exceeded preset limits. After additionai study, however, the bundle was stored in a normal fashion without any adverse impact on operation of the basin.

Underwater Work

The distributions of times required to move casks in and out of the basin are shown in Figure 38. Comparison of the times taken for the modai groups shows that the underwater work using the IF-300 takes the longest ( 9 to $10 \mathrm{hr}$ ), but that there is littie difference between other campaigns (near 4 to $5 \mathrm{hr}$ ). The unloading of additional bundles accounts for most if not all of the difference. Some increase in underwater time might occur because without east-west motion of the cask crane the replacing of the IF-300 cask head is more tedious. 


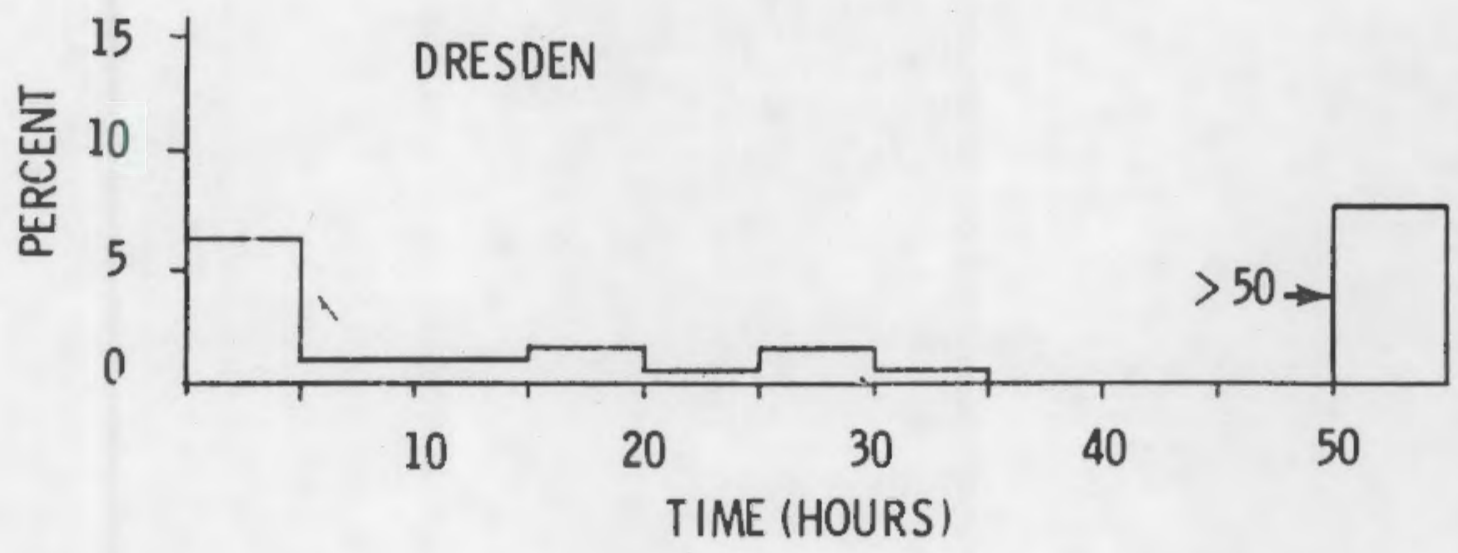

FIGURE 37. Delay Times Before Beginning the Unloading of Dresden Shipments

There were few delays of convenience in the underwater phase. The practice nas been to unload the fuel and move the cask out of the unloading pit as soon as possible since additional time in the water leads to additional decontamination work. Significant tails in this part of the unloading sequence which occurred in early shipments, i.e., Connecticut Yankee, and San Onofre I - and to a lesser extent WEPCO 1, were largely due to difficulties with the first grapples. Control of the grapple position was difficult using just the basin crane; air cylinders had to be filled, and leaks in the air lines allowed tile mechanisms to become wa terlogged.

Difficulty was experienced in replacing IF-100 heads, so they were brought out of the water and set down. The crane was then re-enguged to the cask and the empty cask withdrawn. The head was replaced with the cask in the decontamination area. Extra crane work which resulted was another contributor to the :ong underwater time seen with these casks. 

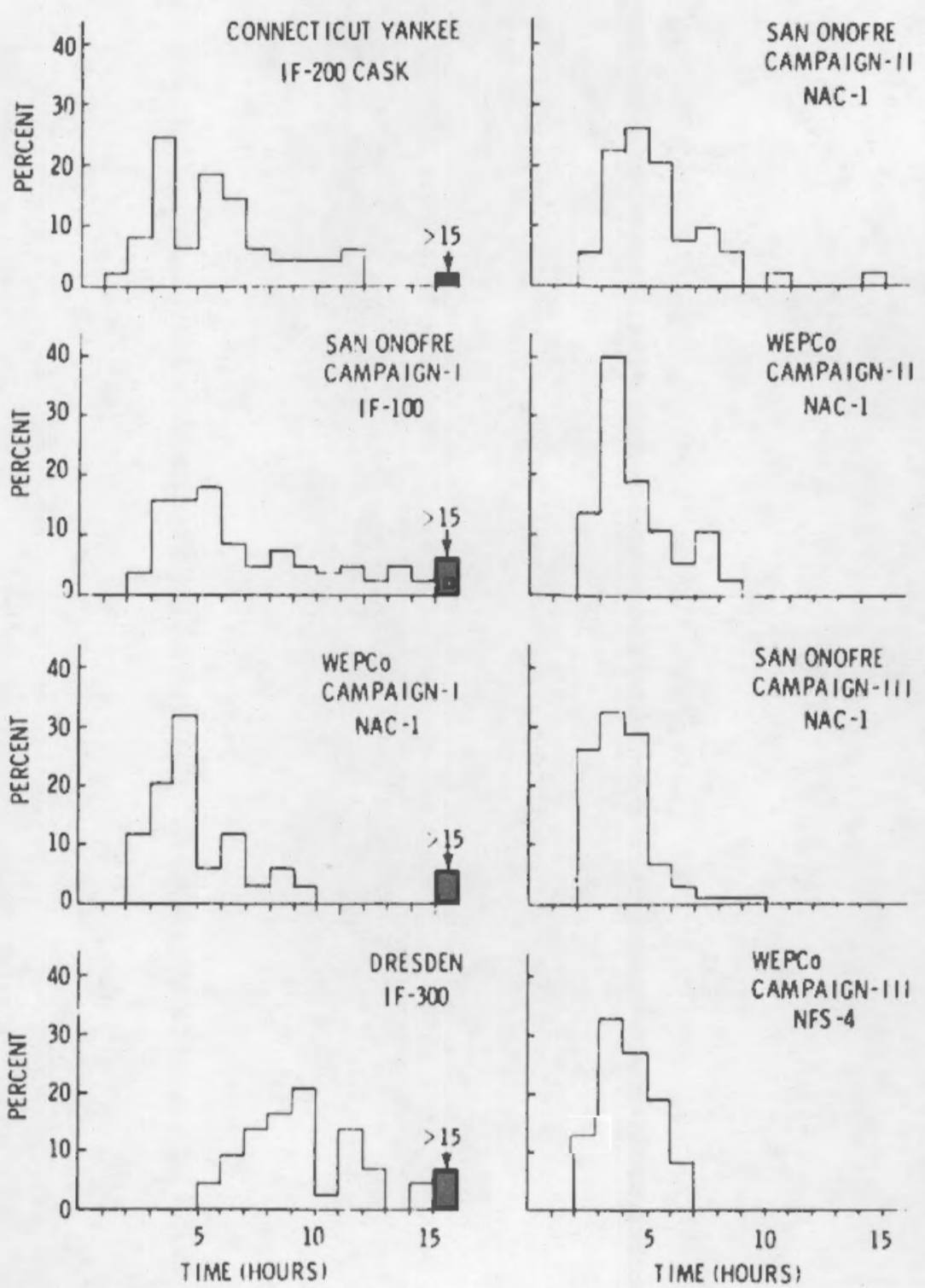

FIGURE 38. Time for Underwater Work 
In addition, early casks wero drained to the basin, thus increasing this time; and some difficulty was seen at first in confirming Connecticut Yankee bundle numbers. A cask tipping incident let to a delay of several days, and accounts for about $1 / 4$ of the shaded area in the San Onofre I graph.

Delays in recent campaigns have not been as frequent, and causes have varied. The grapples have become caught in the spring clip on top of the PWR fuel bundle several times and the grapple guide pin came out once. Finally, the use of head spacers in WEPCo campaigns which caused the fuel to sit lower in the cask has made grappling somewhat more difficult, and NAC-1/NFS-4 " 0 " rings have come off of the head under water and had to be fished out and replaced.

\section{Shipping Preparation}

Figures 39 and 40 show the distribution of times for work preparing the cask for shipping. The first of these figures gives times spent in the decontamination area. It shows significant differences among the behavior of the three cask types. IF-100's and 200 's required longer preparation then the NAC-1/NFS-4 cask; and the IF-300's required an even longer preparation. There are two main reasons for this difference, the surface area and the surface condition. The If-300 is the largest cask, and it has fins, corrugations and corners which are difficult to clean. The IF-100's and 200's are smaller, but they aiso have the fins. Furthermore, the IF-100 and 200 surfaces of passivated stainless steel which had been subjected to harsh decontamination solutions were found to be more difficult to clean than surfaces which had been peened with glass beads. The NAC-I/NFS-4 cask has smooth surfaces, which means there are fewer nooks and crannies, and that it has less surface area than the others. This, along wich their glass peened surface makes them the easiest to clean, and thus reduces the time to prepare them for shipment. The IF-300 also has a glass peened surface.

Torquing requirements also differed. Additional torquing was needed to reseat the IF- 300 head because the hoop seal used had to be compressed. This contributed to the longer times experienced for the IF-300. 

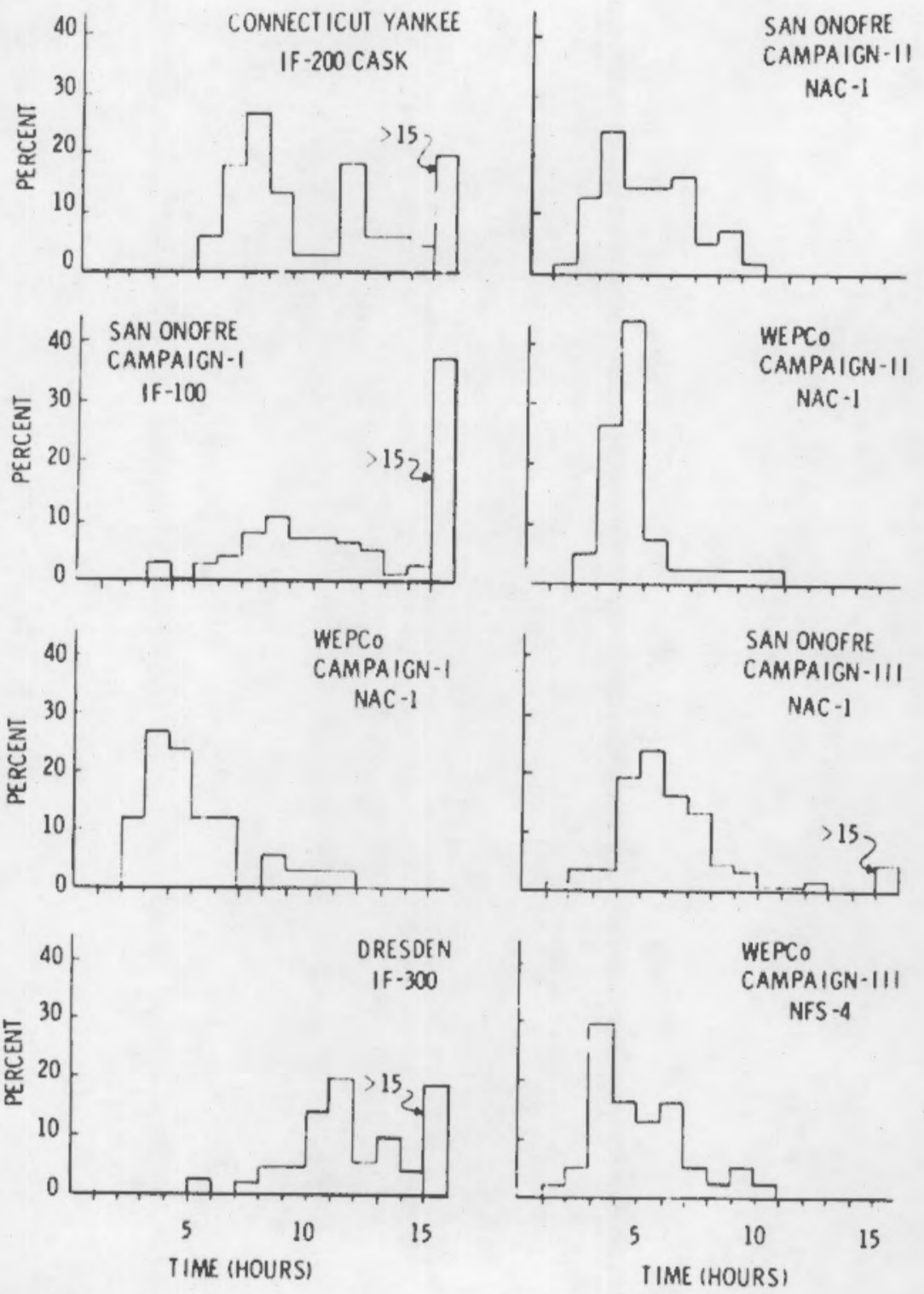

FIGURE 39. Time for Preparing the Empty Cask for Shipment 

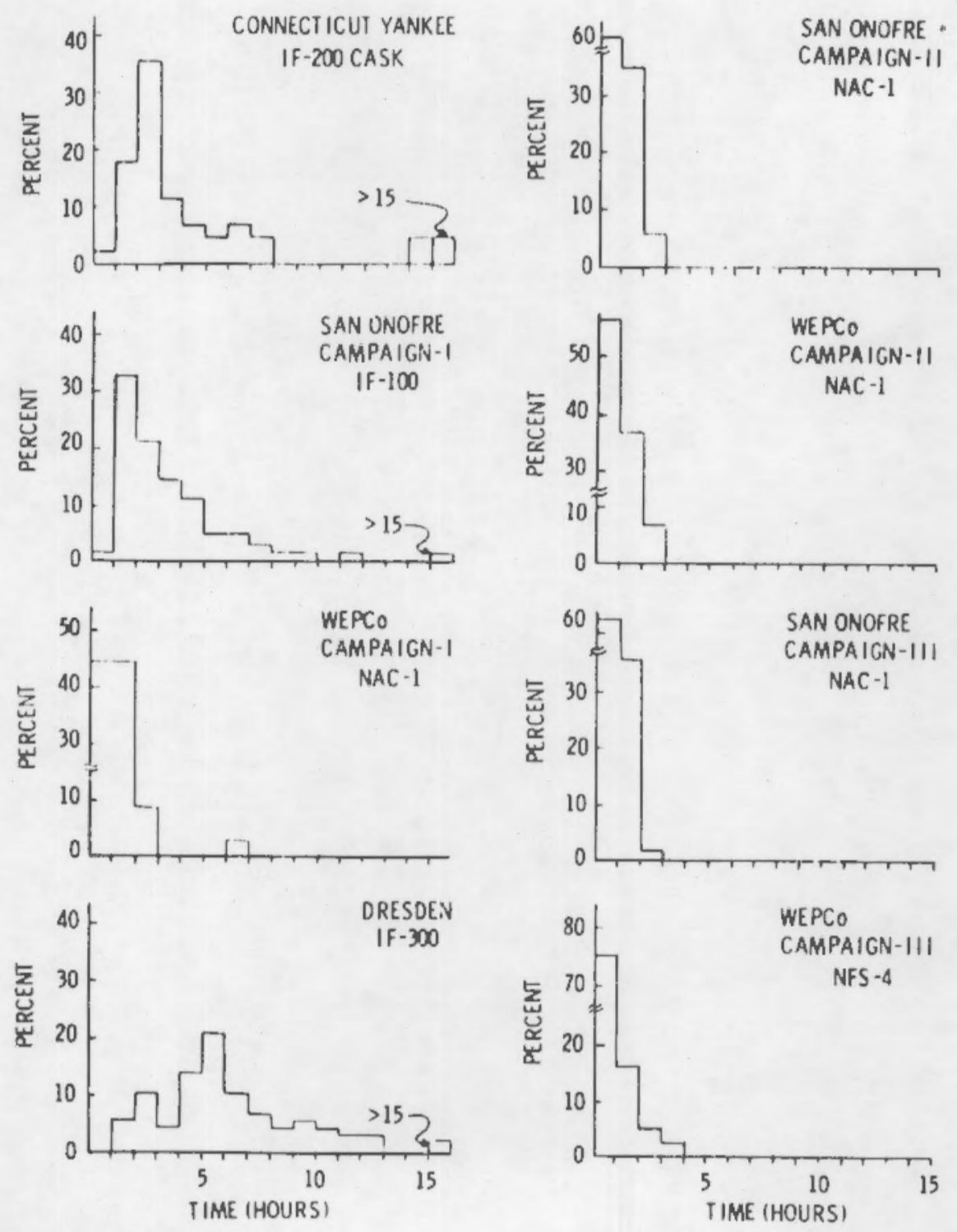

FIGURE 40. Time for Loading the Cask onto the Transport Vehicle 
Individual delays occurred when additional decontamination was needed for casks that were especially dirty, or in the IF-100 campaign, when lacquer which had been applied to the cask to fix radioactivity had to be removed. Delays also occurred agdin at this stage because of conflicts between early shipments and start-up efforts.

The times required for the final step, i.e., the securing of the cask to the vehicle is shown in the second figure, Figure 40 . Onloading of the IF-300 seems to take the longest, and NAC-1/NFS-4 the shortest times. Two generic differences help explain this. First there was an occasional need to respot IF-100 and 200 trailers. Positioning which was adequate for removing the cask did not meet the higher degree of perfection required for replacing it, and since there is not east-west crane motion the only option was to have a driver come in and move the trailer. The tilting cradle design of the IF-200 made the onloading still more difficult. Secondly, extra time was required to iffix the auxiliary hardware to the IF-300 cask. As it had taken longer to remove this at first, so it takes longer to re-install it prior to shipment.

Other things which have impacted the time for this stage have been failure of the crane radio-control, delays waiting for maintenance personnel required for the IF-300 diesel cneck-off, and time required for trailer repairs.

Even with the cask secured to the trailer, shipment was not always prompt. Further delays occurred in obtaining drivers for truck casks, and in coordinating rail transfer with the adjacent Dresden facility. These times are shown in Figure 41 for one truck and the one rail campaign.

\section{OVERALL PERFORMANCE}

The distribution of times required for unloading shipments oi spent fuel is shown in Figure 42. Data for the Dresden campaign has been reduced by removal of times spent at the beginning of the unloading sequence waiting to put the vehicle in the cask receiving area and at the end, waiting to ship it. This was necessary to show the Dresden experience on the sume scale used for 


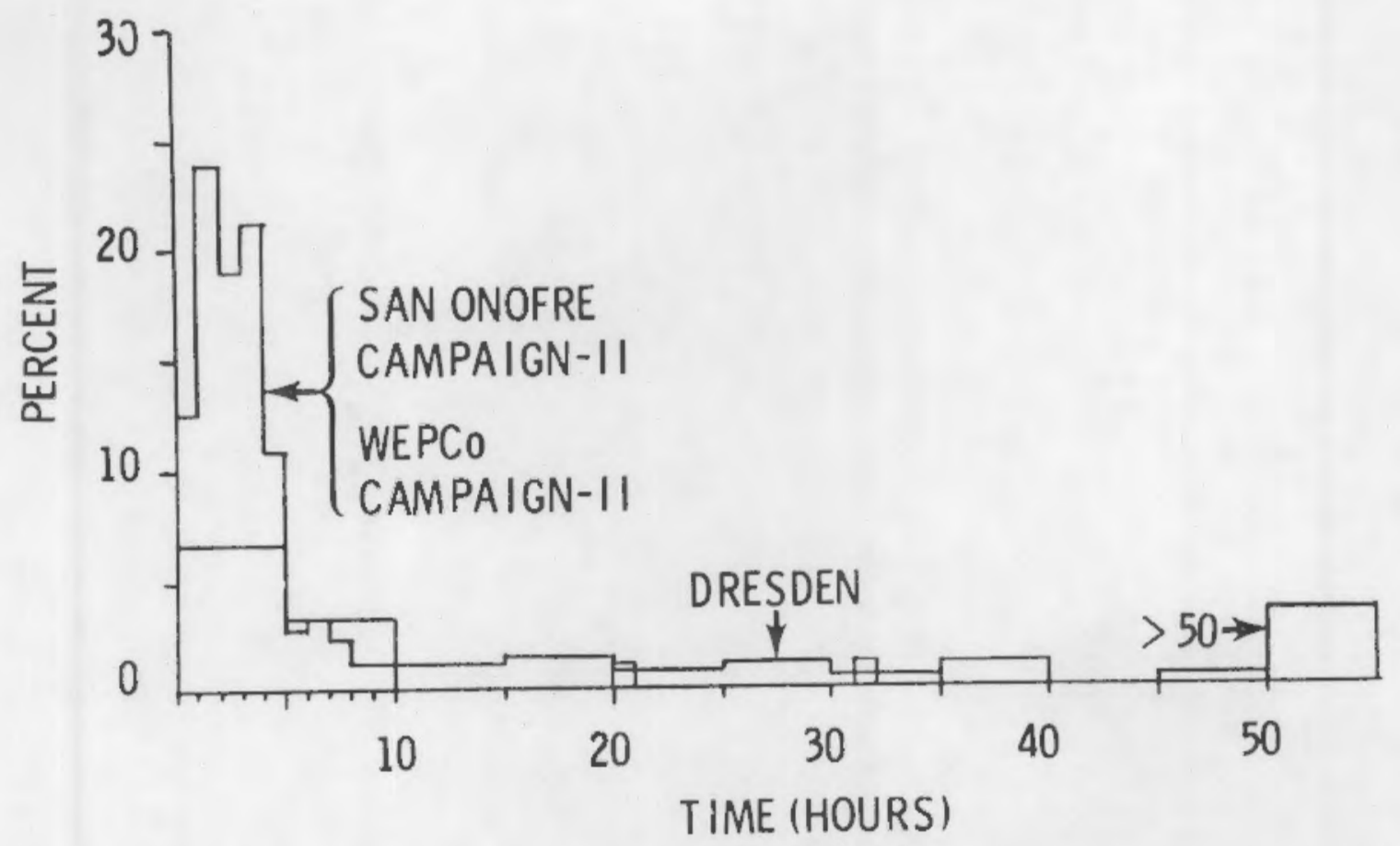

FIGURE 41. Pre-Shipping Lelays for 1976 Campaigns

other campaigns. Therefore, the tails in the other distribution should be largely ignored and pruper comparison made between the modal groups. (a)

On this basis turnarounds were most often 20 to $22 \mathrm{hr}$ for unloading of IF-100 and IF-200 casks, 13 to $21 \mathrm{hr}$ for unloading of NAC-1/NFS-4 casks, and $39 \mathrm{hr}$ for unloading of the IF-300s.

In one period during the summer of 1976, Dresden campaign overlapped with first the San Onofre II and then the WEPCO II campaigns. Some delay was routine and the modal classes for these campaigns are shifted to the right and are responsible for modal values of 17 and $21 \mathrm{hr}$. Delays were not as apparent when the San Onofre III and WEPCO III campaigns overlapped in 1977, probably

(a) Such a comparison by modal groups is an effective way to identify differences in unloading due to the various cask types or handling systems. However, these modal values must not be used to define the cask turnaround time because problems and delays which invariably occur in some shipinents are not included. 

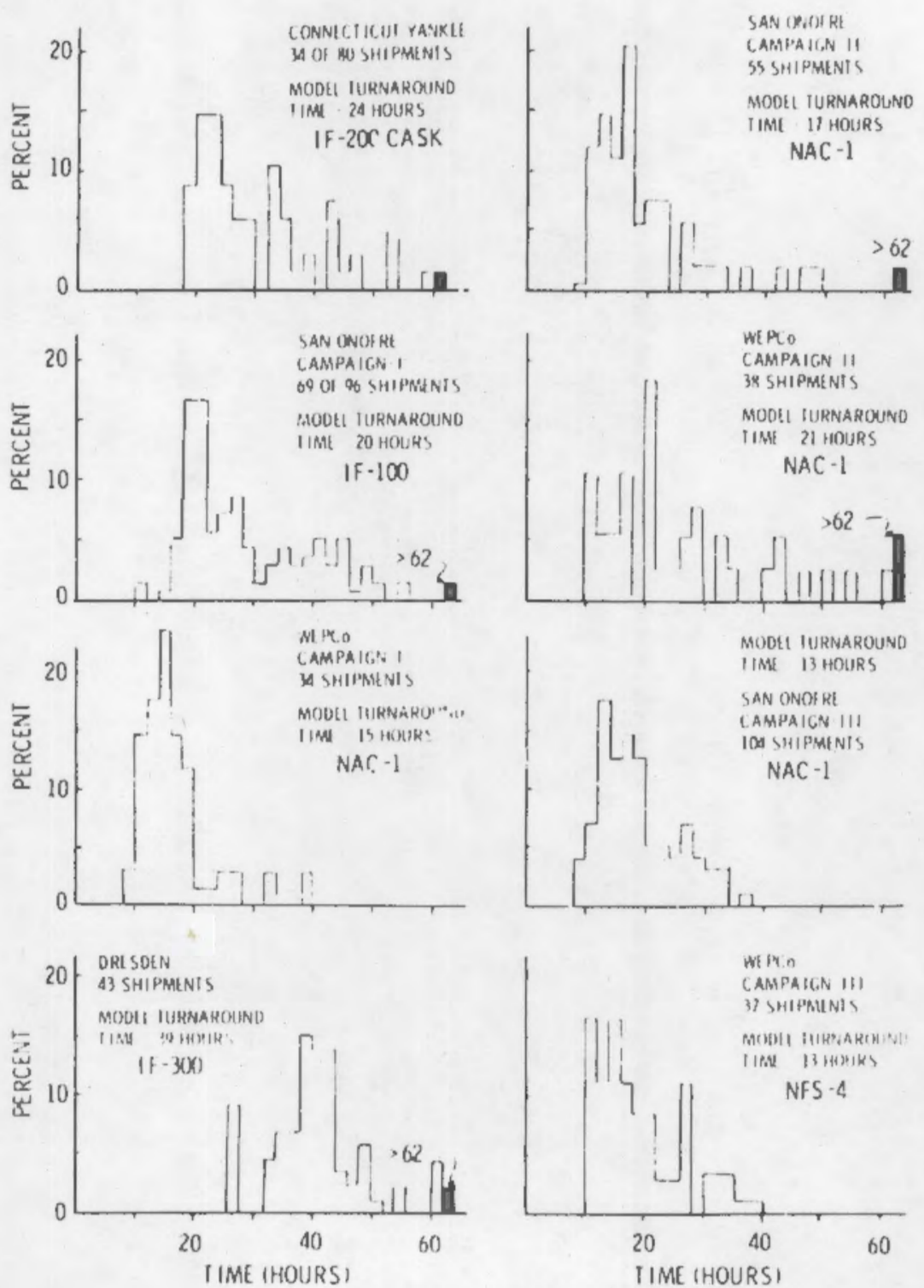

FIGURE 42. Turnaround Times for Cask Unloading at Morris Operation 
because the same type of cask was used for both. These overlaps can be seen in Figure 43. Here the distribution of shipping campaigns in time, listed in Table 8 , is shown diagramatically.

Some activities in the cask turnaround sequence have been identified through experience at Morris Operation in which improvements will reduce the timie and effort required for unloading. Other steps in the process have little potential for improvement because inherent limitations, crane speed for example, determine how much time is required.

Changes that would impact on the times required include 1) the provision of flexible crane operation 2) the minimizing of extra cask hardware, 3) streamlining of cask surfaces and 4) provision for underwater protection of the cask from tramp radioactive material released during fuel movements.

Some added crane flexibility has already been achies"nd at Morris Op ration witil the installation of the fuel handling crane. However, east-west mo-ion of the cask crane would be a desirable addition.

Hardware on the IF-300 shipping cask designed originally for shipmer: with very high heat loads $(200,000 \mathrm{Btu} / \mathrm{hr})$ could be removed since handing of this type of fuel is no longer projected. That would eliminate the time spent tending the diesel engines and air ducts.

Improvements in cask surfaces have been achieved through glass bead peening but reduction of the surface area and simplification of the shic future casks, particularly for the descendents of the If- 300 would be de able.

Finally, the development of a system to isolate or protect the cas irom contamination during periods of immersion vould impact favorably on the me and effort spent deconning the cask. 


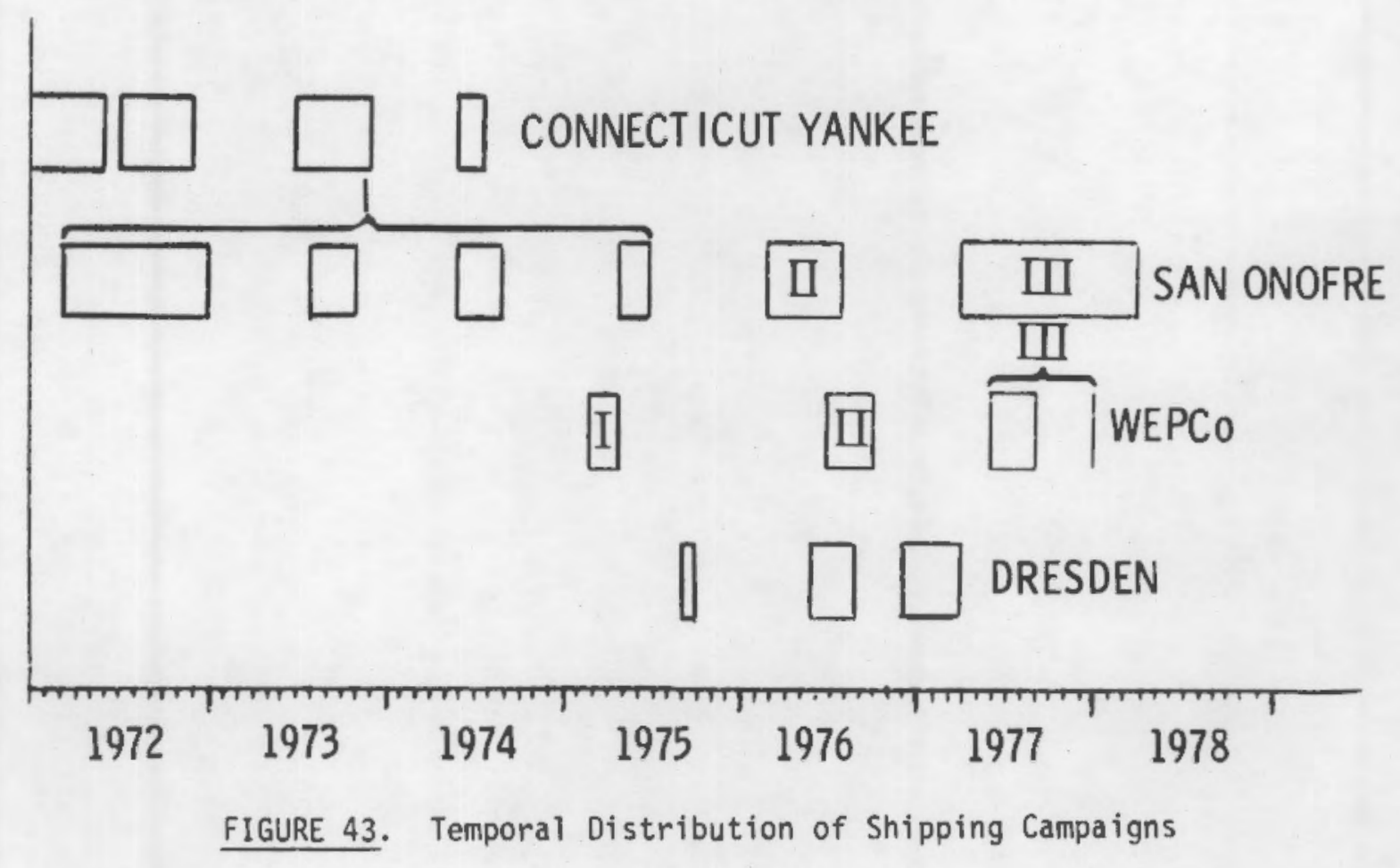

